University of Louisville

ThinkIR: The University of Louisville's Institutional Repository

Electronic Theses and Dissertations

$12-2004$

\title{
A characterization of micromanipulator controlled dry spinning of micro- and nanoscale polymer fibers.
}

Scott Berry

University of Louisville

Follow this and additional works at: https://ir.library.louisville.edu/etd

\section{Recommended Citation}

Berry, Scott, "A characterization of micromanipulator controlled dry spinning of micro- and nanoscale polymer fibers." (2004). Electronic Theses and Dissertations. Paper 106.

https://doi.org/10.18297/etd/106

This Master's Thesis is brought to you for free and open access by ThinkIR: The University of Louisville's Institutional Repository. It has been accepted for inclusion in Electronic Theses and Dissertations by an authorized administrator of ThinkIR: The University of Louisville's Institutional Repository. This title appears here courtesy of the author, who has retained all other copyrights. For more information, please contact thinkir@louisville.edu. 


\title{
A CHARACTERIZATION OF MICROMANIPULATOR CONTROLLED DRY SPINNING OF MICRO- AND NANOSCALE POLYMER FIBERS
}

\author{
By \\ Scott Berry \\ B.S. University of Louisville, 2003
}

\begin{abstract}
A Thesis
Submitted to the Faculty of the University of Louisville

J.B. Speed School of Engineering As Partial Fulfillment of the Requirements

For the Professional Degree
\end{abstract}

\section{MASTER OF ENGINEERING}

Department of Mechanical Engineering

December 2004 


\section{A CHARACTERIZATION OF MICROMANIPULATOR CONTROLLED DRY SPINNING OF MICRO- AND NANOSCALE POLYMER FIBERS}

Submitted by:

\section{Scott Berry}

A Thesis Approved on $\underline{12-10-04}$

by the Following Reading and Examination Committee:

Robert Keynton, Thesis Director

Roger Bradshaw, Department of Mechanical Engineering

Robert Cohn, Department of Electrical Engineering 


\section{ACKNOLEDGEMENTS}

The author would like to thank Alex Isham and Scott Cambron of the University of Louisville Department of Mechanical Engineering and Mark Crain of the Department of Electrical Engineering for their instruction and expertise involving the equipment used in this thesis, Dr. Steve Harfenist of the Department of Electrical Engineering for guidance and suggestions along the way, Dr. John Naber of the Department of Electrical Engineering for help designing the experimental protocol, Dr. Robert Cohn of the Department of Electrical Engineering and Dr. Roger Bradshaw of the Department of Mechanical Engineering for their revisions to this work and for serving on my Thesis Committee, and lastly, Dr. Robert Keynton of the Department of Mechanical Engineering for serving as Thesis Advisor and sharing his knowledge and patience with me. 


\section{ABSTRACT}

No current microfabrication technique exists for producing roomtemperature, high-precision, point-to-point polymer nanofibers in three dimensions. Producing rounded structures in a third dimension is particularly difficult to accomplish with conventional planar microfabrication techniques. Therefore, the purpose of this study is to characterize a novel method for fabricating such structures.

In this investigation, PMMA micro- and nano- fibers have been fabricated using a technique which involves drawing a solvated polymer bridge between two liquid pools with a stylus positioned by an ultra-high-precision micromill. The solvent in the solution bridge rapidly evaporates, leaving a suspended PMMA fiber between the two pools. In order to characterize this process, fibers were drawn over a $1.8 \mathrm{~mm}$ silicon trench and fiber diameter was measured over a variety of different solution concentrations and polymer molecular weights. In addition, the fluid characteristics of the solutions were measured to allow for comparisons between fiber diameter and properties such as viscosity and surface tension.

Fiber diameters ranging from $450 \mathrm{~nm}$ to $50 \mu \mathrm{m}$ were drawn during the characterization experiments. In addition, fibers as small as $140 \mathrm{~nm}$ were drawn over distances less than $1.8 \mathrm{~mm}$. It was observed that fiber diameter enlarged as both solution concentration and polymer molecular weight increased. In an attempt to decrease fiber diameter variance, different stylus materials were also examined, and it was found that a parylene-coated stylus resulted in a fair reduction, but not elimination, of the diameter variance. Although fiber diameter variances remain somewhat high, possibly due to unwanted solution 
buildup on the stylus tip, this fabrication technique presents a simple method for producing precisely positioned, low temperature, suspended polymer fiber structures on the micro- and nanoscale. 


\section{TABLE OF CONTENTS}

Approval Page

Acknowledgements

Abstract

Nomenclature

iv

List of Tables

viii

List of Figures

I. Introduction

ix

$\mathrm{x}$

II. Literature Review

A. Current Fiber Spinning Processes 3

1. Wet / Dry Spinning 3

2. Melt Spinning 6

3. Electrospinning $\quad 8$

4. Manual Fiber Drawing Technique 10

B. Capillary Breakup Rheology 11

C. Fiber Spinning Summary and Discussion of Molecular 12 Interactions

III. Instrumentation and Equipment 16

A. Micromilling Machine 16

B. Scanning Electron Microscope (SEM) 17

C. Sputtering Device 17

1. Overview 17

2. Operation 18

D. Viscometer 19

E. Surface Tension Measurements 20

F. Thermogravimetric Analyzer 21

$\begin{array}{ll}\text { IV. Procedure } & 23\end{array}$

A. Preparation of Solutions 23

B. Fluid Properties Characterization 24

C. Fiber Diameter Characterization $\quad 27$

V. Results and Discussion $\quad 33$

A. Preparation of Solutions 33

B. Fluid Properties Characterization 34

1. Viscosity 34

2. Surface Tension $\quad 37$

3. Thermogravimetric Analysis $\quad 38$

C. Diameter Measurements 40

D. Fiber Yield 47

E. Processability Parameter 49

VI. Conclusions $\quad 41$

VIII. Recommendations $\quad 52$

A. Smaller Fiber Diameters $\quad 52$

B. Lower Diameter Variance 53

C. Additional Process Parameters 54 
Appendix I-Micromilling Machine Code

Appendix II - Individual Fiber Measurements

Appendix III - SEM Images

83

List of References

108

Vita

112 


\section{NOMENCLATURE}

$\eta$ - Viscosity of solution

$\eta_{\text {solvent }}$ - Viscosity of solvent

TK - Torque Constant

SMC - Spindle multiplier constant

RPM - Spindle rotations per minute

SR - Shear rate

SRC - Shear rate constant

SMF - Solid mass fraction

$\sigma$ - Solution surface tension

$\rho$ - Solution density

$\mathbf{r}$ - Capillary radius

$\mathrm{g}$ - Acceleration due to gravity

$\theta$ - Contact Angle

c-Solution concentration

m - Mass

MW - Molecular Weight

$\mathrm{N}_{\mathrm{A}}$ - Avogadro's number

$\mathrm{V}_{\mathrm{H}}$ - Hydrodynamic radius

$\mathrm{h}$ - Solvent evaporation time constant

P - Processability parameter

$\mathrm{t}$ - Time

D - Fiber diameter 


\section{LIST OF TABLES}

1.) SUMMARY OF CURRENT POLYMER FIBER

SPINNING PROCESSES

2.) INITIAL CONCENTRATIONS (\% PMMA BY WEIGHT)

3.) CONCENTRATIONS USED IN QUANTITATIVE TESTING (\% PMMA BY WEIGHT)

4.) MEAN AND STANDARD DEVIATION (IN MICRONS)

FOR FIBERS DRAWN WITH 495K G/MOL PMMA CONCENTRATIONS USING DIFFERING STYLUS MATERIALS

5.) REGRESSION CURVE FITS AND $R^{2}$ VALUES FOR FIBERS DRAWN WITH 495K G/MOL SOLUTION USING DIFFERING STYLUS MATERIALS 


\section{LIST OF FIGURES}

1.) Wet Spinning Apparatus (Weink, 1995) 4

2.) Electrospinning Apparatus (Theron, 2004) 4

3.) Electrospun Fibers (Fong, 1999) 9

4.) Manually drawn PMMA fibers between two solvated pools 11

5.) Dover Instruments Micro Milling Machine 16

6.) Carl Zeiss LEO Supra 35 SEM 17

7.) The International Scientific Instruments PS2 Coating Unit 18

8.) Brookfield LVDV-II+ Viscometer (Left) and TC-500 20

Refrigerated Bath / Circulator (Right)

9.) Capillary device used to measure surface tension of 21 solutions

10.) TA Instruments Thermogravimetric Analyzer 2950

11.) Setup of the fiber-drawing step of the investigation 28

12.) Solution deposited on silicon substrate immediately before 28 trial run

13.) Viscosity of each MW solution at varying concentration 35

14.) Viscosity of $9 \%$ solutions at varying shear rate 35

15.) Einstein's relationship viscosity predictions 37

16.) Surface tension of the PMMA solutions as a function of 38 concentration

17.) TGA results and exponential curve fits for the solvent mass 39 fraction as a function of time and molecular weight

18.) Fiber diameter versus concentration for tungsten stylus 41

19.) SEM images of fibers drawn in characterization trials 42

20.) Fiber diameter plotted against viscosity for both molecular 43 weights shows an increase in diameter with an increase in viscosity

21.) Solution buildup on stylus tip

22.) Fiber diameter standard deviations with addition stylus 45 materials and $495 \mathrm{k} \mathrm{g} / \mathrm{mol}$ solution

23.) Coefficients of variance describing variation in diameter 46 along an individual fiber for $495 \mathrm{k} \mathrm{g} / \mathrm{mol}$ solutions.

24.) Coefficients of variance describing variation in diameter 47 along an individual fiber for $950 \mathrm{k} \mathrm{g} / \mathrm{mol}$ solutions.

25.) The fraction of stylus passes resulting in an unbroken fiber 48 for the different stylus materials and the $495 \mathrm{k} \mathrm{g} / \mathrm{mol}$ solution

26.) The fraction of stylus passes resulting in an unbroken fiber for the tungsten stylus and the $950 \mathrm{k} \mathrm{g} / \mathrm{mol}$ solution

27.) Fiber diameter increases with increasing Processability 50 Parameter for both molecular weight solutions

28.) Individual fiber measurements for $495 \mathrm{k} / / \mathrm{mol}$ solution with 56 $15.5 \%$ solids and tungsten stylus 
29.) Individual fiber measurements for $495 \mathrm{k} \mathrm{g} / \mathrm{mol}$ solution with $16 \%$ solids and tungsten stylus

30.) Individual fiber measurements for $495 \mathrm{k} \mathrm{g} / \mathrm{mol}$ solution with $17 \%$ solids and tungsten stylus

31.) Individual fiber measurements for $495 \mathrm{k} \mathrm{g} / \mathrm{mol}$ solution with $18 \%$ solids and tungsten stylus

32.) Individual fiber measurements for $495 \mathrm{k} \mathrm{g} / \mathrm{mol}$ solution with $21.6 \%$ solids and tungsten stylus

33.) Individual fiber measurements for $495 \mathrm{k} \mathrm{g} / \mathrm{mol}$ solution with $23 \%$ solids and tungsten stylus

34.) Individual fiber measurements for $950 \mathrm{k} \mathrm{g} / \mathrm{mol}$ solution with $13 \%$ solids and tungsten stylus

35.) Individual fiber measurements for $950 \mathrm{k} \mathrm{g} / \mathrm{mol}$ solution with $15 \%$ solids and tungsten stylus

36.) Individual fiber measurements for $950 \mathrm{k} \mathrm{g} / \mathrm{mol}$ solution with $18 \%$ solids and tungsten stylus

37.) Individual fiber measurements for $950 \mathrm{~kg} / \mathrm{mol}$ solution with $21.3 \%$ solids and tungsten stylus

38.) Individual fiber measurements for $495 \mathrm{k} \mathrm{g} / \mathrm{mol}$ solution with $16 \%$ solids and parylene stylus

39.) Individual fiber measurements for $495 \mathrm{k} \mathrm{g} / \mathrm{mol}$ solution with $17 \%$ solids and parylene stylus

40.) Individual fiber measurements for $495 \mathrm{k} \mathrm{g} / \mathrm{mol}$ solution with $18 \%$ solids and parylene stylus

41.) Individual fiber measurements for $495 \mathrm{k} \mathrm{g} / \mathrm{mol}$ solution with $21.6 \%$ solids and parylene stylus

42.) Individual fiber measurements for $495 \mathrm{k} \mathrm{g} / \mathrm{mol}$ solution with $23 \%$ solids and parylene stylus

43.) Individual fiber measurements for $495 \mathrm{k} \mathrm{g} / \mathrm{mol}$ solution with $15.5 \%$ solids and nonstick stylus

44.) Individual fiber measurements for $495 \mathrm{k} \mathrm{g} / \mathrm{mol}$ solution with $16 \%$ solids and nonstick stylus

45.) Individual fiber measurements for $495 \mathrm{k} \mathrm{g} / \mathrm{mol}$ solution with $17 \%$ solids and nonstick stylus

46.) Individual fiber measurements for $495 \mathrm{k} \mathrm{g} / \mathrm{mol}$ solution with $18 \%$ solids and nonstick stylus

47.) Individual fiber measurements for $495 \mathrm{k} \mathrm{g} / \mathrm{mol}$ solution with $21.6 \%$ solids and nonstick stylus

48.) Individual fiber measurements for $495 \mathrm{k} \mathrm{g} / \mathrm{mol}$ solution with $23 \%$ solids and nonstick stylus

49.) Individual fiber measurements for $495 \mathrm{k} \mathrm{g} / \mathrm{mol}$ solution with $15.5 \%$ solids and glass stylus

50.) Individual fiber measurements for $495 \mathrm{k} \mathrm{g} / \mathrm{mol}$ solution with $16 \%$ solids and glass stylus

51.) Individual fiber measurements for $495 \mathrm{k} \mathrm{g} / \mathrm{mol}$ solution with $17 \%$ solids and glass stylus 
52.) Individual fiber measurements for $495 \mathrm{k} \mathrm{g} / \mathrm{mol}$ solution with

$18 \%$ solids and glass stylus

53.) Individual fiber measurements for $495 \mathrm{k} \mathrm{g} / \mathrm{mol}$ solution with $21.6 \%$ solids and glass stylus

54.) Individual fiber measurements for $495 \mathrm{k} \mathrm{g} / \mathrm{mol}$ solution with $23 \%$ solids and glass stylus

55.) SEM images for $495 \mathrm{k} / \mathrm{mol}$ solution with $16 \%$ solids and tungsten stylus

56.) SEM images for $495 \mathrm{k} \mathrm{g} / \mathrm{mol}$ solution with $17 \%$ solids and tungsten stylus

57.) SEM images for $495 \mathrm{k} \mathrm{g} / \mathrm{mol}$ solution with $18 \%$ solids and tungsten stylus

58.) SEM images for $495 \mathrm{~kg} / \mathrm{mol}$ solution with $21.6 \%$ solids and tungsten stylus

59.) SEM images for $950 \mathrm{k} \mathrm{g} / \mathrm{mol}$ solution with $13 \%$ solids and tungsten stylus

60.) SEM images for $950 \mathrm{k} \mathrm{g} / \mathrm{mol}$ solution with $15 \%$ solids and tungsten stylus

61.) SEM images for $950 \mathrm{k} \mathrm{g} / \mathrm{mol}$ solution with $18 \%$ solids and tungsten stylus

62.) SEM images for $950 \mathrm{k} \mathrm{g} / \mathrm{mol}$ solution with $21.3 \%$ solids and tungsten stylus

63.) SEM images for $495 \mathrm{~kg} / \mathrm{mol}$ solution with $16 \%$ solids and parylene stylus

64.) SEM images for $495 \mathrm{~kg} / \mathrm{mol}$ solution with $17 \%$ solids and parylene stylus

65.) SEM images for $495 \mathrm{k} \mathrm{g} / \mathrm{mol}$ solution with $18 \%$ solids and parylene stylus

66.) SEM images for $495 \mathrm{k} \mathrm{g} / \mathrm{mol}$ solution with $21.6 \%$ solids and parylene stylus

67.) SEM images for $495 \mathrm{k} \mathrm{g} / \mathrm{mol}$ solution with $23 \%$ solids and 95 parylene stylus

68.) SEM images for $495 \mathrm{k} \mathrm{g} / \mathrm{mol}$ solution with $15.5 \%$ solids and 96 nonstick stylus

69.) SEM images for $495 \mathrm{k} \mathrm{g} / \mathrm{mol}$ solution with $16 \%$ solids and 97 nonstick stylus

70.) SEM images for $495 \mathrm{k} \mathrm{g} / \mathrm{mol}$ solution with $17 \%$ solids and 98 nonstick stylus

71.) SEM images for $495 \mathrm{k} \mathrm{g} / \mathrm{mol}$ solution with $18 \%$ solids and 99 nonstick stylus

72.) SEM images for $495 \mathrm{k} \mathrm{g} / \mathrm{mol}$ solution with $21.6 \%$ solids and $\quad 100$ nonstick stylus

73.) SEM images for $495 \mathrm{k} \mathrm{g} / \mathrm{mol}$ solution with $23 \%$ solids and 101 nonstick stylus

74.) SEM images for $495 \mathrm{k} \mathrm{g} / \mathrm{mol}$ solution with $15.5 \%$ solids and $\quad 102$ glass stylus 
75.) SEM images for $495 \mathrm{k} \mathrm{g} / \mathrm{mol}$ solution with $16 \%$ solids and glass stylus

76.) SEM images for $495 \mathrm{k} \mathrm{g} / \mathrm{mol}$ solution with $17 \%$ solids and glass stylus

77.) SEM images for $495 \mathrm{k} \mathrm{g} / \mathrm{mol}$ solution with $18 \%$ solids and glass stylus

78.) SEM images for $495 \mathrm{k} \mathrm{g} / \mathrm{mol}$ solution with $21.6 \%$ solids and 106 glass stylus

79.) SEM images for $495 \mathrm{k} \mathrm{g} / \mathrm{mol}$ solution with $23 \%$ solids and glass stylus 


\section{INTRODUCTION}

Currently there is no procedure for the rapid creation of well-ordered, threedimensionally positioned, micro- and nanoscale fibers. Methods exist for the spinning, or construction, of polymer fibers, but all lack either the precision of a micromanipulatorcontrolled process or the ability to draw such miniscule fibers. If nanoscale fibers could be easily drawn between two discrete points, these fibers could be utilized as scaffolding in the construction of microelectromechanical systems (MEMS) devices. If the fibers were polymer-based, they could be coated with another material and dissolved, leaving a nanoscale channel. Also, transparent polymer fibers could be used as room-temperature fabricated, optical structures.

Currently, polymer fibers are fabricated by a number of processes. Many commercial textiles and other fibers are produced by wet, dry, or melt spinning. Dry spinning involves the extrusion of a polymer solution through a series of orifices that shape the polymer into several fibers. Wet spinning is nearly identical to dry spinning, except a secondary fluid is used to draw the solvent from the polymer solution after extrusion. Melt spinning is another related process, involving the extrusion of a melted polymer through the orifices. Fibers much smaller in diameter (down to $50 \mathrm{~nm}$ ) can be produced through electrospinning, which involves utilizing an electric filed to shape a solvated polymer into a mat of fibers. All of these processes serve some industrial niche, but none of them allows for the precise placement of discrete fibers and only electrospinning allows for the fabrication of sub-micron structures. 
The purpose of this study is to characterize a fiber drawing process using an ultrahigh-precision micromilling/drilling machine by varying polymer solution concentration, polymer molecular weight, and stylus material.

The significance of this project is that it will bridge the gap between a process that is only proven conceptually and one that can be utilized in industry. In order for this fabrication technique to be useful, the user must be able to obtain predictable, controllable, and repeatable results. This characterization will link the user-controlled variables with the process output (the diameter of the fabricated fibers), thereby allowing a user to construct a number of precisely-positioned polymer fibers with a desired diameter for use in various applications. 


\section{LITERATURE REVIEW}

\section{A. Current Fiber Spinning Processes}

Currently, polymer fibers are being produced through wet spinning, dry spinning, melt spinning, and electrospinning. Although useful, these four methods are not designed for precisely placing fibers between two points. In addition to these four, a proof-ofconcept groundwork has been laid for a process closely related to the one discussed in this investigation, which involves the formation of polymer fibers via brushing of a partially dried polymer solution over a substrate.

\section{Wet / Dry Spinning}

In wet spinning, a solution of solvent and polymer, referred to as a "spinning dope", is passed via pump to a spinneret, which is a plate containing one or more orifices or nozzles through which the spinning dope falls. Immediately after passing through the spinneret, the spinning dope encounters an air gap. This gap exposes the dope to air, resulting in partial or complete evaporation of the solvent. The air gap also allows the force of gravity to pull the dope downward, further thinning and elongating the fiber. Next the fiber is plunged into a bath of coagulant, a solution which removes the solvent from the dope, and the fibers are wound around a take-up wheel. This wheel can be externally driven to apply a tensile force on the newly drawn fiber, additionally elongating it. Lastly, the fiber is passed into a rinsing bath and cut to length (Weink, 1995). A diagram of the wet spinning process is shown as Figure 1. The presence of a coagulant immersion step is the defining characteristic of wet spinning. If this process if 
performed with the coagulant immersion step omitted, the resulting process is known as dry spinning.

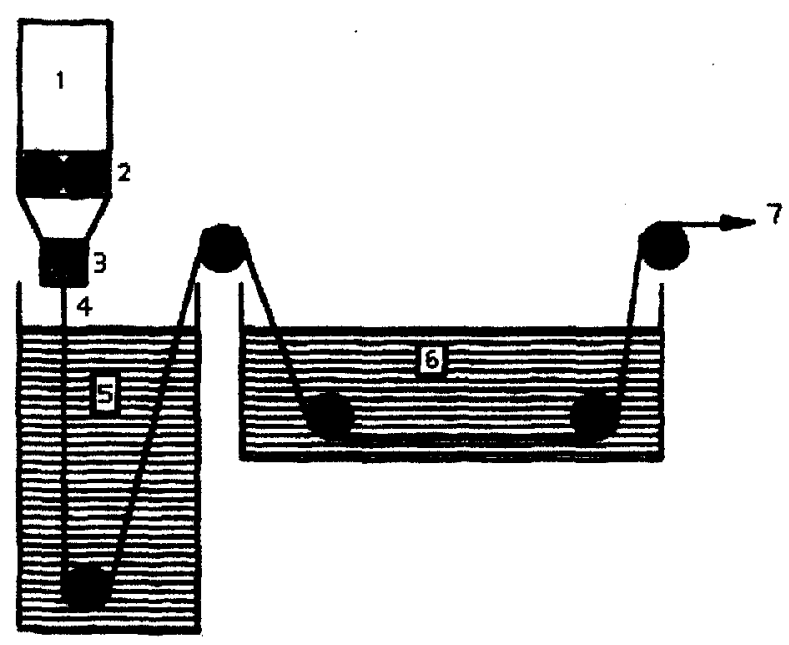

FIGURE 1 - Wet Spinning Apparatus (Wienk, 1995) (1 - Polymer solution, 2 - Pump, 3 - Spinneret, 4-Air gap, 5-Coagulant solution, 6-Rinsing bath, 7-Fiber collection)

A number of different factors influence the product of wet spinning. These parameters include spinneret geometry, temperature, dope extrusion rate, dope and coagulant composition, fiber take-up speed, and length of the air gap (Qin, 2001). A key fiber characteristic, fiber diameter, has been found dependant on several of these variables.

Most obviously, fiber diameter is dependant upon the diameter of the orifices in the spinneret, with the maximum fiber diameter approximately matching the orifice diameter. However, in practice, tensile forces applied by gravity and the take-up mechanism stretch the fiber to a smaller diameter. Wienk et al. (1995) have observed fiber diameters ranging from $1.10 \mathrm{~mm}$ to $1.40 \mathrm{~mm}$ for an orifice diameter of $1.50 \mathrm{~mm}$ at a variety of temperatures, air gap lengths, dope extrusion rates, and take-up speeds. It was observed that the diameter decreased as air gap length, extrusion rate, and take-up speed 
increased. All three of these variables were changed simultaneously, and so the effect of each variable independently on fiber diameter can not be reported. Qin et al. (2001) also reported an increase in fiber diameter if the air gap was eliminated (i.e. the spinneret rests just above the coagulant).

The mechanical properties of the polymer fibers are also dependent on the above parameters. For example, Qin demonstrated that the fibers with no air gap were stronger and had higher stiffness, but were less permeable to water than fibers drawn with an air gap. Qin (2001) postulated that these results were not a factor of gravity induced tensile forces (because the air gap was only $1 \mathrm{~cm}$ ), but instead, they were due to a more ordered molecular structure in the no-air gap conditions (the molecular order structure was locked into place upon coagulation by removing the solvent immediately after passing through the spinneret).

Annular tubes can easily be created via wet spinning by utilizing concentric holes in the spinneret. The polymer dope can be passed through an outer, annular region, while a bore liquid, often water, is passed through the inner hole. The resulting polymer tube can be coagulated in a manner identical to fiber spinning. It has been suggested by many research groups (Qin, 2001; Mok, 1995; Wienk, 1995; Pereira, 2001; Yang, 2001) that these structures can be used as filter membranes with the permeability controlled through the alteration of the previously discussed variables. In addition, composite tubes have been constructed from two different polymers, allowing one polymer to be the primary source of structural support and the other polymer, with favorable membrane qualities such as a hydrophilic boundary, to allow for interaction between the tube wall and a surrounding fluid. 
Mok et al. (1995) has characterized the annular membrane formation process using polyether sulfone (PES) as the primary polymer and polyvinylpyrrolidone (PVP) as the hydrophilic additive. It was observed that the ratio of outer tube radius to inner tube radius increased as bore liquid flow increased, which was likely due to the miscibility of the many common solvents with the bore liquid (often water). The bore liquid removes the solvent from the polymer dope, thereby solidifying the tubes, before the tubes have been thinned and elongated by gravity. Mok (1995) also reported that the outer radius to inner radius ratio decreased with increasing dope temperature and viscosity. Yang et al. (2001) have suggested that PES/PVP membranes could be used for bio-separations and have successfully isolated yeast cells with these annuli.

\section{Melt Spinning}

Melt spinning can be used to create polymer fibers with diameters ranging from microns to over a millimeter and the nature of the recrystallization of a melt spun fiber can be controlled to yield optimal mechanical properties. The process is very similar to that of wet spinning (as shown in Figure 1), but heat rather than solvent is used to decrease the polymer viscosity to the point where it can be drawn through a spinneret. To accomplish this, a heater is installed just above the spinneret and the polymer is heated above its melting temperature. The liquid polymer flows through the spinneret where it is cooled, either by active of passive means, and collected on a take-up wheel (Sperling, 2001). Wu et al. (2001) have shown that fibers can be melt spun at higher velocities, up to 10 kilometers per minute. 
Many factors influence the diameter of a melt spun fiber, most importantly takeup speed and spinneret geometry. Spinneret diameter is directly correlated to the final fiber diameter of a melt spun polymer fiber. Zeng et al. (2004) have produced $4 \mathrm{~mm}$ diameter fibers by allowing melted polymer to freefall through a $4 \mathrm{~mm}$ orifice in the spinneret. Zeng also showed that the fiber diameter can be significantly reduced by applying a tensile force to the polymer melt via a powered take-up wheel. A 60 micron fiber was produced from the same $4 \mathrm{~mm}$ orifice by taking up the spun polymer at a rate of 150 meters per minute.

Wu et al. $[4,15]$ have shown a correlation between increased take-up speed and superior mechanical properties. Specifically, fibers produced by melt spinning poly(ethylene-2,6-napthalate) with take-up rates varying from $0.9 \mathrm{~km} / \mathrm{min}$ to $10 \mathrm{~km} / \mathrm{min}$. It was found that as take-up speed increased from $0.9 \mathrm{~km} / \mathrm{min}$ to $4 \mathrm{~km} / \mathrm{min}$, the density and strength of the fibers increased as well, whereas, when the take-up speed was increased from $4 \mathrm{~km} / \mathrm{min}$ to $10 \mathrm{~km} / \mathrm{min}$, no improvement was observed. Measurements of birefringence and Wide-Angle X-ray Diffraction (WAXD) explained these trends by confirming that crystallinity steadily increased for take-up velocities ranging from 0.9 $\mathrm{km} / \mathrm{min}$ to $4 \mathrm{~km} / \mathrm{min}$, but a maximum level of molecular order was reached at $4 \mathrm{~km} / \mathrm{min}$ (2001, 2002). Samon et al. (2002) have expanded on this idea by reporting that crystallization begins earlier for higher take-up speeds. In addition, Zachmann et al. (1995) have shown via X-ray scattering that not all melt spun polymer material crystallizes, that is, regimes of higher and lower densities first separate, then the higher density areas crystallize, leaving a lower density amorphous region. This phenomenon 
correlates with the concept reported by Sperling (2001) that crystalline polymers actually contain both crystalline and amorphous regions.

Recently, it has been demonstrated that polymer fibers can be reinforced with carbon nanotubes (CNT) prior to melt spinning. Sandler et al. (2004) and Zeng et al. (2004) have both observed increases in tensile modulus by adding CNT to Polyamide-12 and poly(methyl methacrylate), respectively. Both groups also reported large differences in the tensile modulus for fibers reinforced with aligned CNT and those reinforced with entangled CNT, with the aligned CNT yielding a higher tensile modulus. Sandler also reported an increase in yield strength of the fibers as the weight fraction of the CNTs increased.

\section{Electrospinning}

In this process, a polymer is first mixed with a solvent to reduce viscosity in a manner similar to that of wet spinning. Next, it is loaded into a syringe and a high voltage is applied to the solution. As the solvated polymer is forced from the syringe, it is electrically drawn towards a grounded target. As the polymer approaches the target, it begins to spiral in a conical envelope (called a Taylor cone), and higher order, chaotic, spiraling is observed in the region where the polymer solution makes contact with the target. The solvent evaporates, leaving only a nanoscale polymer fiber matrix. The electrospinning process is illustrated in Figure 2. Several different polymers have been electrospun, including PEO (shown as Figure 3), PAA, PVA, PU, and PCL, and fiber diameters range from tens of nanometers to several microns (Theron, 2004; Koski, 2004; Fong, 1999). 


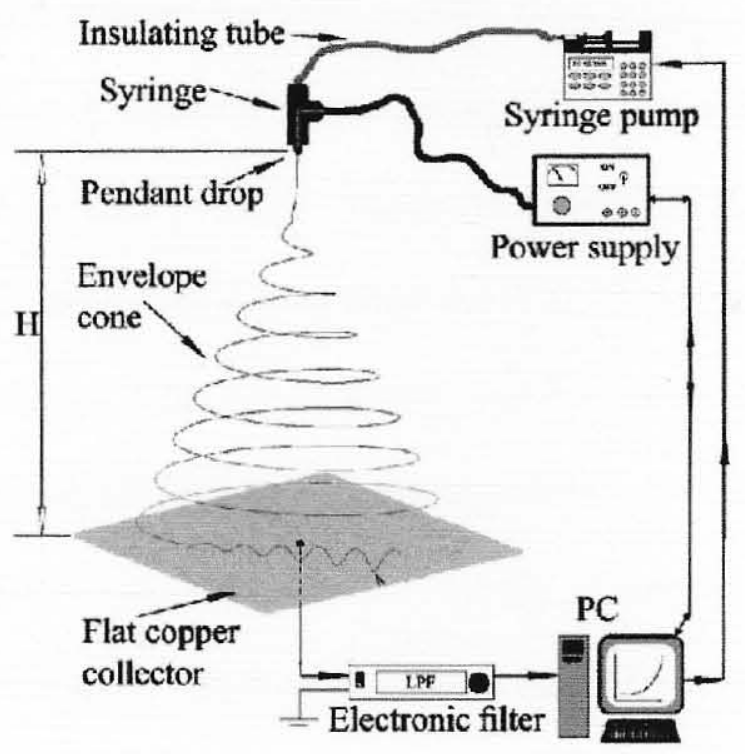

FIGURE 2 - Electrospinning Apparatus (Theron, 2004)

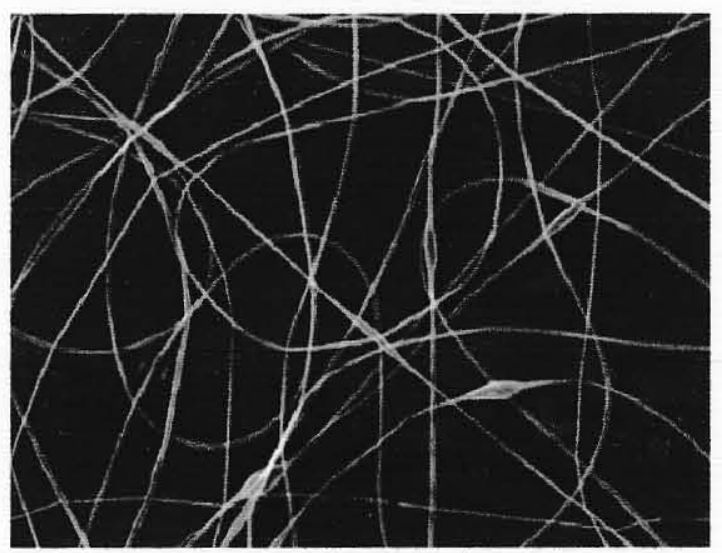

FIGURE 3 - Electrospun Fibers (Fong, 1999)

The primary parameters effecting electrospun fibers are applied voltage, distance from syringe to target ( $\mathrm{H}$ in Figure 2), molecular weight (MW) of the polymer, and polymer-to-solvent ratio. Doshi and Reneker (1995), pioneers of the electrospinning process, first noticed a thinning of the polymer stream as the syringe to target distance increased. Koski et al. (2004) reported an increase in fiber diameter as the polymer molecular weight increased. Specifically, they observed round fibers with diameters of approximately $250 \mathrm{~nm}$ for MWs ranging from $13,000-23,000 \mathrm{~g} / \mathrm{mol}$ and ribbon shaped 
fibers with diameters of 2 microns for MWs ranging from $50,000-89,000 \mathrm{~g} / \mathrm{mol}$. They also observed an increase in diameter as the solvent to polymer ratio increased from a nine $w t \%$ polymer to a $31 \mathrm{wt} \%$ polymer. Similarly, Deitzel et al. (2001) observed this solvent-to-polymer ratio trend, but also noticed the formation of beaded fibers for very low polymer concentrations. This phenomenon was due to the surface tension forces dominating in the solvent-dominated solutions, which tend to pull the solution into beads. Additionally, Deitzel (2001) reported a higher density of beaded fibers as the voltage increased. Koski (2004) reported that beaded fibers for MWs under 10,000 $\mathrm{g} / \mathrm{mol}$ were most likely due to the same reason. Fong et al. (1999) illustrated that the problem of beading can be alleviated through the addition of $\mathrm{NaCl}$ to the polymer solution, possibly due to the increase in conductivity caused by the ionization of the polymer.

\section{Manual Fiber Drawing Technique}

Manual fiber drawing, the basis principle for this investigation, is a new polymer fiber spinning process that allows a user to fabricate micro- or nanoscale fibers by drawing a polymer solution across a substrate. The process begins by mixing polymer with a solvent to create a lower-viscosity solution. A stylus is dipped into a pool of the solution, and the solution adheres to the stylus tip. As the stylus is removed, a small fiber is drawn between the solution pool and the stylus tip. To detach the fiber from the tip, the stylus is submerged in a second pool of solution, causing the fiber to break from the tip and adhere to the second pool. The solution evaporates from the fiber, leaving a solid polymer fiber extending between the two polymer solution pools (Harfenist, 2004). An 
array of fibers, shown as Figure 4, is produced by brushing the polymer solution across an array of points.

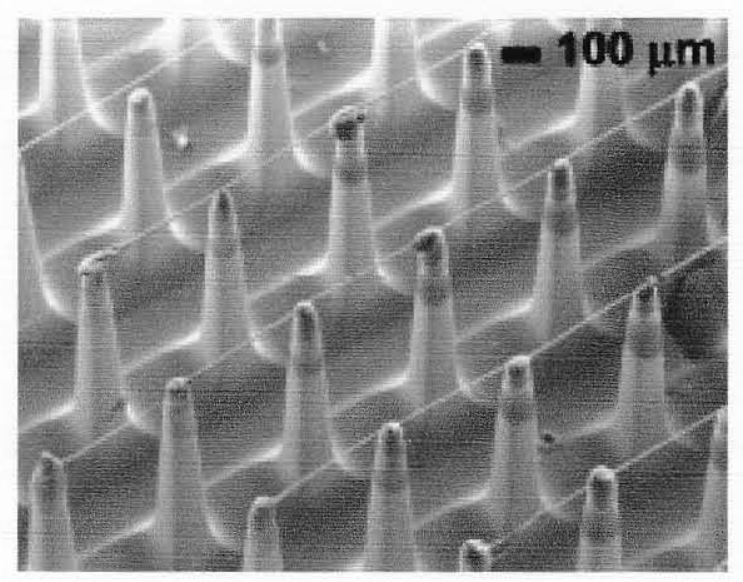

FIGURE 4 - Manually drawn PMMA fibers between two solvated pools. These structures were fabricated by brushing PMMA solution across an array of tips.

\section{B. Capillary Breakup Rheology}

Research done by Tripathi et al. (2000) investigated the unwanted formation of polymer fibers during the processing of adhesive, specifically those based on solvated polymers. In this work Tripathi characterized the fluid properties of these polymer solutions and attempted to link them to the formation of stable polymer fibers. Using intrinsic fluid properties, a unitless "processability parameter" is defined:

$$
P=\frac{h \eta}{\sigma}
$$


where $h$ is the solvent evaporation time constant, $\eta$ is viscosity, and $\sigma$ is surface tension. Qualitative experimentation regarding which polymer solutions readily formed stable fibers was undertaken and it was reported that polymer solutions with values of $P$ less

that $3 \times 10^{-4}$ could not be drawn into fibers whereas solutions with $\mathrm{P}$ values over $10^{-3}$ formed fibers.

\section{Fiber Spinning Summary and Discussion of Molecular Interactions}

Both wet spinning and melt spinning act as controlled methods of rapidly producing polymer fibers. However, nanoscale fibers spun by these methods are inconceivable since both methods require a liquefied polymer to be forced through a spinneret; an enormous pressure gradient would be required to force a highly viscous liquid through a nanoscale orifice. Electrospinning offers nanoscale resolution, but offers the user little control over fiber orientation. Table I provides a quick comparison of the four methods discussed in this section. 


\section{TABLE I}

\section{SUMMARY OF CURRENT POLYMER FIBER SPINNING PROCESSES}

\begin{tabular}{|c|c|c|c|}
\hline & $\begin{array}{l}\text { Diameter } \\
\text { Range }\end{array}$ & Advantages & Drawbacks \\
\hline $\begin{array}{l}\text { Wet / Dry } \\
\text { Spinning }\end{array}$ & microscale & $\begin{array}{l}\text { Easy to create long, smooth } \\
\text { oriented fibers. No } \\
\text { external power required. }\end{array}$ & $\begin{array}{l}\text { Cannot be applied to } \\
\text { nanoscale. }\end{array}$ \\
\hline Melt Spinning & microscale & $\begin{array}{c}\text { Easy to create long, } \\
\text { smooth, oriented fibers. } \\
\text { No solvents are required. }\end{array}$ & $\begin{array}{l}\text { Cannot be applied to } \\
\text { nanoscale. }\end{array}$ \\
\hline Electrospinning & nanoscale & $\begin{array}{l}\text { Quickly creates kilometers } \\
\text { of nanoscale fibers. }\end{array}$ & $\begin{array}{l}\text { Fiber orientation cannot } \\
\text { be controlled. Beaded } \\
\text { fibers form under many } \\
\text { operating conditions. }\end{array}$ \\
\hline
\end{tabular}

It has been shown with electrospinning that fiber diameter increased as polymer molecular weight increased. Also, an increase in diameter was observed as the solvent to polymer ratio decreased. One explanation of both of these relationships stems from the fact that polymer molecules were becoming increasingly entangled as they became longer and a greater percentage of the total solution. As this occurs, entanglements began to form between the polymer molecules. As the number of entanglements increased, solution viscosity also increased, since more energy was needed to shear the additional links. This condition opposed the tendency for a spun fiber to elongate and thin under the axial forces encountered in spinning, resulting in a larger overall fiber diameter.

In both wet spinning and melt spinning, a decrease in diameter was observed with an increase in axial force induced by a powered take-up wheel or gravity. A number of different mechanisms could explain this observation. First, the axial force acted to shear the physical entanglements discussed previously. The force then caused the polymer molecules to slide past one another in solution and reestablish entanglement networks in 
a more elongated orientation. Secondly, the fiber thinning may be due to the realignment of individual molecules rather than bulk reordering of the entire solution. Assuming polymer molecules in solution can be modeled as random coils (a valid assumption in dilute polymer solutions), an application of an opposing force to each end of the coil would cause the molecule to become uncoiled, longer, and thinner; then re-cross-link in this more crystalline orientation. Sperling (2001) points out that this mechanism is still under debate and large amounts of force may be necessary to see any noticeable decrease in molecule coil radius. The final force-thinning mechanism is simple mechanical deformation since much of the tensile-stressed material is actually nearly pure, solid polymer. Immediately after the polymer solution passed through the spinneret it began to solidify either due to cooling in melt spinning or removal of the solvent in wet spinning. As tensile force was applied to the solid fiber, Hookean deformation occurred, resulting in axial elongation and diameter thinning. Long elongations (some over $100 \%$ of the original length) were possible with many solid polymers and therefore large diameter reductions were possible.

Increases in strength were apparent as the degree of crystallization increased in polymer fibers, particularly in melt spinning. X-ray scattering analyses confirmed that crystallization increased as spinning velocity increased. Since axial force (induced by the take-up mechanism) also increased with spinning velocity, this observation correlated well with the second theory in the previous paragraph - the suggestion that increasing tensile force caused the polymer molecules to align in a more crystalline, closely-packed, parallel orientation. This highly ordered orientation positioned the individual polymer 
molecules optimally to (chemically) cross-link with adjacent molecules, giving the bulk material superior mechanical properties such as tensile modulus and tensile strength. 


\section{INSTRUMENTATION AND EQUIPMENT}

\section{A. Micro Milling Machine}

A custom-made ultra-high-precision micro milling machine manufactured by Dover Instrument Corporation (Westboro, Massachusetts) was used in this investigation to control the stylus used to draw the fibers (Friedrich, 1996). This machine operated in a manner similar to a standard milling machine, but the mill stage is capable of translations in the horizontal plane in increments of $1.25 \mathrm{~nm}$ and the mill head is capable of translation in the vertical direction in increments of $20 \mathrm{~nm}$. Also, the micro milling machine can be programmed to allow the user to execute a series of translations with one keystroke. With this instrument (shown as Figure 5), the polymer fibers can be precisely placed in all three dimensions.

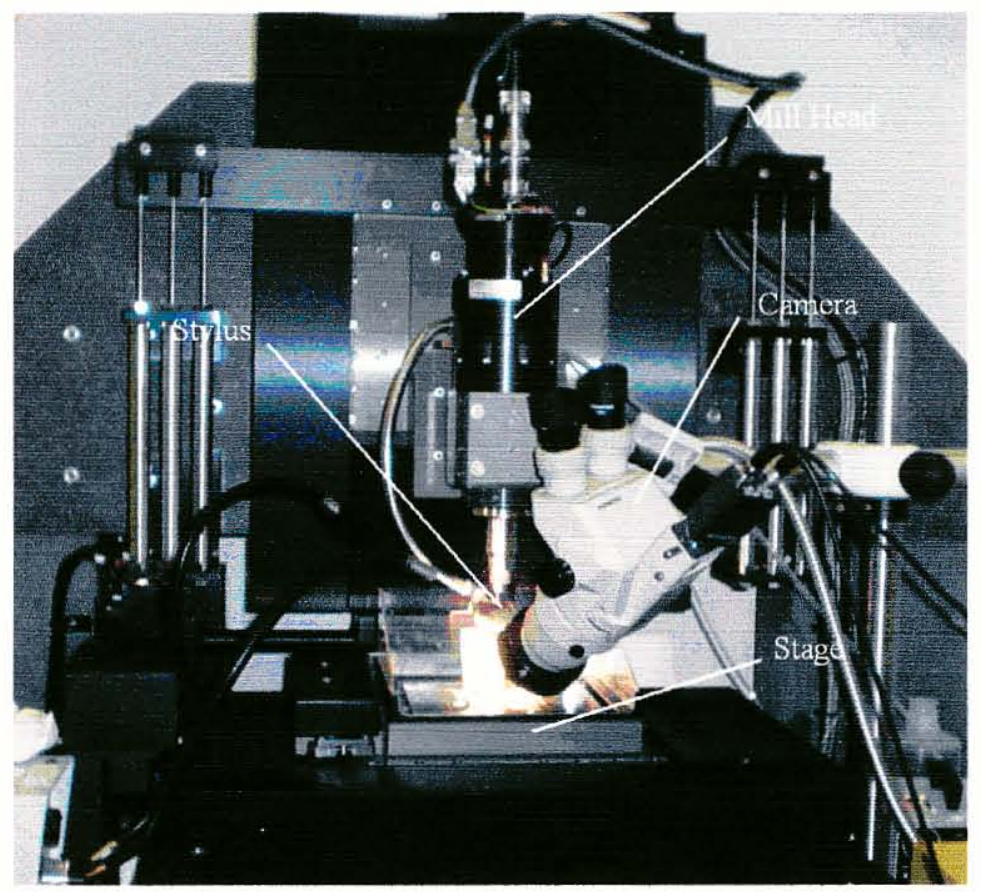

FIGURE 5 - Dover Instruments Micro Milling Machine - The stage translates in the horizontal plane whereas the stylus, which is attached to the mill head, translates vertically. 


\section{B. Scanning Electron Microscope (SEM)}

Since the polymer fibers created in this experiment are micro- or nano-scale, they cannot be measured with an optical microscope. A LEO Supra 35 scanning electron microscope (SEM) (Carl Zeiss, Oberkochen, Germany) was used to image the fibers in this investigation. During analysis, focused electrons strike the sample resulting in the emission of secondary electrons. These electrons are then detected and the signals compiled to display an image. The Supra 35 is capable of resolutions up to $2 \mathrm{~nm}$ at 30 kV (Carl Zeiss Website, 2004). It is shown as Figure 6.

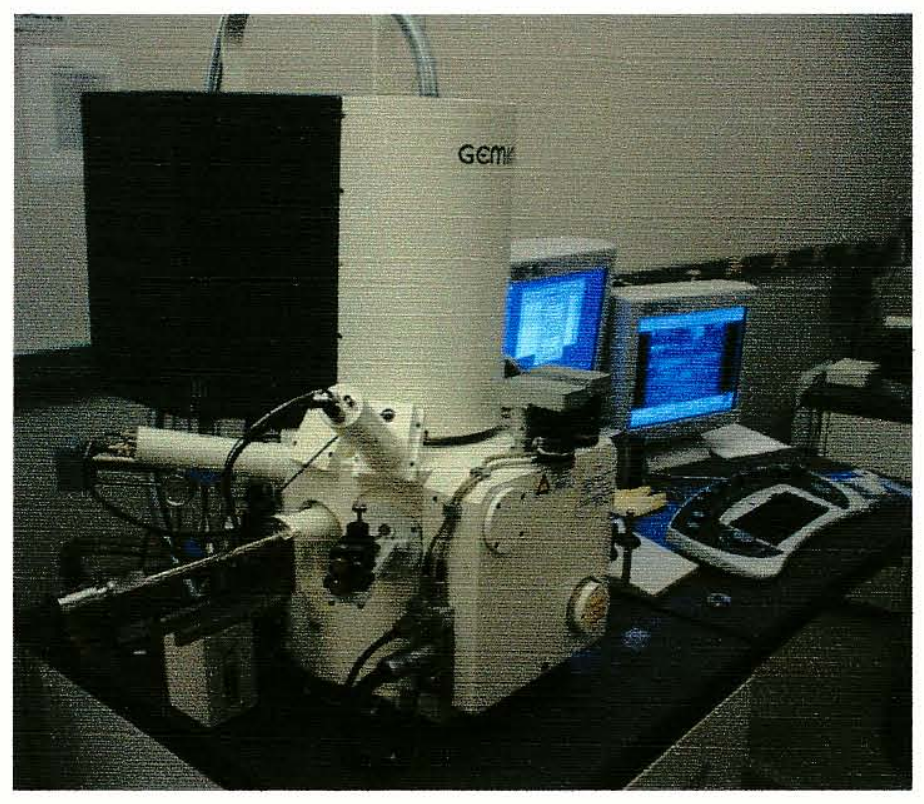

FIGURE 6 - Carl Zeiss LEO Supra 35 SEM

\section{Sputtering Device}

\section{Overview}

Before the fibers are measured with the SEM, they may first be coated with a conducting layer to enhance imaging by increasing the conductance of the sample. A 
thin film of gold was deposited using a PS2 Coating Unit (International Scientific Instruments, Santa Clara, CA). This instrument uses an intense electric field to transform an inert gas into high-energy plasma. The plasma bombards a gold target, releasing gold atoms which then travel to the sample and deposit in the form of a layer estimated to be only a few nanometers thick. The exact thickness of this layer can be controlled by altering the strength of the applied field or by simply allowing the process to continue for longer. Since the purpose of the layer is only to make the sample conductive, the precise value of the layer thickness is unimportant unless nanoscale additions to fiber diameter are unacceptable. This instrument is shown as Figure 7.

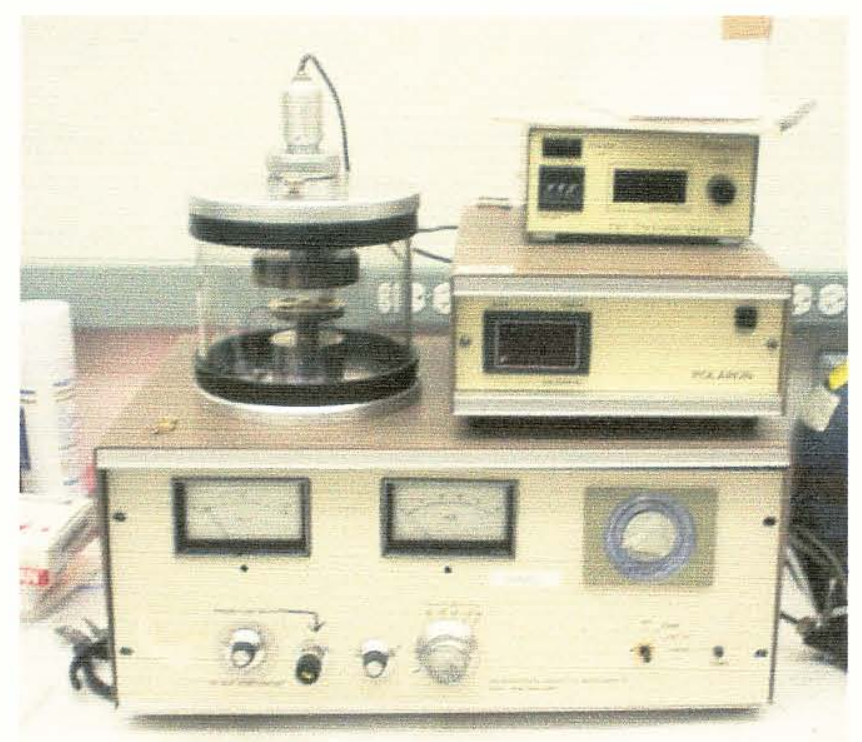

FIGURE 7 - The International Scientific Instruments PS2 Coating Unit

\section{Operation}

First, the sample is sealed inside the sample chamber and the vacuum pump is switched on. When the pressure inside the chamber reaches 0.1 torr, the nitrogen valve is opened to allow non-reactive nitrogen gas inside. When the pressure reaches 0.2 torr the nitrogen valve is partially closed to impede the flow of more gas. The valve should be 
adjusted so the chamber pressure ultimately reaches an equilibrium of 0.1 torr with the vacuum pump running. Lastly, the sputtering time and voltage are set. The samples in this experiment were sputtered at $1 \mathrm{kV}$ for 4 minutes. When the sputtering is complete, the chamber is vented and the sample removed.

D. Viscometer

An LVDV-II+ viscometer (Brookfield, Middleboro, MA) interfaced with a coneand-plate (CP-40 and CP-41, Brookfield) was used to measure the viscosities of the polymer solutions. This device operates by attempting to rotate a cone in contact with a solution and measuring the resistance to this rotation exerted by the fluid. Using preprogrammed scaling factors, the viscometer converts the resistance torque to a viscosity. The viscometer is also equipped with a water jacket (TC-500 Refrigerated Bath / Circulator, Brookfield, Middleboro, MA) that wraps around the cone and plate to provide a constant, controllable temperature. The viscometer and cooling unit is shown as Figure 8. 


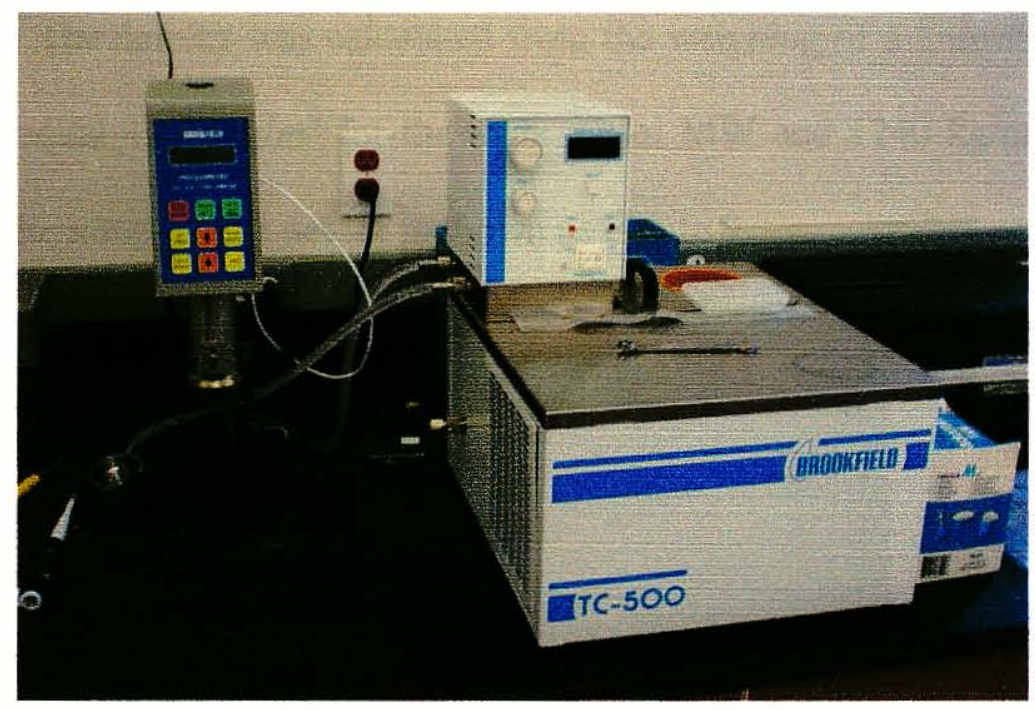

FIGURE 8 - Brookfield LVDV-II+ Viscometer (Left) and TC-500 Refrigerated Bath / Circulator (Right).

\section{E. Surface Tension Measurement}

The surface tensions of the solutions were measured using the capillary method. A capillary is submerged into a beaker of the solution and the solution is allowed to rise until equilibrium is reached. The height the fluid climbs up into the capillary is measured and a close-up photograph is taken to determine the angle of contact between the fluid and the capillary wall. The surface tension is given by:

$$
\sigma=\frac{\rho \cdot r \cdot h \cdot g}{2 \cos \theta}
$$

where $\sigma$ is the surface tension, $\rho$ is the density of the solution, $r$ is the radius of the capillary, $\mathrm{h}$ is the height of the climb, $\mathrm{g}$ is the acceleration due to gravity, and $\theta$ is the 
contact angle. The density was calculated from the weighing of a known volume and it was found to equal $1160 \mathrm{~kg} / \mathrm{m}^{3}$ for the $495 \mathrm{k} \mathrm{g} / \mathrm{mol} \mathrm{MW}$ and $1240 \mathrm{~kg} / \mathrm{m}^{3}$ for the $950 \mathrm{k}$ $\mathrm{g} / \mathrm{mol} \mathrm{MW}$. The setup of this device is shown as Figure 9.

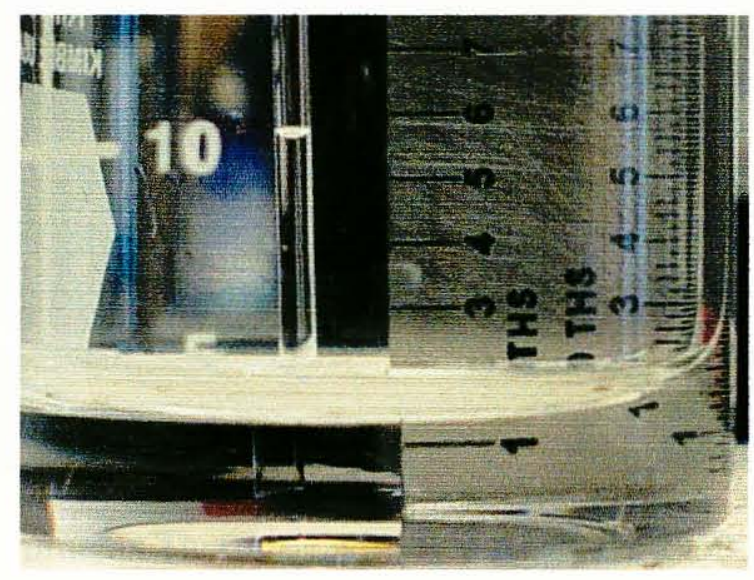

FIGURE 9 - Capillary device used to measure surface tension of solutions.

\section{F. Thermogravimetric Analyzer}

Thermogravimetric analysis was performed using a TA Instruments TGA 2950 (New Castle, DE). This device is capable of recording high-precision weight measurements at a varying temperature so that drying behaviors can be investigated. It consists of a balance enclosed in a vented furnace which can be set to follow a number of different temperature profiles. The TGA device is shown as Figure 10. 


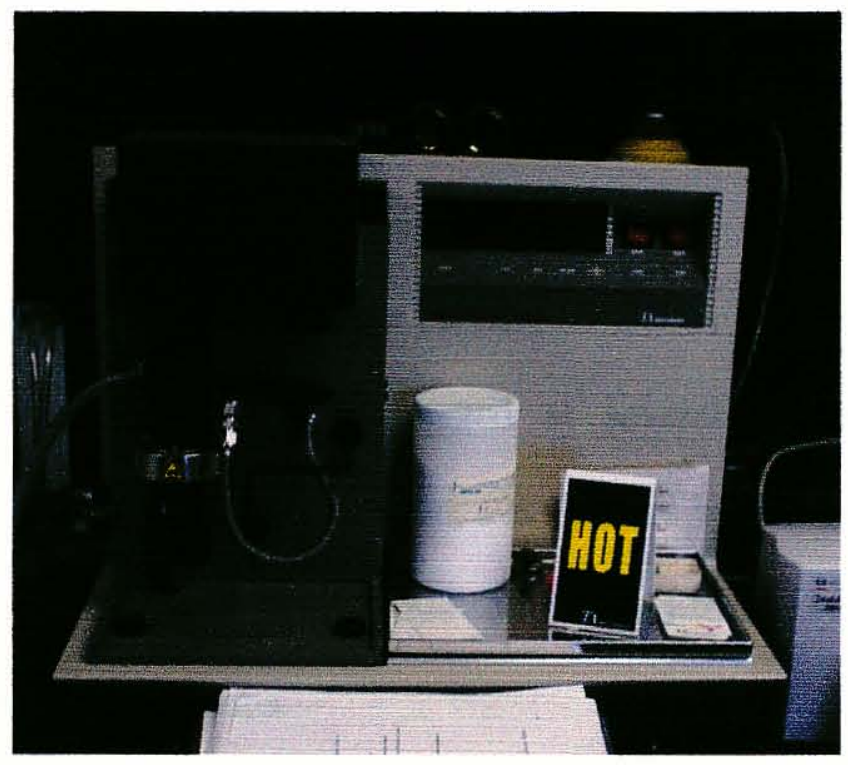

FIGURE 10 - TA Instruments Thermogravimetric Analyzer 2950 


\section{PROCEDURE}

\section{A. Preparation of Solutions}

The characteristics of two different PMMA molecular weight solutions $(495,000$ $\mathrm{g} / \mathrm{mol}$ and $950,000 \mathrm{~g} / \mathrm{mol}$ ) were investigated at several different concentrations. However, since only one stock concentration, 9\% PMMA by weight in chlorobenzene, was available for each molecular weight, this solution had to be thickened or diluted to obtain all the desired concentrations.

Initially, $100 \mathrm{~mL}$ of both $9 \%$ solutions were poured into large beakers and allowed to sit for one day in a fume hood with intermittent stirring. Since the chlorobenzene in the solution evaporates but the PMMA does not, the solution increased in PMMA concentration with time. The new solution concentration was found by:

$$
C=\frac{0.09^{*} m_{\text {Initial }}}{m_{\text {Final }}}
$$

where $\mathrm{C}$ is the concentration, $\mathrm{m}_{\text {Initial }}$ is the initial mass of the solution, and $\mathrm{m}_{\text {Final }}$ is the final mass. After allowing the solution to evaporate for several hours, it was calculated that the $495 \mathrm{k} \mathrm{g} / \mathrm{mol}$ solution had thickened to $23.4 \%$ PMMA by weight and the $950 \mathrm{k}$ $\mathrm{g} / \mathrm{mol}$ solution had thickened to $18.6 \%$ PMMA by weight.

These new stock solutions were then diluted with pure chlorobenzene to produce a number of less concentrated solutions. These solutions were sealed in individual amber 
glass bottles and kept for a maximum time of two weeks as a precaution against slow but unwanted evaporation that occurred even in the sealed environment. As such, new dilutions were made at several points during the investigation. The initial solutions made are listed in Table II.

TABLE II

INITIAL CONCENTRATIONS (\% PMMA BY WEIGHT)

\begin{tabular}{|c|c|}
\hline $495 \mathrm{k} \mathrm{g} / \mathrm{mol}$ & $1 \%, 2.5 \%, 3.5 \%, 5 \%, 7 \%, 9 \%, 11.7 \%, 17.6 \%, 23.4 \%$ \\
\hline $950 \mathrm{k} \mathrm{g} / \mathrm{mol}$ & $1 \%, 2.5 \%, 3.5 \%, 5 \%, 7 \%, 9 \%, 11.2 \%, 14.9 \%, 18.6 \%$ \\
\hline
\end{tabular}

\section{B. Fluid Properties Characterization}

Tripathi et al. (2000) have surmised that the final diameter of a necking fluid column, where the fluid consists of a solvent and solid, is dependent on the viscosity of the solution, its surface tension, and the rate of evaporation of the solvent. Also, preliminary trials of this investigation have shown an apparent relationship between viscosity and fiber diameter. As a supplement to the fiber diameter characterization, the dependency of the diameter on these three parameters will be discussed. Therefore, these parameters must first be measured for each molecular weight solution.

The viscosity of each solution listed in Table II was measured with a Brookfield cone-and-plate viscometer. Immediately upon powering, the viscometer ran an autodiagnostic program and prompted the user to affix the cone to the spindle. Two different cones were available, the CP-40 and the CP-41. Each cone makes a different angle with the plate and is tailored to measure a specific viscosity range. This range is given by: 


$$
\mu=T K * S M C * \frac{10000}{R P M}
$$

where $\mu$ is the viscosity, RPM is the speed of the spindle, TK is the torque constant, equal to 0.09373 , and SMC is the spindle multiplier constant, equal to 0.327 for the $\mathrm{CP}-40$, and 1.228 for the CP-41. Equation 4 indicated that the CP-41 is capable of handling a solution roughly four times more viscous than the CP-40. However, the CP-41 cone required $2.0 \mathrm{~mL}$ of solution whereas the $\mathrm{CP}-40$ cone only required $0.5 \mathrm{~mL}$. As such, the lower viscosity fluids were measured with the $\mathrm{CP}-40$ cone and the higher viscosity fluids were measured with the CP-41.

The viscometer is also capable of measuring viscosities at varying shear rates. The shear rate can be found by:

$$
S R=S R C^{*} R P M
$$

Where SR is the shear rate in $\left(\mathrm{s}^{-1}\right)$ and SRC is the shear rate constant, equal to 7.5 for the CP-40 and 2.0 for the CP-41. Unless otherwise noted, all measurements taken in this investigation were performed at a low shear rate (less than $3 \mathrm{~s}^{-1}$ ) to avoid any shear thinning or thickening.

After the cone was affixed to the spindle, the spindle ID, CP-40 or CP-41 was selected in order to allow the viscometer to automatically calculate viscosity and shear 
rate from Equations 4 and 5. The fluid was dispensed into the cup under the cone and the cup secured in place. The micrometer adjustment ring was turned counter-clockwise to move the cone towards the cup until cup/cone contact was indicated by the contact light. The cone was next raised 0.005 " into its operating position by turning the ring one tick mark clockwise.

Measurements were taken by inputting the desired spindle RPM and recording the viscosity from the display. It is important to allow the viscosity to reach a stable value before recording the data point. Five spindle rotations are suggested to achieve a valid reading. All measurements were taken at a controlled $22.0^{\circ} \mathrm{C}$. In addition, the $9 \%$ solution of each molecular weight was subjected to viscosity measurements at all shear rates the viscometer could apply without traveling above or below the viscometer's useable range.

Surface tension measurements were performed on some of the solutions listed in Table II via the capillary method discussed in Section III-E. It was found that surface tension did not vary by orders of magnitude with concentration like the viscosity. In fact, Tripathi's (2000) investigation assumed a concentration-independent value for the surface tension of each solvent-solid pair.

Lastly, a thermogravimetric analysis (TGA) was performed on the $9 \%$ solution of both molecular weights. One hundred $\mu \mathrm{L}$ of each solution was loaded onto the balance pan and covered with the vented furnace. The TGA was programmed to measure the weight of the solution for four hours at a constant $22.0^{\circ} \mathrm{C}$ by selecting the isothermal operation mode. Weight measurements were recorded approximately every five seconds and plotted. Both trials were allowed to continue for several hours until the mass of the 
solution had ceased its decline. This data could then be plotted to extract a time constant, $h$, for evaporation.

\section{Fiber Diameter Characterization}

Each trial consisted of several wires being drawn in rapid succession between two $50 \mu \mathrm{L}$ pools of the solution. These pools were deposited with a piston micropipette on a silicon wafer substrate on opposing sides of a $1.8 \mathrm{~mm}$ wide trench machined by Alex Isham using a DAD 321 Disco Dicing Saw (Tokyo, Japan). The pools were deposited in a manner such that they were as close to the trench as possible without actually contacting the edge of the trench. It was discovered in preliminary studies that fibers drawn from pools located on the trench edge tended to fall into the trench (although some of these fibers had diameters as small as $140 \mathrm{~nm}$ ). To prevent falling, the pools were moved a slight distance $(\sim 1 \mathrm{~mm})$ from the trench edge to provide a supportive ledge at the ends of the fiber until the fiber has solidified. A diagram of the individual trial setup is shown as Figure 11 and a photograph of this setup is given as Figure 12. The substrate was clamped to the stage of the micromill and the stylus affixed to the milling head. Initially, all 10 solutions listed in Table III were tested using a tungsten needle as the stylus. 


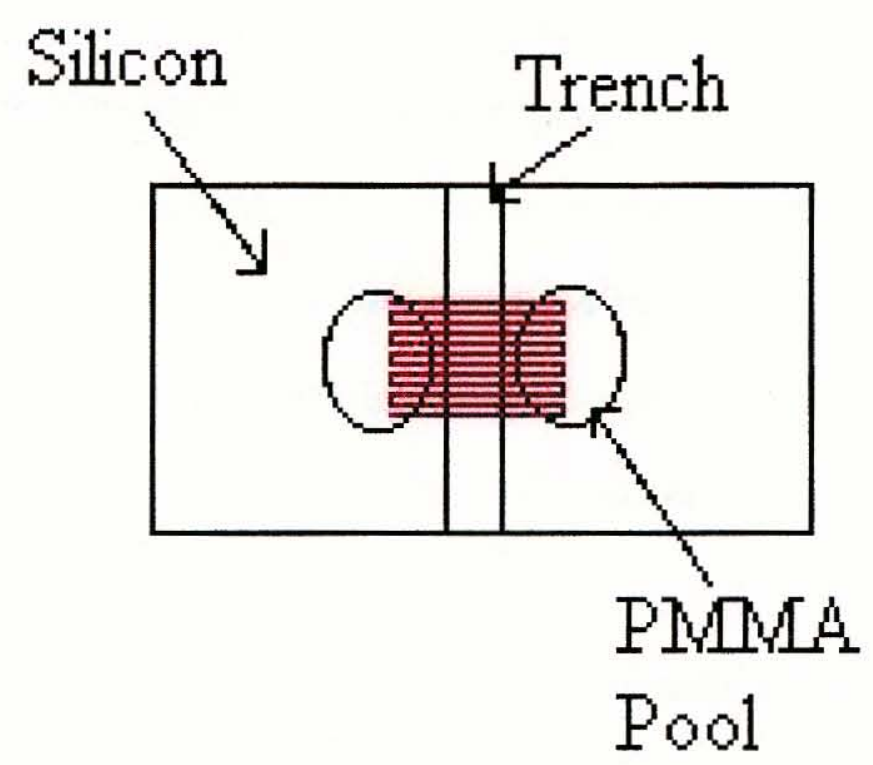

FIGURE 11 - Setup of the fiber-drawing step of the investigation. The red line indicates the path of the stylus between the two solution pools.

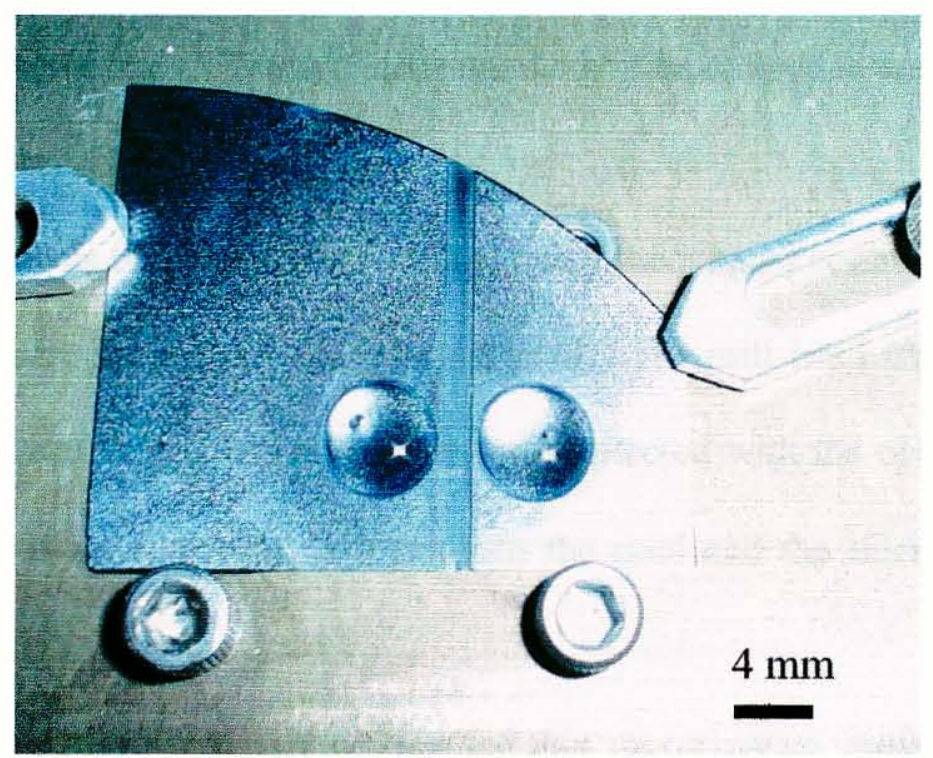

FIGURE 12 - Solution deposited on silicon substrate immediately before trial run.

To start the micromill, the main air valve was opened to supply the air bearings and counter balance with compressed air. Next, the computer, main power, and laser interferometers were switched on. The interferometers, used to position the milling 
stages, require approximately 20 minutes warming time. The illumination of the green warming lights behind the interferometer access panel was used to gauge the laser status. Once the interferometers warmed, PMAC Executive, the milling control software, was started. The micro milling machine was initialized by entering " $\$ \$$ " on the PMAC Executive command line and then pressing the green start button on the mill. The stages were homed by entering the command " $\mathrm{P} 900=9$ " and waiting for the stages to finish moving.

Once the mill was online and initialized a movement program could be loaded into memory. A text editor was opened under the edit menu in the PMAC Executive. Once the code had been entered, the compile button was clicked to load the program into the micro milling machine. Lastly, the PMAC Executive command "B1 R" was used to run the program in memory. The " $\mathrm{A}$ " command could be entered at any time to abort the program in progress.

The stylus was first roughly positioned using the manual controls of the micromill above the top center position of the leftmost pool. The mill head was slowly lowered until contact between the stylus and solution was detected with the optical camera. The stylus was lowered an additional $200 \mu \mathrm{m}$ into the pool and the micromilling program shown in Appendix I was run.

The micromilling program written for this investigation moves the stylus in a serpentine manner between the two pools, attempting to form a fiber on each pass. First, the stylus lifted up $250 \mu \mathrm{m}$ to clear the top of the pool. Next, it translated from the leftmost pool to the rightmost pool, where it dropped $250 \mu \mathrm{m}$ into the solution and completed the first fiber. The milling stage then translated the substrate back $200 \mu \mathrm{m}$ and 
an identical right-to-left traverse was made, forming a second fiber parallel to the first. The process was repeated until the back edge of the pools was reached where the program was halted. The value of the $\mathrm{Q} 100$ variable, which indicates the number of passes made, was recorded to calculate the yield, which is defined as the ratio of the number of passes made to the number of unbroken fibers which span the trench. The path of the stylus as seen from above is indicated by the red line on Figure 11.

This entire process was performed as quickly as possible since any drying of the solution is unwanted. It should be noted that it took approximately one minute from the time the pools were deposited on the silicon substrate to position the stylus and start the program. The stylus moved at a constant $5 \mathrm{~mm} / \mathrm{s}$ and a delay of 1.5 seconds was added between each pass to allow the fiber time to dissolve from the stylus upon reaching its destination pool. This value was determined in preliminary experimentation to be the minimum value required to ensure that all fibers detach from the stylus. (The $50 \mathrm{~ms}$ delays shown in Appendix I were added to account for the lag time of the micromill) Summing the timing of all events, the entire trial took approximately 2.5 minutes from pool deposition to the end of the micromill program.

Once the solution pools and fibers have dried, the sample was imaged by the SEM. The sample chamber was first vented with nitrogen and opened, and the sample(s) were placed on the sample carousel. Next, the sample chamber was sealed and pumped to a vacuum. Once under vacuum the electron beam was restored to a voltage of $20 \mathrm{kV}$ and the variable pressure secondary electron detector was activated. Zoom, panning, brightness, contrast, stigmation, and focal plane controls were all utilized to adjust the viewing area and provide a sharp image of the polymer fibers. The measurement toolbar 
was accessed and the point-to-point measurement tool was used to measure the fiber diameters. The sample was scanned for fibers that span the entire trench. Broken fibers or those that had fallen into the trench were undesired and therefore not counted as a successful draw. Each complete fiber was measured for diameter in three locations, at the center and at each point where the fiber crossed over the edge of the trench

To unload the sample, the SEM was again vented and opened, the sample removed, and the chamber resealed and re-vacuumed before the system was shutdown. Care was taken to avoid touching any SEM component with bare hands during loading or unloading. After the measurements were recorded, the silicon substrate and stylus were cleaned with acetone and reused.

Two problems arose involving the imaging of the PMMA fibers. First, since PMMA is not conductive, it would not produce the secondary electrons necessary for satisfactory viewing under normal operating vacuum. To alleviate this, a 0.75 torr atmosphere of nitrogen was added to the sample chamber to help provide a path for the electrons discharge to ground state. The second problem encountered stems from the fact that the PMMA solution is a positive electron-beam resist used for microfabrication photolithographic processing. This indicates that irradiation of the PMMA with an electron beam breaks bonds in the PMMA molecules that can lead to fiber breakage. Because of this, care was taken to avoid focusing the electron beam of the SEM in one place for too long.

Originally both of these problems were approached by sputter coating the polymer fibers with a thin film of gold with the PS2 Coating Unit. This layer somewhat protected the PMMA from the electron beam and also drastically increased the 
conductivity of the fibers. However, this process was abandoned in the final round of testing because the added thickness of the film falsely added value $(<1$ micron) to the diameter measurements.

During the original, tungsten-stylus trials, the increased buildup of solution on the stylus tip between passes was identified as an uncontrolled variable. In an attempt to control this factor, the effect of the tip material on the fiber diameters was investigated. In addition to tungsten, parylene, glass, and nonstick (perflourooctaltrichlorosilane) styluses were considered. The experimental setup of the trials run with the additional styluses was methodologically identical to the setup used with the tungsten stylus. 


\section{RESULTS AND DISCUSSION}

The characterization of the fiber drawing process was accomplished by first identifying the properties of the polymer solutions and then relating these properties to fiber diameter. In addition, variances of the fiber diameters are discussed and attempted to be minimized by modifying the stylus materials. Fiber yield and uniformity is also examined and a universal parameter to aid in the characterization of additional materials is investigated.

\section{A. Preparations of Solutions}

All solutions used in this investigation were made from stock solutions prepared intermittently throughout the course of the study. The concentrations of the stock solutions were calculated using Equation 3 to determine exactly how much the solutions had thickened during the fume hood evaporation. Qualitative experimentation with the solutions listed in Table II yielded an insight into which concentrations would produce useable, unbroken fibers and which would be too dilute or concentrated to be of any utility. This information led to the creation of a number of test concentrations, listed in Table III, that were known to produce unbroken fibers. These solutions were created by diluting the stock solutions with pure chlorobenzene to reduce them to the desired values. 
TABLE III

CONCENTRATIONS USED IN QUANTITATIVE TESTING (\% PMMA BY

WEIGHT)

\begin{tabular}{|c|c|}
\hline $495 \mathrm{k} \mathrm{g} / \mathrm{mol}$ & $15.5 \%, 16 \%, 17 \%, 18 \%, 21.6 \%, 23 \%$ \\
\hline $950 \mathrm{k} \mathrm{g} / \mathrm{mol}$ & $13 \%, 15 \%, 18 \%, 21.3 \%$ \\
\hline
\end{tabular}

\section{B. Fluid Properties Characterization}

\section{Viscosity}

The viscosities of the solutions listed in Table II were measured at a low shear rate (less than $3 \mathrm{~s}^{-1}$ ) and plotted on Figure 13. This semilog plot illustrates that viscosity increases exponentially with concentration and the higher molecular weight polymer has a higher viscosity at a given concentration. Specifically, viscosity and concentration are related by $\eta=7.0256 \mathrm{e}^{46.828 c}$ with $R^{2}=0.9704$ for the $495 \mathrm{k}$ molecular weight and $\eta=3.476$ $\mathrm{e}^{34.721 \mathrm{c}}$ with $\mathrm{R}^{2}=0.9847$ for the $950 \mathrm{k}$ molecular weight. The accompanying Figure 14 shows the viscosity of the $9 \%$ solution for each molecular weight at varying shear rates. Figure 14 illustrates that there is no noticeable shear thinning of the solutions at the tested shear rates, therefore, the measured viscosity can be assumed to equal the zero shear rate viscosity. 


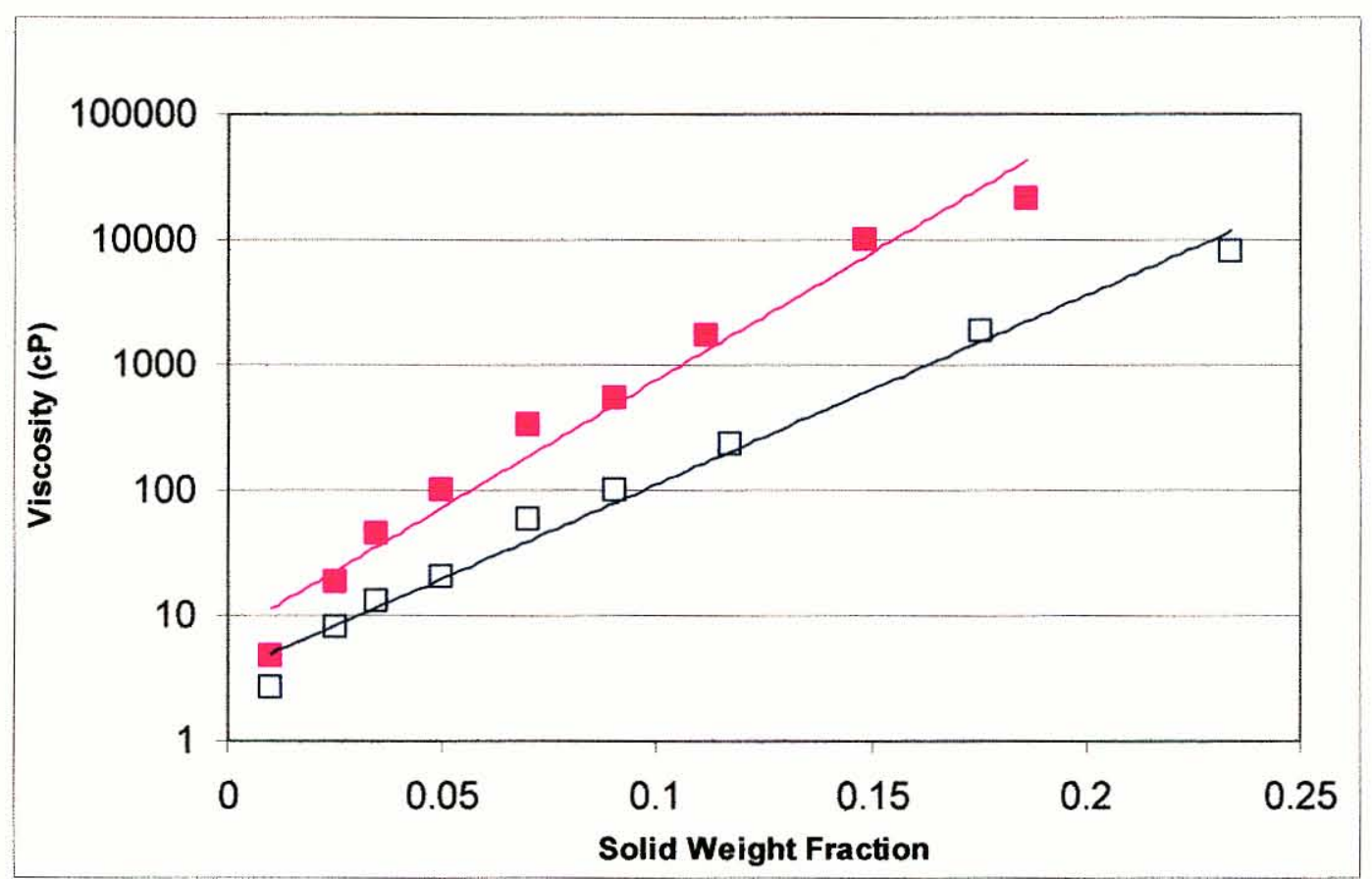

FIGURE 13 - Viscosity of PMMA solution with given MW at varying concentration. The hollow data points and lower line represent the measured data and curve fit for the 495k MW PMMA solution, respectively, and the solid data points and upper line represent the measured data and curve fit for the 950k MW PMMA solution, respectively.

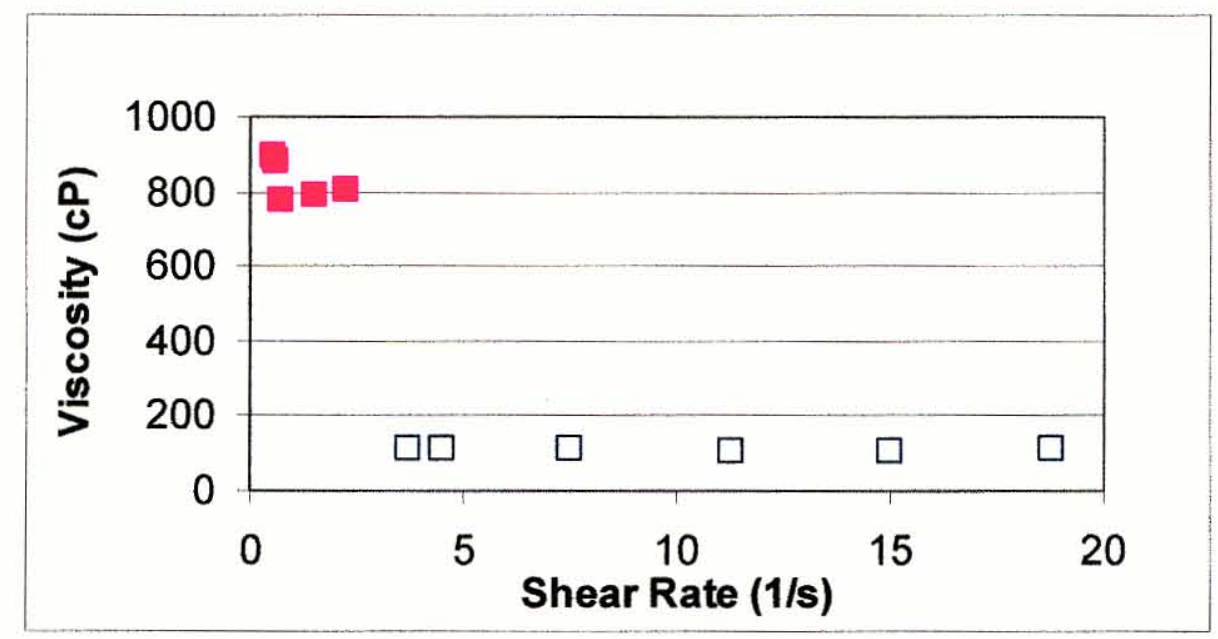

FIGURE 14 - Viscosity of $9 \%$ solutions at varying shear rate. The hollow data points represent viscosity measurements performed on the $9 \% 495 \mathrm{k}$ MW solution whereas the solid data points represent those taken on the $9 \% 950 \mathrm{k}$ MW solution. 
Sperling suggested that the Einstein's viscosity relationship can be used to approximate the viscosity of polymers in solution if there is no intermolecular interaction. The predicted viscosity is given by:

$$
\eta=\eta_{\text {solvent }}\left[2.5\left(\frac{\rho \cdot c \cdot N_{A}}{M W}\right) \cdot V_{H}+1\right]
$$

where $\eta_{\text {solvent }}$ is the viscosity of the solvent, $0.92 \mathrm{cP}$ for chlorobenzene, $\mathrm{c}$ is the concentration of the solution, $\mathrm{N}_{\mathrm{A}}$ is Avogadro's number, $\mathrm{MW}$ is the molecular weight, and $V_{H}$ is the equivalent hydrodynamic radius, approximated by solving Equation 6 for $V_{H}$ with the experimental data for $c=0.09$. Figure 15 shows the Einstein relationship plotted over the same concentration range as Figure 13. A simultaneous comparison of Figure 13 and Figure 15 clearly indicates that the assumptions of Einstein's viscosity relationship are invalid since regression analysis on the actual data (Figure 13) yielded an exponential relationship between viscosity and concentration whereas the Einstein plot (Figure 15) yields the linear relationships $\eta=1078.7 c+0.92$ and $\eta=6037.2 c+0.92$, for the $495 \mathrm{k} \mathrm{g} / \mathrm{mol}$ and $950 \mathrm{k} \mathrm{g} / \mathrm{mol}$ solutions, respectively. These results suggest that the intermolecular interactions become more prevalent as concentration increases (Einstein's model assumes no intermolecular interaction), which is logical since it is anticipated that contact between molecules would increase as molecular concentration rises. As a result of this, it can be seen via the figure comparison that actual viscosity measurements at 
higher concentrations surpass the theoretical Einstein values by an order of magnitude or more. In fact, polymeric theory suggests that an exponentially increasing viscosity curve indicates the increasing presence of entanglement couplings, or physical knots between polymer molecules formed by random thermal motion (i.e., Brownian motion), and also that such couplings are common in polymer solutions where the concentration exceeds $\sim 3 \%$ (Bird, 1977, pp. 77-78).

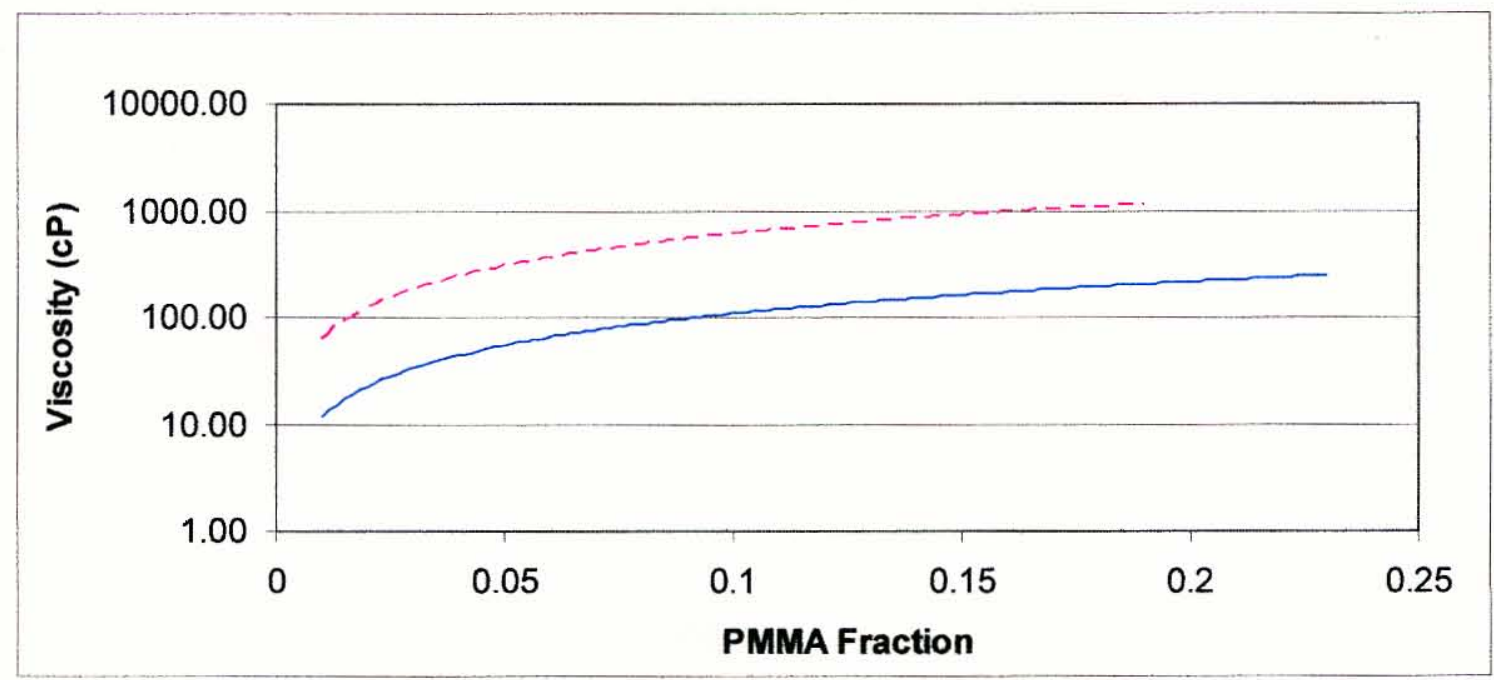

FIGURE 15 - Einstein's relationship viscosity predictions. The solid and dashed lines represent the linear relationships predicted by Einstein's relationship (Equation 6) for the $495 \mathrm{k}$ MW solutions and the $950 \mathrm{k}$ MW solutions, respectively.

\section{Surface Tension}

Surface tension measurements of the polymeric solutions were taken at zero, five, seven, and nine percent concentrations for each molecular weight (Figure 16). These values were tested initially since their lower viscosity would allow them to flow more quickly into the capillary used to measure surface tension. Unlike viscosity, which changes more than an order of magnitude over this span of weight fraction, surface tension tended to be relatively independent of concentration and molecular weight as 
evidenced by the data points given in Figure 16. This independence led Tripathi's investigation (2000) to assume a concentration-independent value for the surface tension of each solvent-solid pair. The same strategy was used for this investigation and the surface tension values were chosen as the average of the three non-trivial data points in Figure 16 for each molecular weight. Specifically, the surface tension value is $0.039 \mathrm{~N} / \mathrm{m}$ and $0.041 \mathrm{~N} / \mathrm{m}$ for the $495 \mathrm{~kg} / \mathrm{mol}$ and $950 \mathrm{k} \mathrm{g} / \mathrm{mol}$ solutions, respectively.

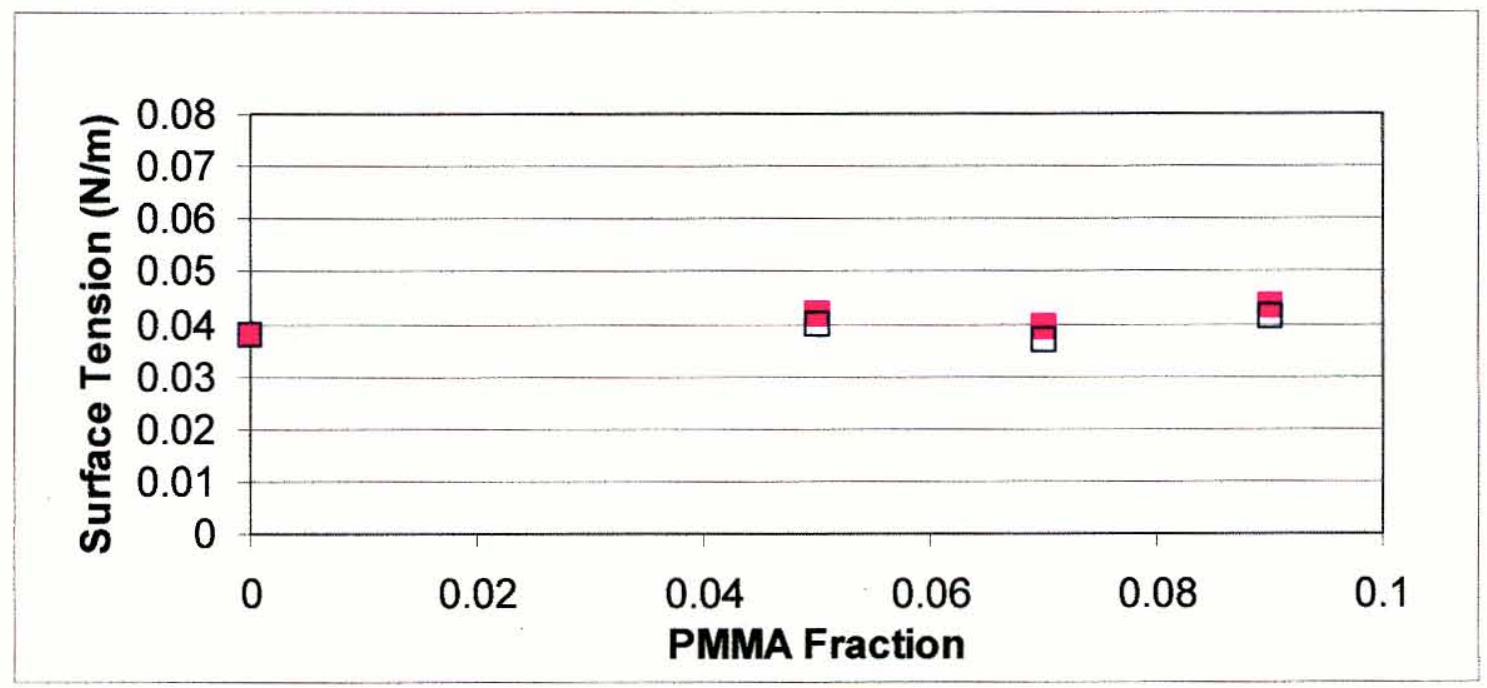

FIGURE 16 - Surface tension of the PMMA solutions as a function of concentration. The hollow data points represent the surface tensions measurements of the $495 \mathrm{k} \mathrm{g} / \mathrm{mol}$ solutions whereas the solid data points represent those of the $950 \mathrm{k} \mathrm{g} / \mathrm{mol}$ solutions.

\section{Thermogravimetric Analysis}

A thermogravimetric analysis in the form of a drying test was performed on 100 $\mu \mathrm{L}$ of $9 \%$ solution for each molecular weight. Figure 17 shows the solvent mass fraction of each solution for 210 minutes of drying time. Data collected after this point was omitted from the figure because the solution had reached its final solvent fraction plateau, $\mathrm{SMF}_{\infty}$. 


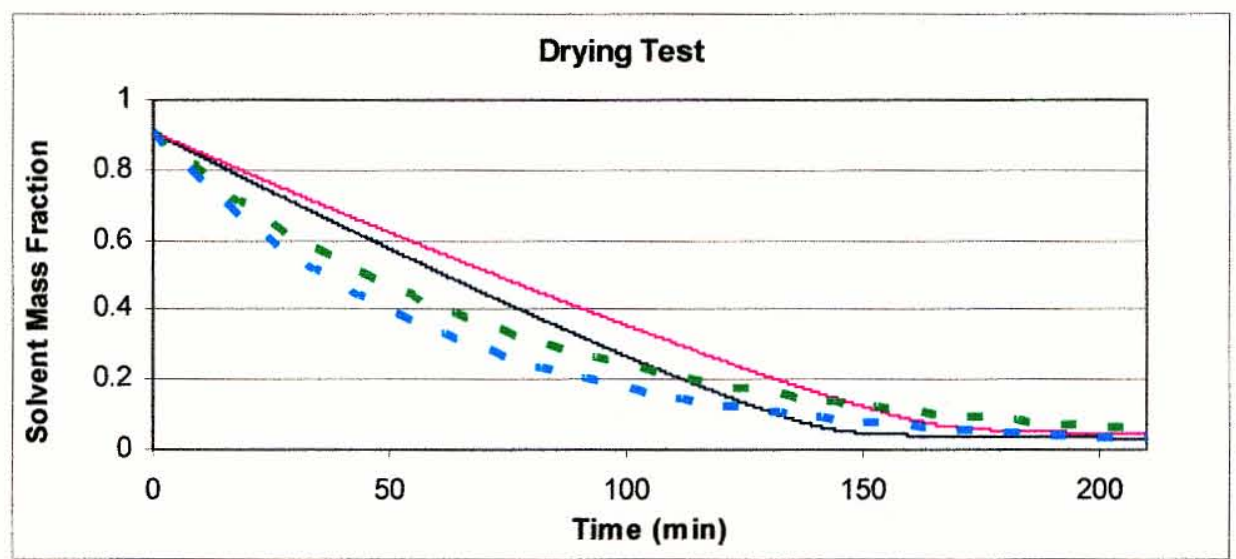

FIGURE 17 - TGA results and exponential curve fits for the solvent mass fraction as a function of time and molecular weight. The lower solid and upper solid lines represent the actual data recorded by the TGA for the $9 \%$ solution of $495 \mathrm{k} \mathrm{g} / \mathrm{mol}$ polymer and $950 \mathrm{k}$ $\mathrm{g} / \mathrm{mol}$ polymer, respectively. The lower dotted and upper dotted lines are exponential curve fits for the actual $495 \mathrm{k} \mathrm{g} / \mathrm{mol}$ and $950 \mathrm{k} \mathrm{g} / \mathrm{mol}$ data, respectively.

The solvent mass fraction was defined as:

$$
S M F=\frac{m_{\text {solution }}-m_{P M M A}}{m_{\text {initial }}}
$$

where $\mathrm{m}_{\text {solution }}$ is the measured mass of solution, $\mathrm{m}_{\mathrm{PMMA}}$ is the mass of the PMMA (assumed to be constant with time), and $\mathrm{m}_{\text {initial }}$ is the initial mass of the solution. This transformation of the raw data was required to allow an exponential curve to be fitted to the data so that a time constant could be extracted. Exponential curves were found by regression analysis to be $\mathrm{SMF}=0.91 \mathrm{e}^{-0.0166 \mathrm{t}}$ with an $\mathrm{R}^{2}=0.9272$ for the $495 \mathrm{~kg} / \mathrm{mol}$ solution and $\mathrm{SMF}=0.91 \mathrm{e}^{-0.0134 \mathrm{t}}$ with an $\mathrm{R}^{2}=0.9125$ for the $950 \mathrm{~kg} / \mathrm{mol}$ solution. The exponential coefficient was normalized by dividing by the surface area to volume ratio of 
the drying test solution in order to obtain a time constant applicable to any surface to volume ratio. The ratio used in the TGA test was found to be $785\left(\mathrm{~m}^{-1}\right)$ given the known volume of the solution and exposed area of the TGA sample pan. The end result of this process was a solvent mass evaporation time constant of $2.10 * 10^{-5} \mathrm{~m} / \mathrm{s}$ for the $495 \mathrm{k}$ $\mathrm{g} / \mathrm{mol}$ solution and $1.71 * 10^{-5} \mathrm{~m} / \mathrm{s}$ for the $950 \mathrm{k} \mathrm{g} / \mathrm{mol}$ solution. The procedure for extracting the time constant was modeled after the one used by Tripathi et al. (2000). Figure 17 illustrates that both molecular weights dry at similar rates, with the heavier molecular weight, $950 \mathrm{k} \mathrm{g} / \mathrm{mol}$, drying slightly faster.

\section{Diameter Measurements}

Figure 18 presents the effect of solution concentration on fiber diameter. The fibers were drawn using a tungsten needle as the stylus with a stylus speed of $5 \mathrm{~mm} / \mathrm{s}$. Each data point represents the average diameter for a number of fibers, which ranged from 4 to 13 , constructed at that concentration. In addition, the reported diameter of each individual fiber represents an average of three measurements taken along the length of the fiber. Regression analysis of Figure 18 results in a logarithmic curve fit of $D=$ $46.978 \operatorname{Ln}(c)-126.4$ with an $R^{2}=0.9209$ for the $495 \mathrm{~kg} / \mathrm{mol}$ data and one of $\mathrm{D}=45.096$ $\operatorname{Ln}(\mathrm{c})-110.74$ with an $\mathrm{R}^{2}=0.9306$ for the $950 \mathrm{k} / \mathrm{mol}$ data where $\mathrm{D}$ is fiber diameter and c is concentration. All measurements presented in Figure 18 are shown in tabular and graphical form in Appendix II. 


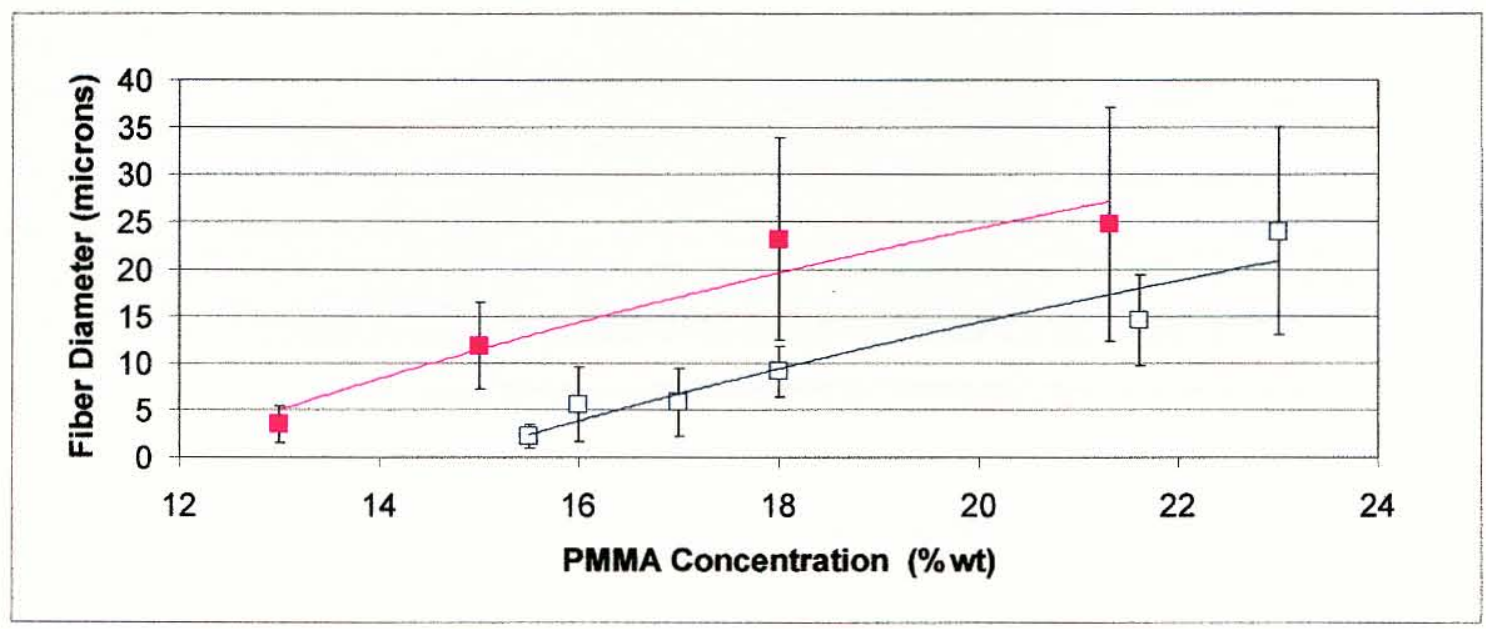

FIGURE 18 - Fiber diameter versus concentration for tungsten stylus. The hollow and solid data points and lines represent the average measured diameters of the drawn fibers and the corresponding curve fits for the $495 \mathrm{~kg} / \mathrm{mol}$ data and the $950 \mathrm{~g} / \mathrm{mol} \mathrm{data}$, respectively. The error bars represent the standard deviation of each data point.

Figure 18 illustrates that fiber diameter increases with solid concentration. An unpaired, 2-tailed, Student's T-Test was performed on each molecular weight, comparing the lowest concentration data point to the highest concentration data point. Results showed that fiber diameter increases with increasing solid concentration as indicated by the lower solid concentration producing significantly smaller fiber diameters $(\mathrm{P}<0.001)$ compared to the higher solid concentration for both molecular weight cases. In addition a T-Test comparison was performed on the $18 \%$ (wt $\%)$ concentrations, since this was the only case where both molecular weights were studied for the same concentration, and it was found that fiber diameter significantly increased $(\mathrm{P}<0.025)$ with increasing molecular weight. Some of the fibers drawn during the characterization trials are shown as Figure 19. The completer listing of fiber images is shown as Appendix III. 


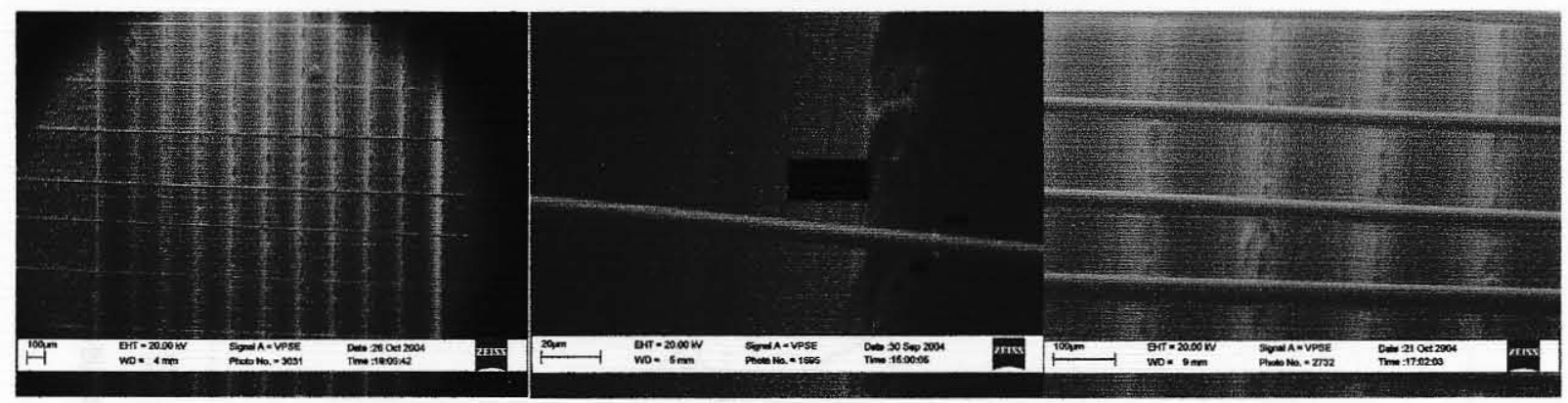

FIGURE 19 - SEM images of fibers drawn in characterization trials.

It was also discovered that fiber diameter increases with viscosity. Figure 20, a semilog plot, shows an increasing logarithmic relationship between viscosity and fiber diameter for both molecular weights $\left(D=7.144 \operatorname{Ln}(\eta)-44.645\right.$ with $R^{2}=0.9326$ for $495 \mathrm{~kg} / \mathrm{mol}$ and $\mathrm{D}=5.6028 \mathrm{Ln}(\eta)-39.278$ with $\mathrm{R}^{2}=0.8941$ for $\left.950 \mathrm{~kg} / \mathrm{mol}\right)$. The macroscopic explanation for this trend is as such, when a fluid bridge is formed between two points it has a tendency to undergo necking as the fluid moves away from the center of the bridge towards the ends of the fiber. If this is allowed to continue for long, the fiber diameter near the center of the bridge will reach such a miniscule value that the fiber will fracture. Once the fluid bridge has been drawn, however, its high surface area to volume ratio leads to the rapid evaporation of the remaining solvent, which consequently, results in the solidification of the bridge. The key to successfully drawing an intact fiber is to promote solidification of the bridge by slowing the necking process via increasing solution viscosity; thereby, increasing the resistance to flow away from the necking point. 


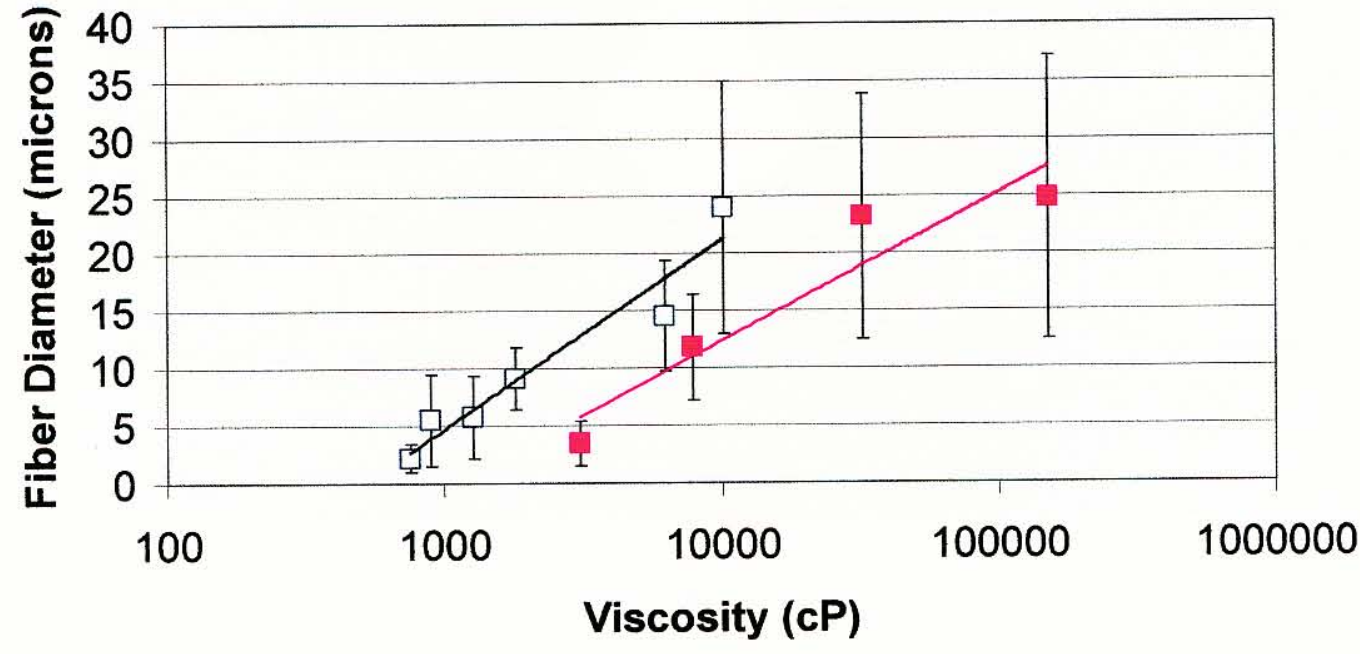

FIGURE 20 - Fiber diameter plotted against viscosity for both molecular weights shows an increase in diameter with an increase in viscosity. The hollow data points and upper line represent the measured data and curve fit, respectively, for the $495 \mathrm{k} \mathrm{g} / \mathrm{mol}$ solutions and the corresponding solid data points and lower curve represent the $950 \mathrm{k} \mathrm{g} / \mathrm{mol}$ solution.

The drawback of this method is the large standard deviation, as indicated by the large error bars, of the fiber diameters, as illustrated by Figure 18, implying that the precise control of a fiber diameter is difficult. During fiber drawing, a large buildup of solution was observed on the tip of the stylus. This buildup, which essentially changed the tip geometry between fiber drawing passes, was identified as an uncontrolled variable that may contribute to these large variances. An example of solution buildup is shown as Figure 21. 


\section{Stylus $\longrightarrow$}

\section{Fiber $\rightarrow \quad$ Buildup}

FIGURE 21 - Solution buildup on stylus tip.

In an attempt to alleviate this problem, a number of different stylus materials were tested in hopes that buildup would not occur as extensively, particularly with a lowerfriction stylus. In this second round of fiber diameter testing, only the $495 \mathrm{k} \mathrm{g} / \mathrm{mol}$ solution was used, since it produced the more desirable, smaller fibers as indicated by Figure 18. Table IV reveals that the difference between the diameters of the fibers drawn with styluses made from differing materials is not statistically significant. The regression curve fit parameters for this data are given in Table V. Figure 22 shows a comparison of the fiber diameter standard deviations for the four tested stylus materials. Inspection shows that fiber diameter standard deviation is minimized at five of the six tested concentrations through the use of a parylene stylus. Although diameter variance is not eliminated, the reduction seen with the parylene tip is a marked improvement over the original tungsten stylus. However, no unbroken fibers were drawn by the parylene stylus at a concentration of $15.5 \%$, illustrating a potential downside of utilizing a low-adhesion material for a stylus. 
TABLE IV

MEAN AND STANDARD DEVIATION (IN MICRONS) FOR FIBERS DRAWN WITH 495K G/MOL PMMA CONCENTRATIONS USING DIFFERING STYLUS MATERIALS

\begin{tabular}{|c|c|c|c|c|}
\hline PMMA Conc. & Tungsten & Parylene & Nonstick & Glass \\
\hline $15.5 \%$ & $2.22 \pm 1.20$ & No Data & $10.81 \pm 6.88$ & $2.43 \pm 1.09$ \\
\hline $16 \%$ & $5.54 \pm 3.95$ & $7.41 \pm 2.49$ & $8.76 \pm 2.84$ & $4.38 \pm 3.11$ \\
\hline $17 \%$ & $5.80 \pm 3.59$ & $6.78 \pm 1.38$ & $7.92 \pm 5.08$ & $4.20 \pm 2.04$ \\
\hline $18 \%$ & $9.07 \pm 2.68$ & $6.27 \pm 3.02$ & $4.69 \pm 2.69$ & $4.84 \pm 2.71$ \\
\hline $21.6 \%$ & $14.53 \pm 4.82$ & $19.03 \pm 1.40$ & $15.24 \pm 7.58$ & $18.37 \pm 6.36$ \\
\hline $23 \%$ & $23.96 \pm 11.00$ & $26.98 \pm 2.03$ & $34.80 \pm 11.61$ & $17.29 \pm 5.43$ \\
\hline
\end{tabular}

\section{TABLE V}

REGRESSION CURVE FITS AND $\mathrm{R}^{2}$ VALUES FOR FIBERS DRAWN WITH 495K G/MOL SOLUTION USING DIFFERING STYLUS MATERIALS

\begin{tabular}{|c|c|c|}
\hline Stylus Material & Regression Curve Fit & $\mathrm{R}^{2}$ Value \\
\hline Tungsten & $\mathrm{D}=46.978 \mathrm{Ln}(\mathrm{c})-126.40$ & 0.9209 \\
\hline Parylene & $\mathrm{D}=55.944 \mathrm{Ln}(\mathrm{c})-151.23$ & 0.8820 \\
\hline Nonstick & $\mathrm{D}=53.97 \mathrm{Ln}(\mathrm{c})-143.84$ & 0.5879 \\
\hline Glass & $\mathrm{D}=42.609 \mathrm{Ln}(\mathrm{c})-115.30$ & 0.9138 \\
\hline
\end{tabular}

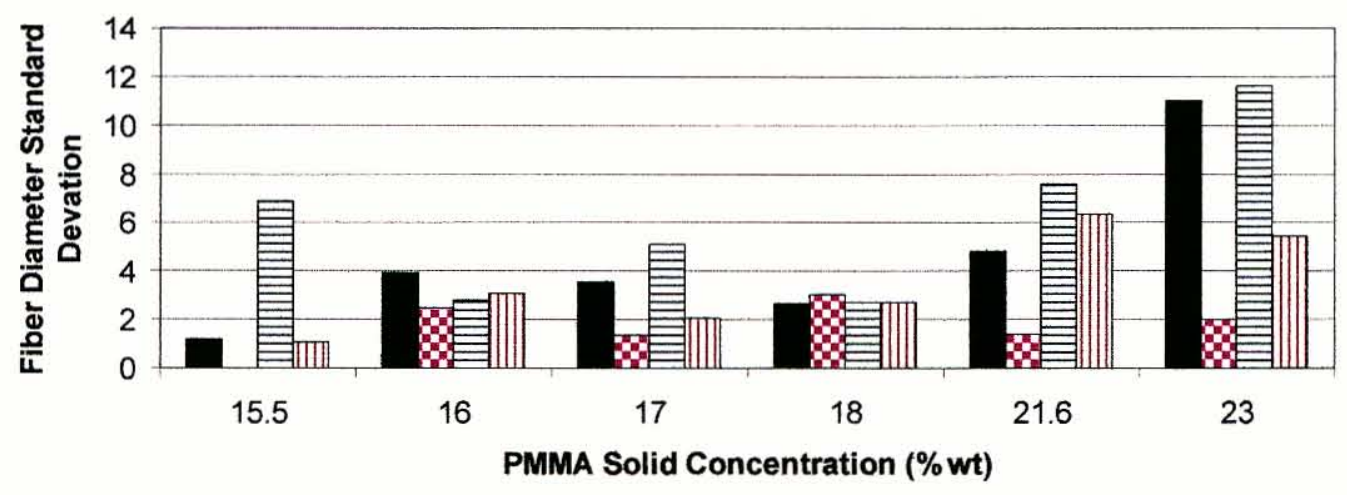

FIGURE 22 - Fiber diameter standard deviations with additional stylus materials and $495 \mathrm{k} \mathrm{g} / \mathrm{mol}$ solution. The solid bars represent the tungsten stylus, the checkered bars represent parylene, the horizontal striped bars represent nonstick, and the vertical striped bars represent glass. 
Since multiple measurements were taken on each fiber, diameter consistency along an individual fiber can be investigated. Figures 23 and 24 show the average standard deviations calculated from the three measurements along each fiber for the $495 \mathrm{k}$ $\mathrm{g} / \mathrm{mol}$ and $950 \mathrm{k} \mathrm{g} / \mathrm{mol}$ solutions, respectively. Individual standard deviations can be found in Appendix II.

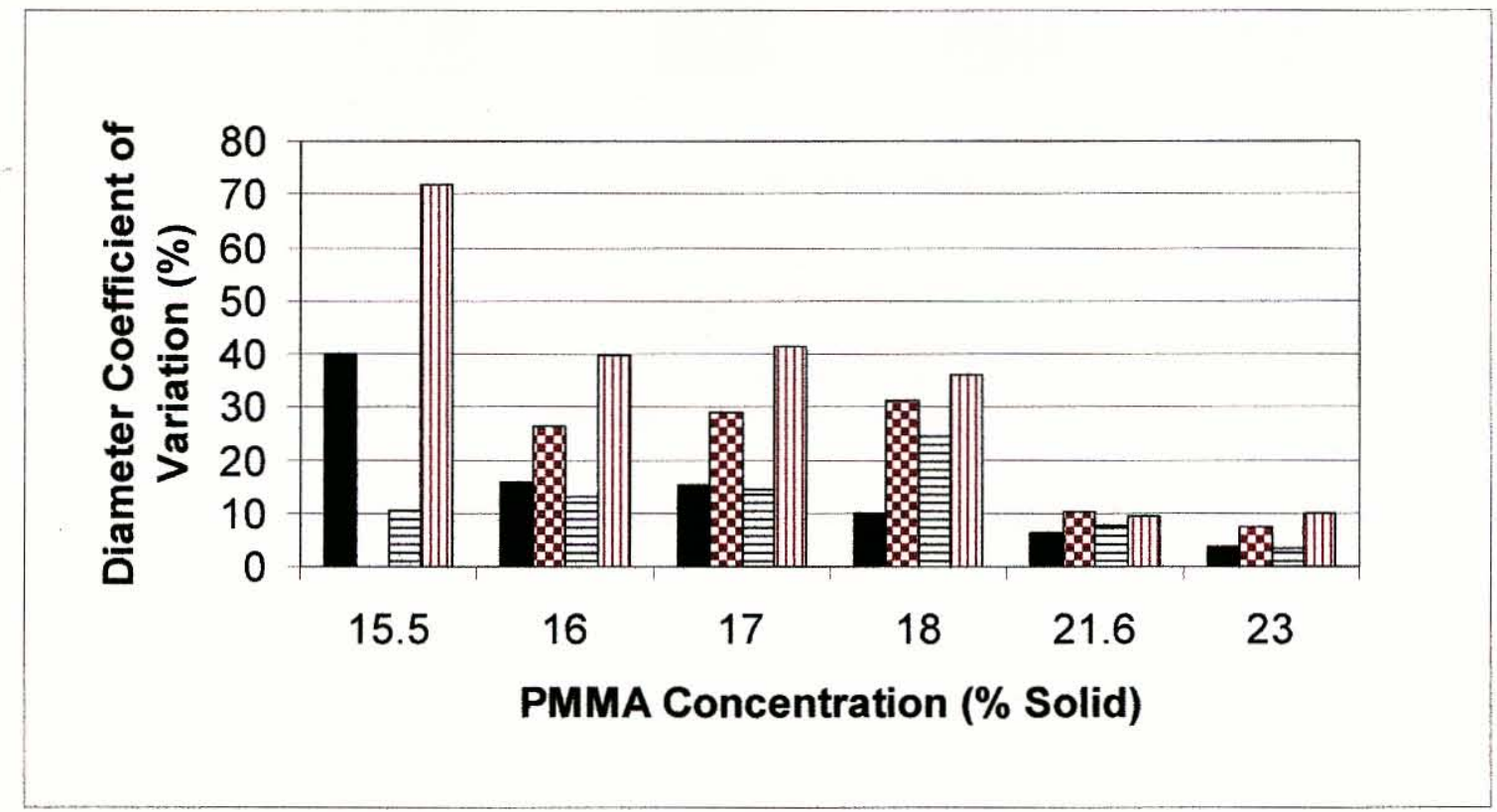

FIGURE 23 - Coefficients of variance describing variation in diameter along an individual fiber for $495 \mathrm{k} \mathrm{g} / \mathrm{mol}$ solutions. The solid bars represent the tungsten stylus, the checkered bars represent parylene, the horizontal striped bars represent nonstick, and the vertical striped bars represent glass. 


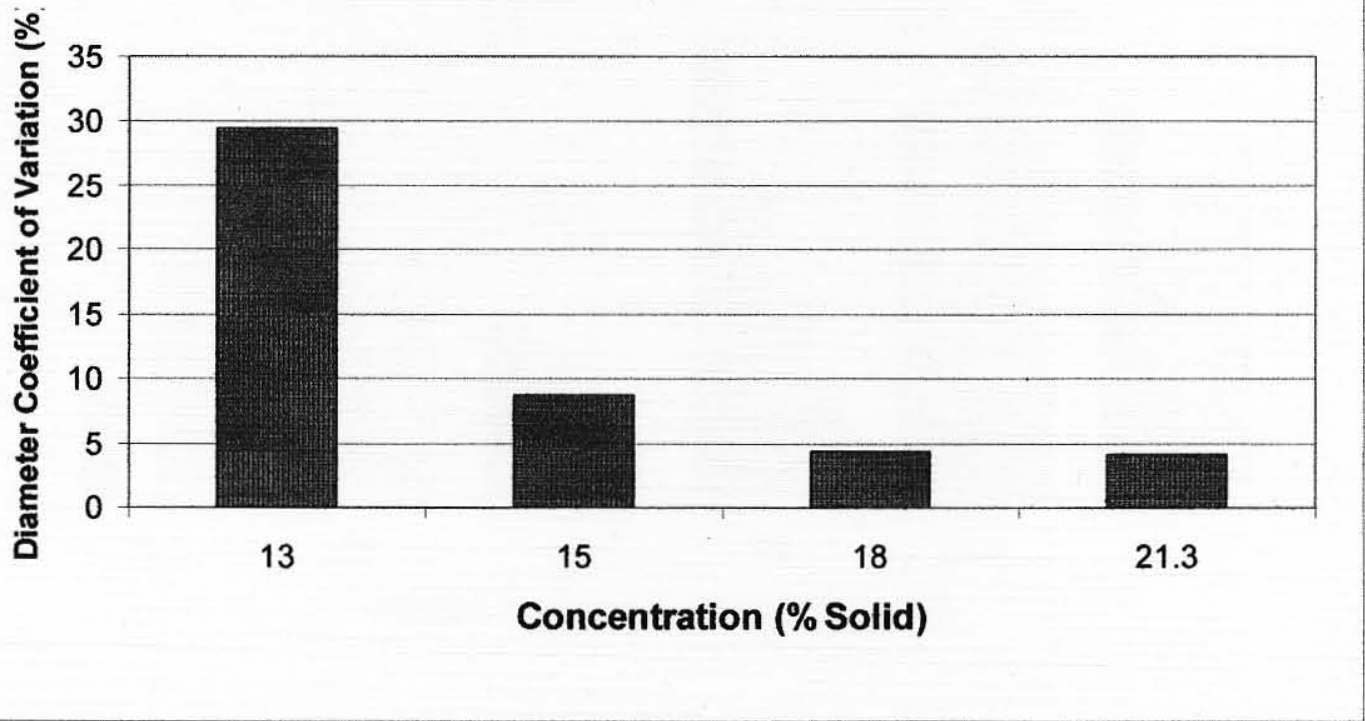

FIGURE 24 - Coefficients of variance describing variation in diameter along an individual fiber for $495 \mathrm{k} \mathrm{g} / \mathrm{mol}$ solutions (tungsten stylus).

Figures 23 and 24 indicate the average percent change in fiber diameter along the length of an individual fiber. The solutions with higher solid concentrations (and higher fiber diameters) produce fibers with more uniform diameters. This data may be utilized by a potential user of this fabrication process to estimate the uniformity of a fiber drawn under these experimental parameters.

\section{Fiber Yield}

In addition to fiber diameter, fiber yield was also an important parameter to optimize for this process. Fiber yield is defined as the number of unbroken fibers divided by the number of drawing passes made with the stylus. The yields for the $495 \mathrm{k} \mathrm{g} / \mathrm{mol}$ trials and $950 \mathrm{k} \mathrm{g} / \mathrm{mol}$ trials are shown as Figures 25 and 26, respectively. 


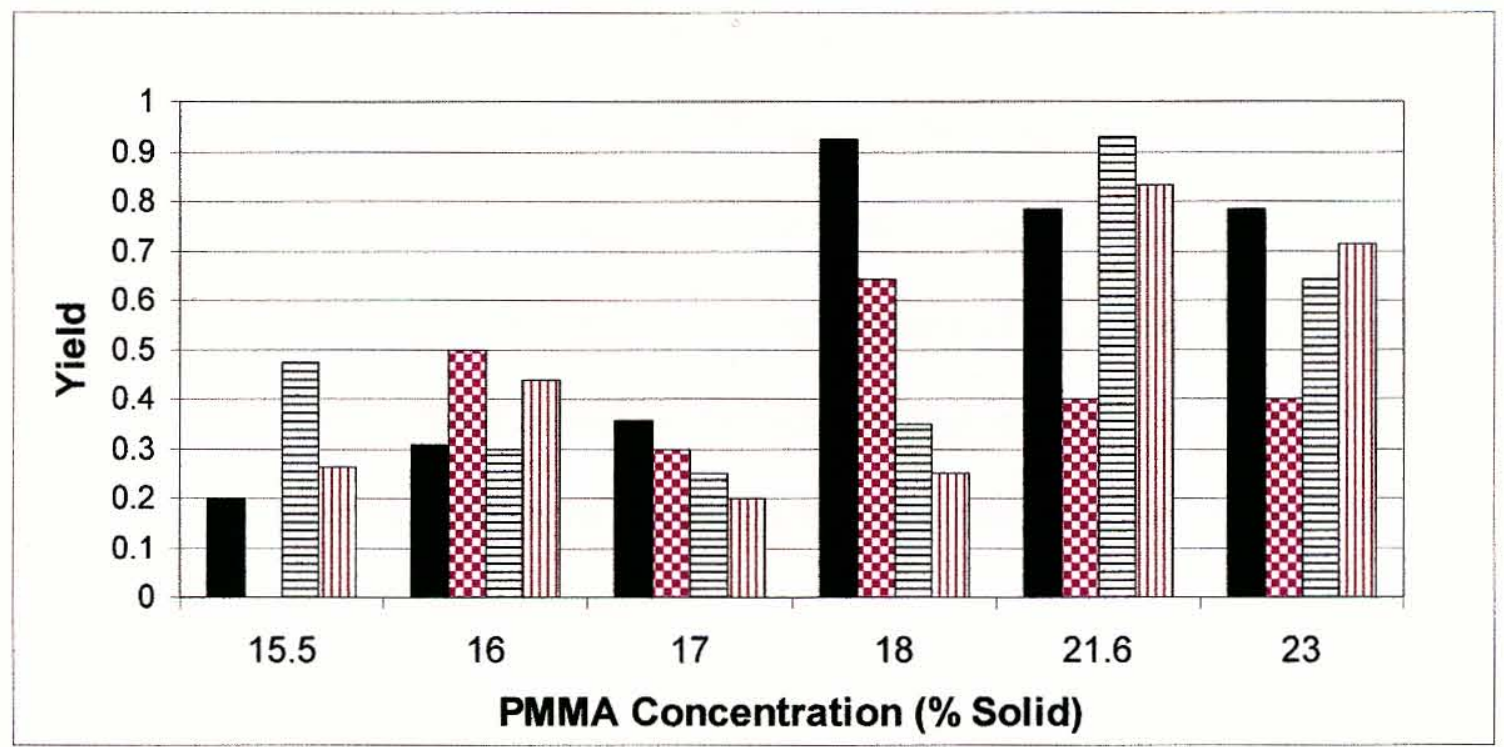

FIGURE 25 - The fiber yield for the $495 \mathrm{k} \mathrm{g} / \mathrm{mol}$ molecular weight with each concentration and each stylus. The solid bars represent the tungsten stylus, the checkered bars represent parylene, the horizontal striped bars represent nonstick, and the vertical striped bars represent glass.

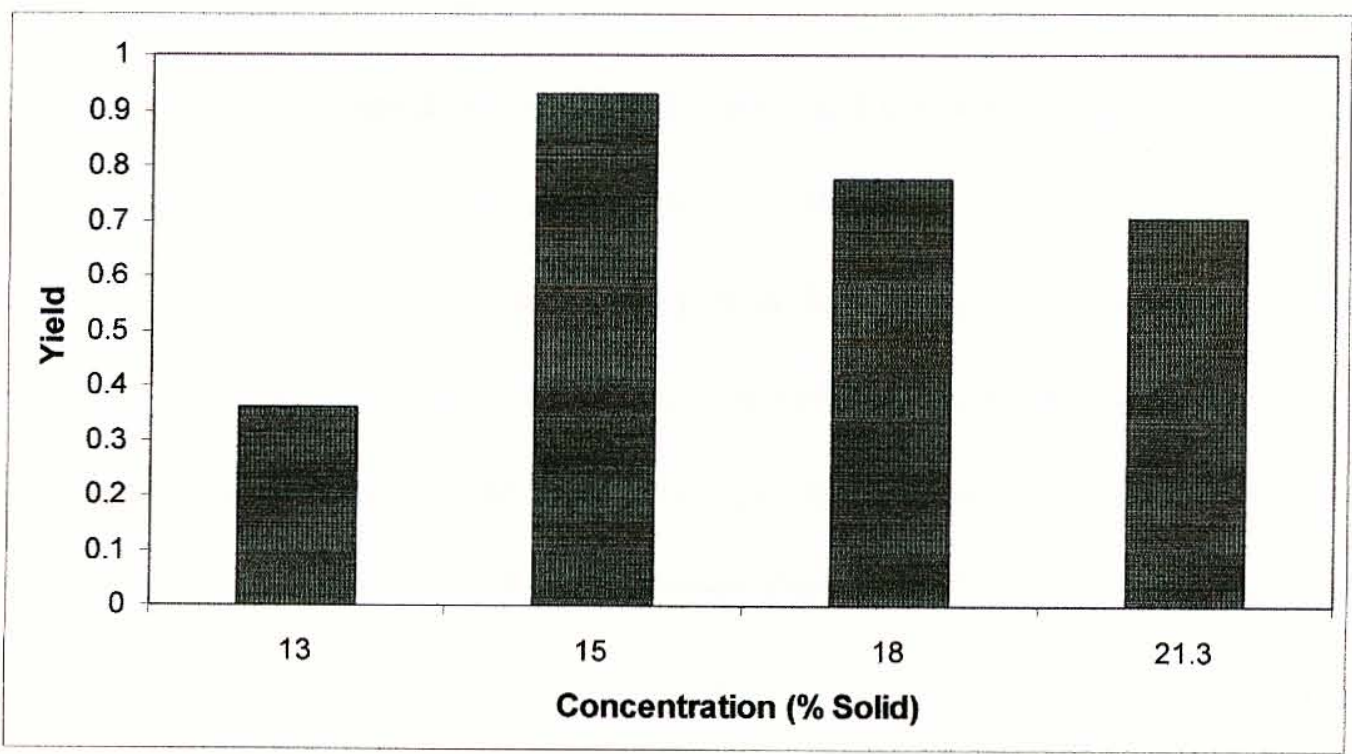

FIGURE 26 - The fiber yield for the $950 \mathrm{k} \mathrm{g} / \mathrm{mol}$ molecular weight with each concentration and the tungsten stylus.

Figure 25 illustrates that fiber yield seems relatively independent of stylus material. It can be seen, particularly with the tungsten stylus in both Figures 25 and 26, 
that fiber yield decreases with decreasing solution concentration. As previously mentioned, low PMMA concentration results in low fiber diameter, which is synonymous with a higher fiber aspect ratio, defined as the ratio of length to diameter, and increased fiber fragility. This implies that many drawing attempts of this length $(>1.8 \mathrm{~mm})$ made with concentrations on the low end of the experimental spectrum will result in broken fibers. If low fiber yield must be prevented, solution concentration could be raised or fiber length could be shortened.

\section{E. Processability Parameter}

Tripathi et al. (2000) reported a correlation between a "processability parameter", $\mathrm{P}$, and the creation of fibers drawn from a polymer solution. This parameter is defined by Equation 1 in Section II-B. Tripathi theorized that fiber diameter increased with P, but only tested this theory qualitatively. This theory and Equation 1 suggest that a solution with high viscosity and a quick-drying solvent (high $h$ ) would lead to large fiber diameters. This phenomenon is illustrated by directly plotting fiber diameter versus $\mathbf{P}$ for each molecular weight in Figure 27. This concept also correlates well with the idea presented earlier in Section V, Part C of this paper and Figure 20 which shows the trend between diameter and viscosity. Fiber diameter does indeed increase with increasing $\mathbf{P}$ $\left(D=6.837 \mathrm{Ln}(\mathrm{P})+56.282\right.$ with $\mathrm{R}^{2}=0.9326$ for $495 \mathrm{k} \mathrm{g} / \mathrm{mol}$ solutions and $\mathrm{D}=5.2463 \mathrm{Ln}(\mathrm{P})$ +40.827 with $\mathrm{R}^{2}=0.8941$ for $950 \mathrm{~kg} / \mathrm{mol}$ solutions). Tripathi reported "stringiness" or fiber formation with polymer solutions with $\mathrm{P}$ values greater than $10^{-3}$. Examination of Figure 27 shows this correlates well with the data collected in this investigation. In addition, Tripathi reported no stable fiber formation from polymer solutions with a $\mathrm{P}$ 
value less than $3 \times 10^{-4}$, again a good correlation with the lower limit observed in Figure 27, (since solutions with $\mathrm{P}$ values lower than those appearing on the figure produced no stable fibers).

The fact that the two lines do not overlap suggests that an additional variable(s) may be involved in this process. Ideally, if all undesired variables could be eliminated, one parameter would exist that relates the intrinsic properties of a fluid to the expected fiber diameter. This would allow rapid characterization of additional solvent / polymer / molecular weight sets since only the fluid properties characterization section of this investigation would need to be repeated. However, the results presented in this paper show that $\mathrm{P}$ does not completely normalize this process to be independent of molecular weight and therefore, consideration of additional parameters is still required.

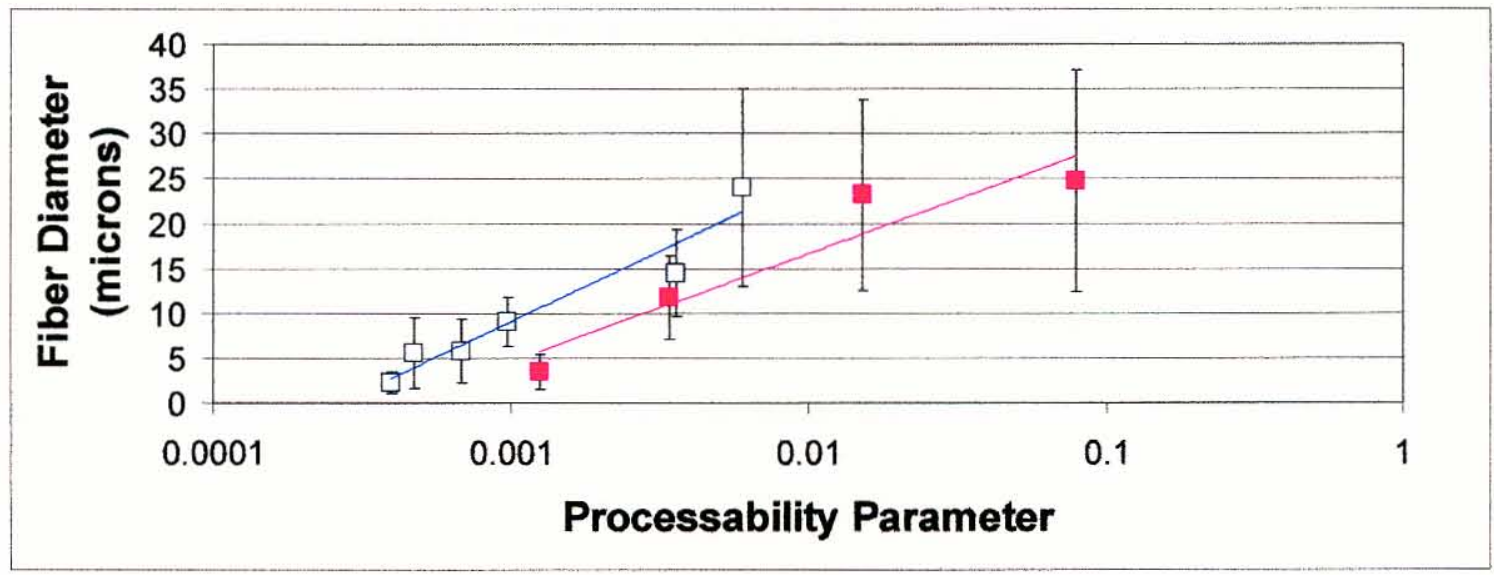

FIGURE 27 - Fiber diameter increases with increasing Processability Parameter for both molecular weight solutions. The hollow data points and upper line represent the measured data and curve fit, respectively, for the $495 \mathrm{k} \mathrm{g} / \mathrm{mol}$ solutions and the solid data points and lower line represent the $950 \mathrm{k} \mathrm{g} / \mathrm{mol}$ solution. 


\section{CONCLUSIONS}

Polymer micro- and nano- fibers can be drawn from a polymer solution using a stylus controlled by a custom-made ultra-high-precision micromill. PMMA fibers ranging in diameter from less than a micron to over 40 microns have been successfully fabricated to span a $1.8 \mathrm{~mm}$ trench in a silicon substrate. In addition, preliminary experimentation with the micromill-drawing method has yielded shorter fibers with diameters reaching down as far as $140 \mathrm{~nm}$. However, fibers of this magnitude fracture when drawn to a length of $1.8 \mathrm{~mm}$ or more.

Characterization of the micromill process has indicated that fiber diameter increases as the solid concentration in the polymer solution increases. In addition, it was shown that increasing the molecular weight of the PMMA resulted in larger fiber diameters. Fiber diameter was also observed to increase with the increase of a processability parameter, defined by Equation 1 (Section II - B) as a function of solvent evaporation rate, viscosity, and surface tension.

Diameters along individual fibers seem to vary an average of one to two microns along the length of the fiber. In addition, there seems to be a large variance between fibers drawn under the same experimental conditions. A suspected culprit of this variance is the varying solution buildup that accumulates during the drawing process. As such, a number of different stylus materials were tested in hopes of reducing this variance, and it was discovered that the use of a parylene stylus somewhat reduced the severity of this variance. 


\section{RECOMMENDATIONS}

Further advancements must be made in order to maximize the viability of micromill-drawn polymer fibers as an alternative microfabrication technique. Preliminary studies have shown this process can be scaled downward to produce submicron fibers. However, this concept has not been properly characterized. Also, for this technique to be useful in industry, a method for the further reduction of fiber diameter variance must be developed. Lastly, the effect of other process parameters on fiber diameter can be investigated in hopes of determining methods of varying diameter without changing concentration of molecular weight.

\section{A. Smaller Fiber Diameters}

In preliminary trials as well as research done by Harfenist et al. (2004), it has been demonstrated that sub-micron fibers can be drawn from polymer solutions. In fact, the micromill-drawn method has produced fibers as small as $140 \mathrm{~nm}$ in diameter to date. Despite these findings, this investigation has presented data largely on the microscale. Attempts were made to utilize the experimental procedure outlined in Section IV to produce smaller diameter fibers, but it was found that all fibers drawn with concentrations less than those given in Table III tended to break before measurements could be made.

The procedural difference in the preliminary studies that produced many submicron fibers was that the solution pools were closer together $(<1 \mathrm{~mm})$ and the fiber was not suspended over a trench, but merely allowed to rest on the substrate. The procedure 
described in Section IV required all fibers to be at least $1.8 \mathrm{~mm}$ long in order to span the substrate trench. Sub-micron fibers this length would obviously be very fragile due to their enormous aspect ratios. If the methodology presented in this paper was altered to include a substrate trench only a few hundred microns wide, it seems reasonable to expect that sub-micron fiber yield would increase.

\section{B. Lower Diameter Variance}

Large fiber diameter variance was seen in all trials, both in preliminary studies and those associated with this investigation. The first recommendation toward variance reduction is to determine if solution buildup on the stylus is indeed the cause of the large standard deviations. This could be accomplished by cleaning the stylus, perhaps by dipping it in acetone or chlorobenzene between each drawing attempt. This may prove unsuccessful since it was observed during some (not all) trials that solution buildup was essential for the fibers to adhere to the stylus long enough to reach the terminating pool. Even if variance is reduced with no sacrifice in yield, this solution to the problem may be unsatisfactory in industry since an additional cleaning step is required between each draw.

A more exotic solution would be to develop a hollow-point stylus that dispenses polymer solution as needed. This device might work in a manner similar to a ball-point pen, in which a small amount of fluid is delivered every time the stylus makes contact with the substrate. As the stylus moves away from the substrate, a liquid bridge would form between the deposited fluid and the remaining fluid in the stylus. 


\section{Additional Process Parameters}

In addition to concentration and molecular weight, other variables which influence fiber diameter may exist. The characterization of these parameters may lead to other methods of controlling fiber diameter. Specifically, the variation of factors which influence the processability parameter would be expected to produce changes in fiber diameter. For example, since viscosity (and therefore the processability parameter) is highly dependent on temperature, the increase of temperature would be expected to decrease fiber diameter and vice versa. This could lead to a faster way of controlling diameter since only one solution concentration and molecular weight would be required to achieve a number of different diameters. In addition, the validity of the relationship between the processability parameter and fiber diameter could be tested by drawing fibers with different concentrations at differing temperatures, but with identical processability parameters, and determining if fiber diameter remains relatively constant, as predicted by the processability model (fibers beginning to form at $0.0003<P<0.001$ ).

Other polymer / solvent pairs could be characterized using the procedure described in this investigation. These new pairs would presumably have different viscosity ranges, surface tensions, and solvent evaporation rates than PMMA / chlorobenzene and therefore would have a different range of processability parameters and fiber diameters. The threshold processability value $(P=0.001)$ could be used to expedite the characterization process by providing a starting low-end concentration (as opposed to the trial and error method used in this investigation) by solving Equation 1 for viscosity and finding the corresponding solid concentration. 


\section{APPENDIX I \\ MICRO MILLING MACHINE CODE}

;PMMA MICRO/NANOWIRE PULLING CHARACTERIZATION

;Written by: Scott Berry

\section{CLOSE}

DELETE GATHER

OPEN PROG 1

CLEAR

INC

;Movement Commands in Incremental Mode

$$
\begin{aligned}
& \mathrm{Q} 1=7.7 \\
& \mathrm{Q} 2=.200 \\
& \mathrm{Q} 3=5 \\
& \mathrm{Q} 4=.25
\end{aligned}
$$

;Width (MM)

$$
\text { ;Fiber Spacing (MM) }
$$

;Stylus Speed (MM/S)

;Plunge Depth (MM)

$\mathrm{Q} 100=1$

WHILE (Q100<8)

;Loop Counter

;Initialize Loop - Each Pass of Loop Draws 2 Fibers

$\mathrm{F}(\mathrm{Q} 3)$

$Z(-Q 4)$

Y(Q1)

DWELL 50

Z(Q4)

DWELL 1500

$\mathrm{X}(\mathrm{Q} 2)$

DWELL 50

Z(-Q4)

$\mathrm{Y}(-\mathrm{Q} 1)$

DWELL 50

Z(Q4)

DWELL 1500

$\mathrm{X}(\mathrm{Q} 2)$

DWELL 50

;Set Speed

;Lift Stylus from Pool 1

;Traverse Gap

;Sink Stylus into Pool 2

;Delay to Allow Fiber to Detach from Stylus

;Move to Next Fiber Position

;Lift Stylus from Pool 2

;Traverse Gap

;Sink Stylus into Pool 1

;Delay to Allow Fiber to Detach from Stylus

;Move to Next Fiber Position

$\mathrm{Q} 100=\mathrm{Q} 100+1 \quad$;Increase Loop Variable

ENDWHILE

;Close Loop Function

CLOSE

;End Program 


\section{APPENDIX II}

\section{INDIVIDUAL FIBER MEASUREMENTS}

Individual fiber measurements for $495 \mathrm{k} \mathrm{g} / \mathrm{mol}$ solution with $15.5 \%$ solids and tungsten stylus - (all measurements in microns)

\begin{tabular}{|lr|}
\hline Average & 2.219166667 \\
\hline Standard Deviation & 1.199981435 \\
\hline Yield & 0.2 \\
\hline Average Fiber Deviation & 0.888467585 \\
\hline
\end{tabular}

\begin{tabular}{|c|c|c|c|c|c|}
\hline Wire \# & Left & Middle & Right & Average & Std. Dev \\
\hline & 3.912 & 2.459 & 1.509 & 2.626667 & 1.210242 \\
\hline & 4.446 & 2.754 & 2.101 & 3.100333 & 1.210255 \\
\hline & 3.815 & 2.302 & 1.993 & 2.703333 & 0.97505 \\
\hline & 0.549 & 0.526 & 0.264 & 0.446333 & 0.158324 \\
\hline
\end{tabular}

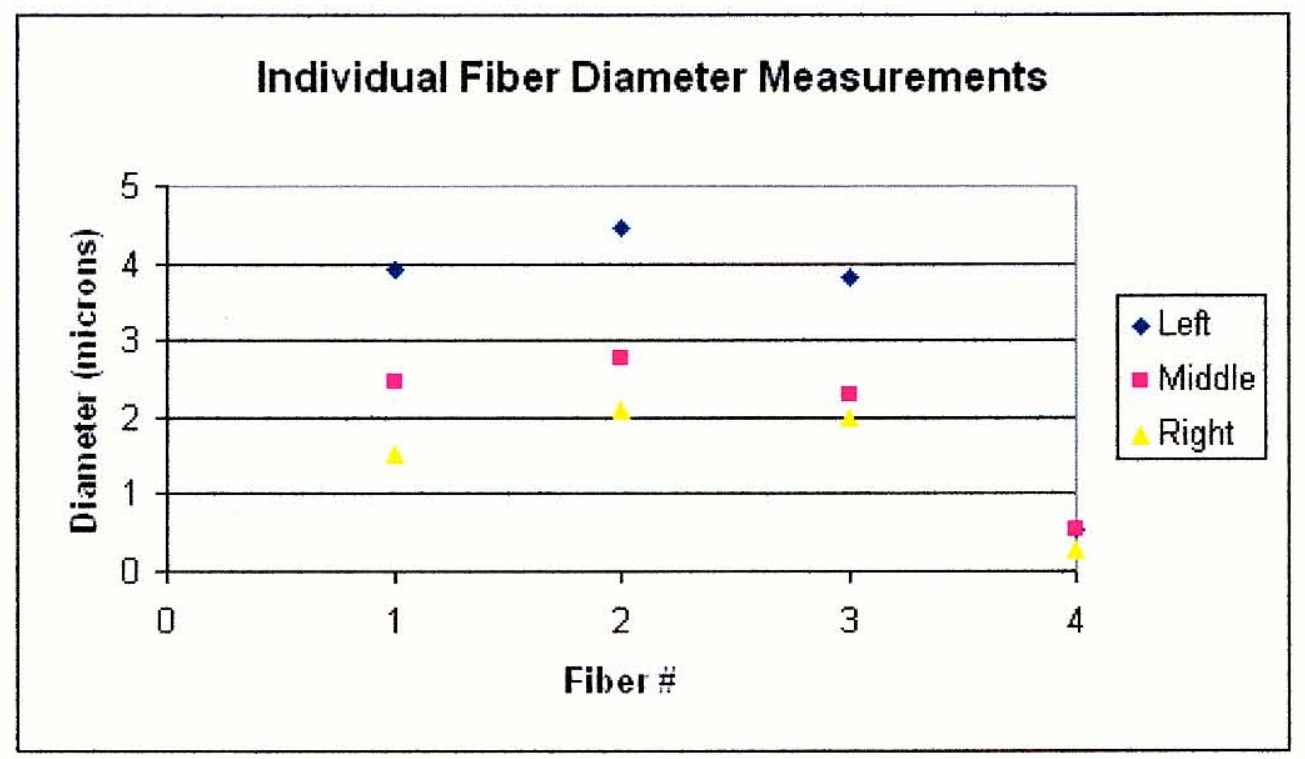


Individual fiber measurements for $495 \mathrm{k} \mathrm{g} / \mathrm{mol}$ solution with $16 \%$ solids and tungsten stylus - (all measurements in microns)

\begin{tabular}{|c|c|c|c|c|c|c|c|c|}
\hline \multicolumn{3}{|l|}{ Average } & \multicolumn{2}{|c|}{5.5446666667} & & & & \\
\hline \multicolumn{3}{|c|}{ Standard Deviation } & \multicolumn{2}{|c|}{3.9519502} & & & & \\
\hline \multicolumn{3}{|l|}{ Yield } & \multicolumn{2}{|c|}{0.307692308} & & & & \\
\hline \multicolumn{3}{|c|}{ Average Fiber Deviation } & \multicolumn{2}{|c|}{1.600886228} & & & & \\
\hline \multirow[t]{9}{*}{ Wire \# } & \multicolumn{2}{|c|}{ Left } & \multicolumn{2}{|l|}{ Middle } & \multicolumn{2}{|l|}{ Right } & \multirow{2}{*}{$\begin{array}{l}\text { Average } \\
1772333\end{array}$} & \multirow{2}{*}{$\begin{array}{l}\text { Std. Dev } \\
1.347914\end{array}$} \\
\hline & \multirow{2}{*}{$\begin{array}{l}1 \\
2\end{array}$} & 0.584 & \multicolumn{2}{|r|}{1.496} & & \multirow{2}{*}{$\begin{array}{l}3.237 \\
5.624\end{array}$} & & \\
\hline & & \multirow{2}{*}{$\begin{array}{l}1.166 \\
2.489\end{array}$} & \multirow{2}{*}{\multicolumn{2}{|c|}{$\begin{array}{l}3.012 \\
4211\end{array}$}} & & & 3.467333 & $\begin{array}{l}1.347914 \\
1.968892\end{array}$ \\
\hline & 3 & & & & & 6.511 & 4.403667 & 2.01791 \\
\hline & 4 & 5.517 & \multicolumn{2}{|r|}{5.32} & & 6.258 & 5.698333 & 0.494593 \\
\hline & 5 & 8.025 & \multicolumn{2}{|r|}{5.748} & & 3.846 & 5.873 & 2.092302 \\
\hline & \multirow{2}{*}{$\begin{array}{l}6 \\
7\end{array}$} & \multirow{2}{*}{$\begin{array}{r}12.57 \\
\end{array}$} & & 14.18 & & 16.83 & 14.52667 & 2.151054 \\
\hline & & & & 6.146 & & 5.033 & 5.983 & 0.879897 \\
\hline & & 0.848 & & 2.501 & & 4.55 & 2.633 & 1.854527 \\
\hline & & Indi & idual Fil & ber Dia & neter $M$ & asuren & lents & \\
\hline & $\left.\begin{array}{l}18 \\
16\end{array}\right]$ & & & & & $\Delta$ & & \\
\hline-1 & & & & & & m & & \\
\hline & & & & & & + & & \\
\hline 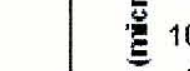 & & & & & & & & $\left|\begin{array}{l}- \text { Left } \\
- \text { Middle }\end{array}\right|$ \\
\hline & $8-$ & & & & & & - & Right \\
\hline$\frac{5}{5}$ & 4. & & 2 & 5 & & & I & \\
\hline & 2. & $\Delta$ & 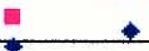 & & & & & 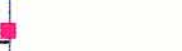 \\
\hline & 0 & + & & & & & $T$ & 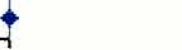 \\
\hline & 0 & 1 & 3 & 4 & 5 & 6 & 7 & 8 \\
\hline & & & & Filbe & & & & \\
\hline
\end{tabular}


Individual fiber measurements for $495 \mathrm{k} \mathrm{g} / \mathrm{mol}$ solution with $17 \%$ solids and tungsten stylus - (all measurements in microns)

\begin{tabular}{|ll|}
\hline Average & 5.795533333 \\
\hline Standard Deviation & 3.587922252 \\
\hline Yield & 0.357142857 \\
\hline Average Fiber Deviation & 1.552334447 \\
\hline
\end{tabular}

\begin{tabular}{|c|c|c|c|c|c|}
\hline Wire \# & Left & Middle & Right & Average & Std. Dev \\
\hline 1 & 2.358 & 1.654 & 1.74 & 1.917333 & 0.384043 \\
\hline 2 & 3.619 & 6.418 & 5.615 & 5.217333 & 1.441251 \\
\hline 3 & 7.124 & 12.59 & 10.87 & 10.19467 & 2.794878 \\
\hline 4 & 6.656 & 7.702 & 11.8 & 8.719333 & 2.718715 \\
\hline 5 & 2.442 & 3.202 & 3.143 & 2.929 & 0.422785 \\
\hline
\end{tabular}

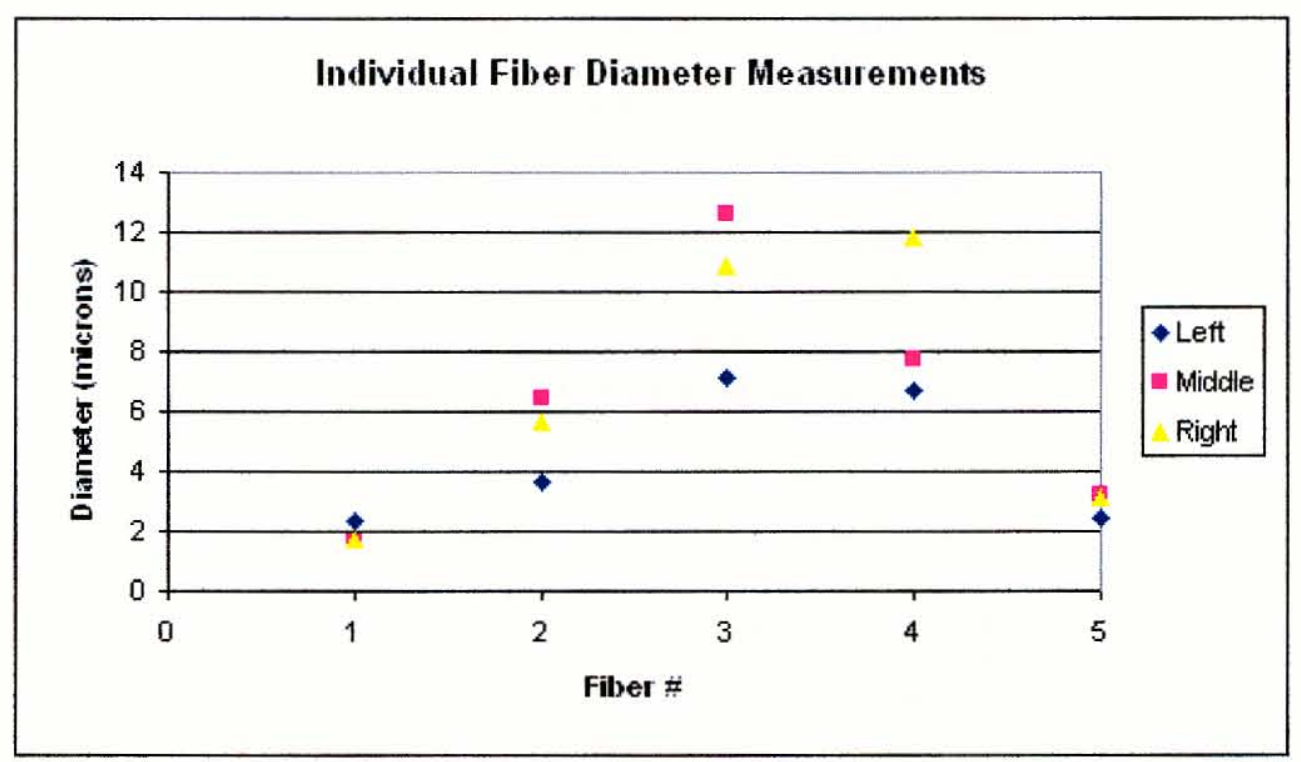


Individual fiber measurements for $495 \mathrm{k} \mathrm{g} / \mathrm{mol}$ solution with $18 \%$ solids and tungsten stylus - (all measurements in microns)

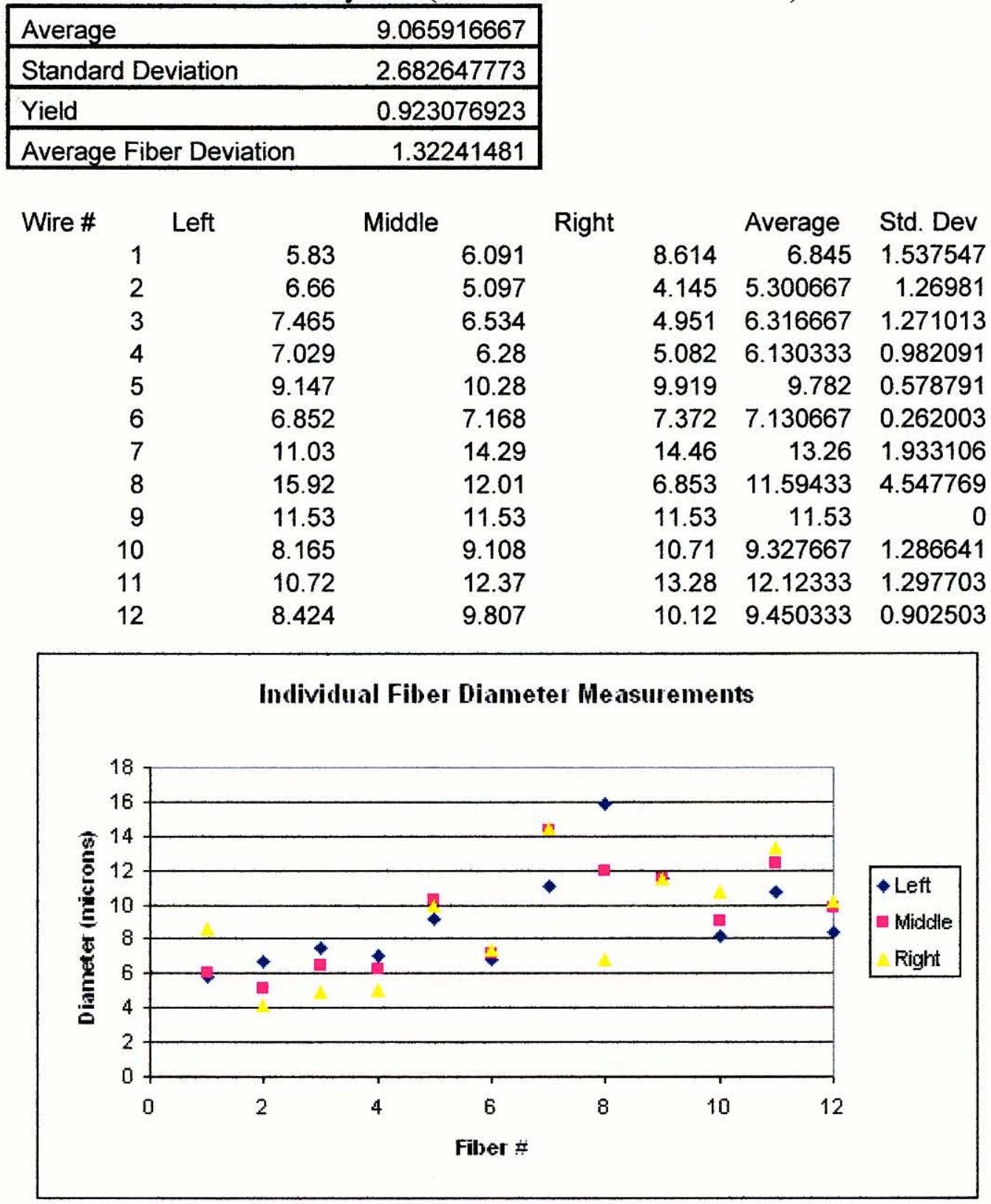


Individual fiber measurements for $495 \mathrm{k} \mathrm{g} / \mathrm{mol}$ solution with $21.6 \%$ solids and tungsten stylus - (all measurements in microns)

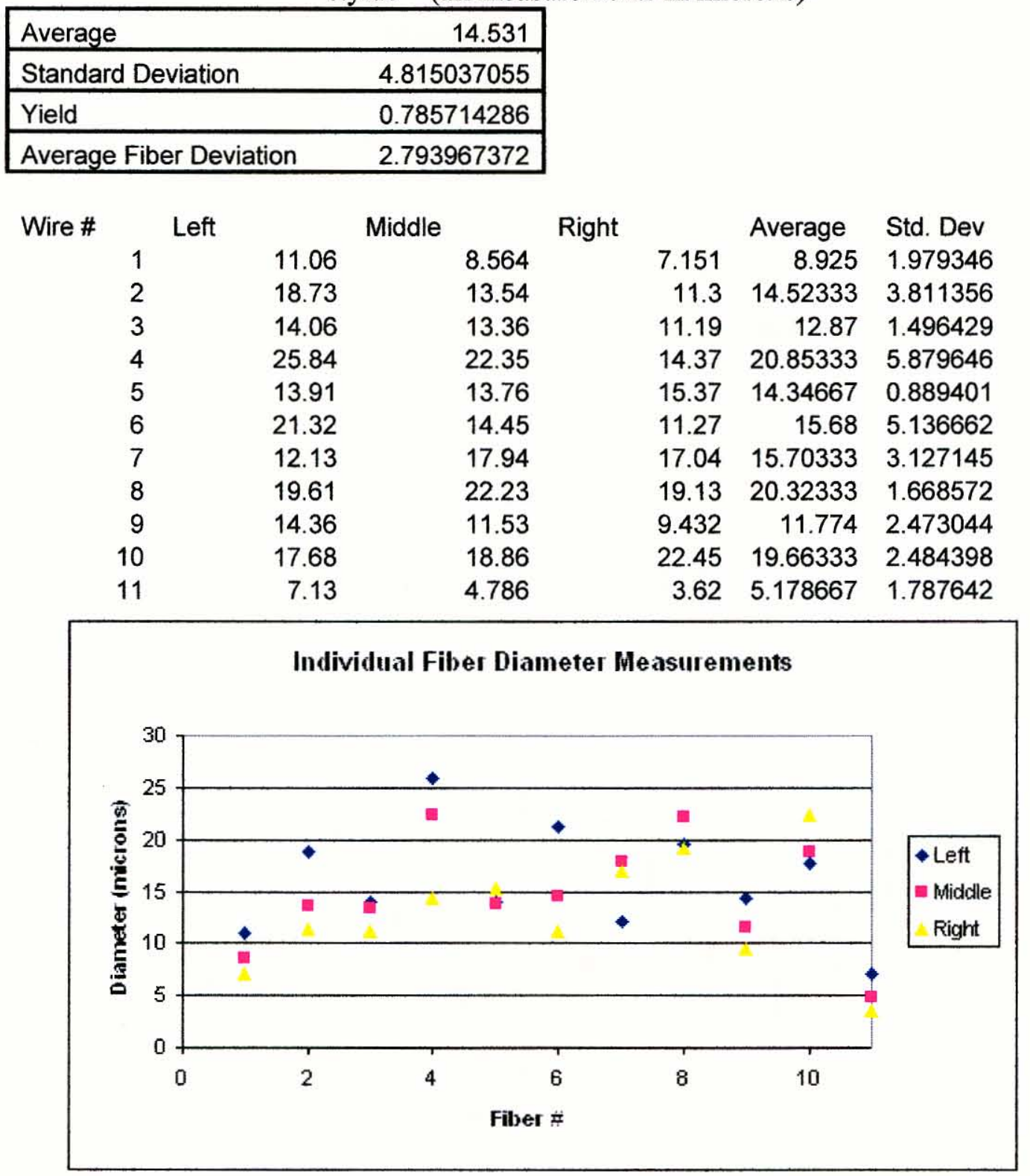


Individual fiber measurements for $495 \mathrm{k} \mathrm{g} / \mathrm{mol}$ solution with $23 \%$ solids and tungsten stylus - (all measurements in microns)

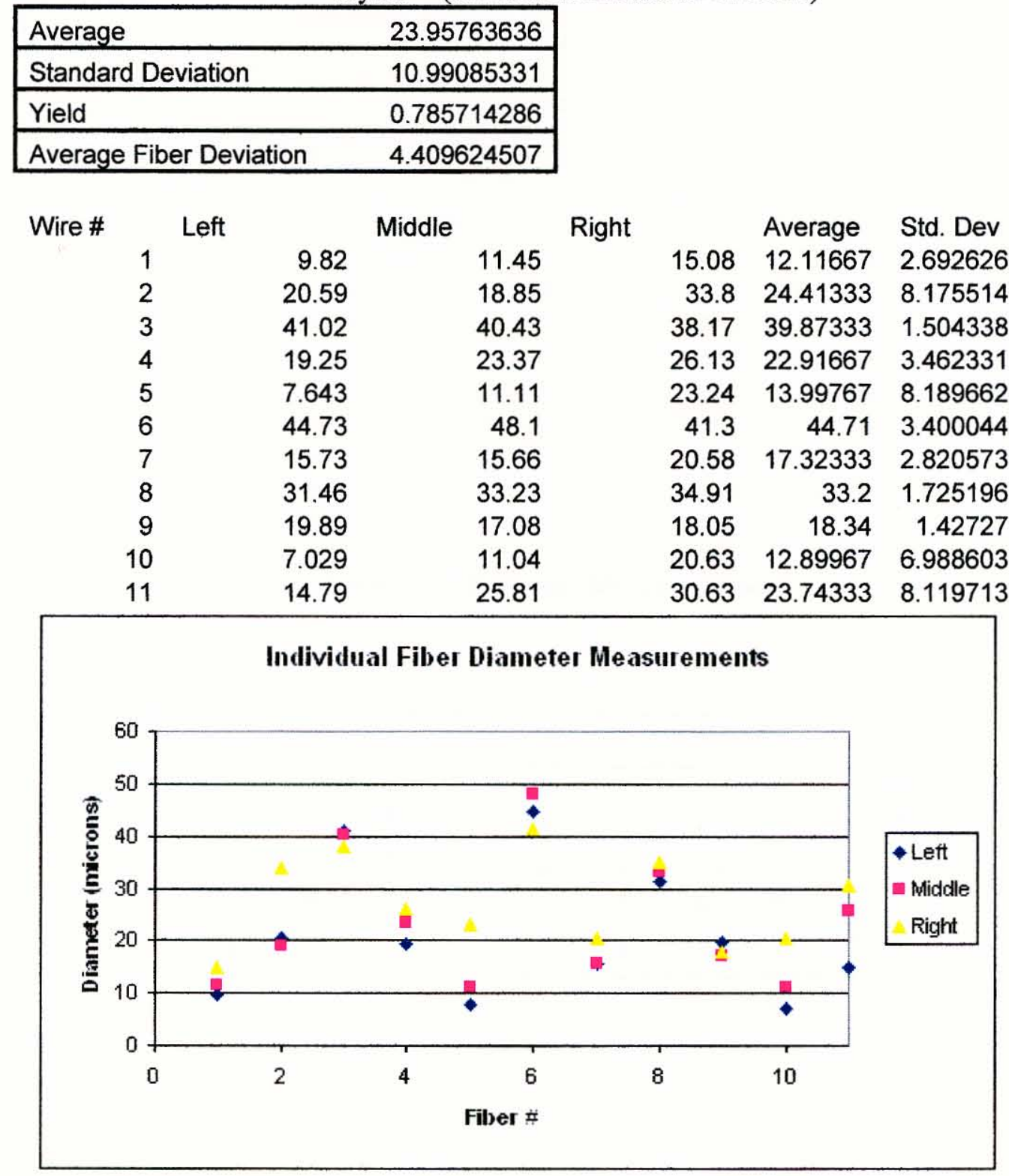


Individual fiber measurements for $950 \mathrm{k} \mathrm{g} / \mathrm{mol}$ solution with $13 \%$ solids and tungsten stylus - (all measurements in microns)

\begin{tabular}{|lr|}
\hline Average & 3.458925926 \\
\hline Standard Deviation & 1.98292579 \\
\hline Yield & 0.36 \\
\hline Average Fiber Deviation & 1.019792176 \\
\hline
\end{tabular}

\begin{tabular}{|c|c|c|c|c|c|}
\hline Wire \# & Left & Middle & Right & Average & Std. Dev \\
\hline 1 & 1.127 & 0.862 & 1.39 & 1.126333 & 0.264001 \\
\hline 2 & 2.665 & 2.666 & 2.246 & 2.525667 & 0.242199 \\
\hline 3 & 4.53 & 6.131 & 9.537 & 6.732667 & 2.55715 \\
\hline 4 & 6.363 & 6.217 & 6.153 & 6.244333 & 0.107635 \\
\hline 5 & 5.567 & 3.975 & 3.124 & 4.222 & 1.240088 \\
\hline 6 & 0.918 & 1.324 & 3.164 & 1.802 & 1.196868 \\
\hline 7 & 2.594 & 3.158 & 5.91 & 3.887333 & 1.774235 \\
\hline 8 & 3.531 & 2.98 & 1.793 & 2.768 & 0.888183 \\
\hline 9 & 2.854 & 1.465 & 1.147 & 1.822 & 0.907771 \\
\hline
\end{tabular}

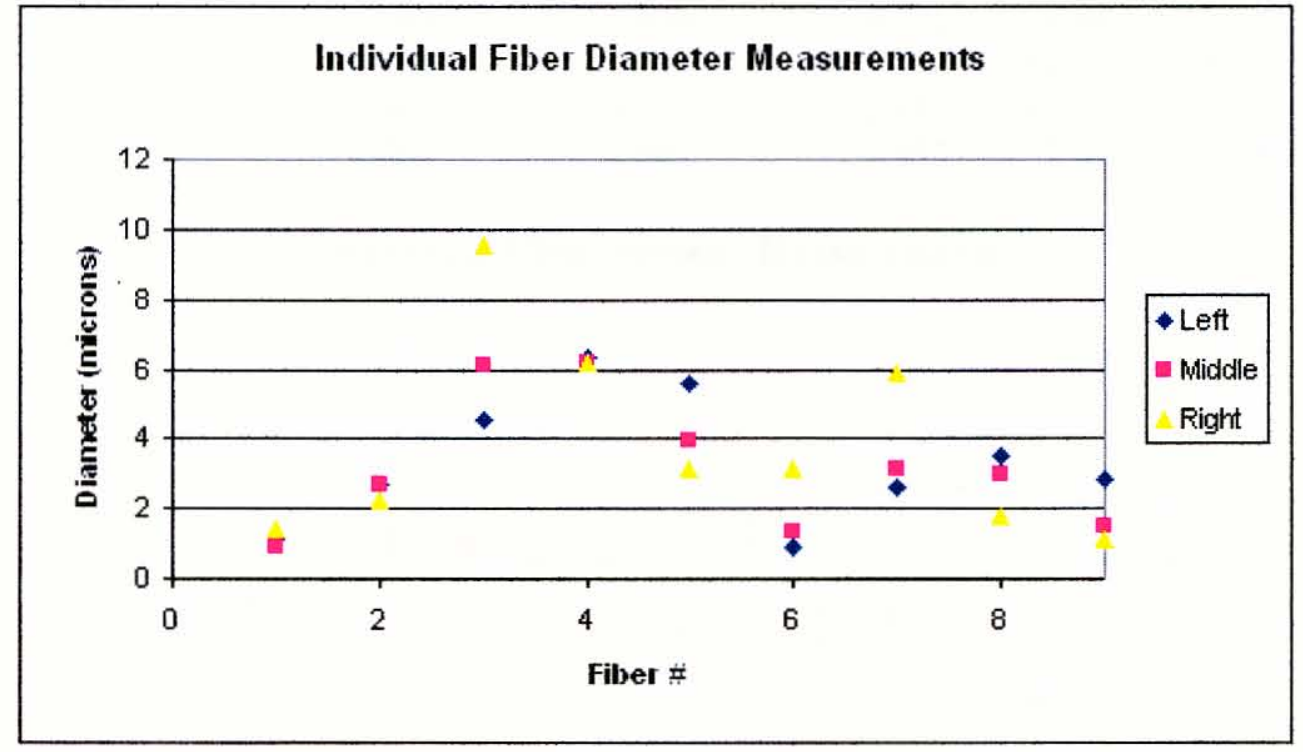


Individual fiber measurements for $950 \mathrm{~kg} / \mathrm{mol}$ solution with $15 \%$ solids and tungsten stylus - (all measurements in microns)

\begin{tabular}{|ll|}
\hline Average & 11.76692308 \\
\hline Standard Deviation & 4.638621872 \\
\hline Yield & 0.928571429 \\
\hline Average Fiber Deviation & 1.480954879 \\
\hline
\end{tabular}

\begin{tabular}{|c|c|c|c|c|c|}
\hline Wire \# & Left & Middle & Right & Average & Std. Dev \\
\hline 1 & 16.94 & 11.84 & 8.774 & 12.518 & 4.125003 \\
\hline 2 & 13.64 & 12.62 & 13.13 & 13.13 & 0.51 \\
\hline 3 & 15.52 & 16.56 & 18.67 & 16.91667 & 1.605003 \\
\hline 4 & 13.65 & 16.03 & 15.3 & 14.99333 & 1.219276 \\
\hline 5 & 14.67 & 24.2 & 13.9 & 17.59 & 5.73736 \\
\hline 6 & 15.21 & 14.66 & 14.57 & 14.81333 & 0.346458 \\
\hline 7 & 9.666 & 9.921 & 10.73 & 10.10567 & 0.555518 \\
\hline 8 & 17.77 & 15.78 & 15.78 & 16.44333 & 1.148927 \\
\hline 9 & 9.346 & 11.15 & 12.06 & 10.852 & 1.381323 \\
\hline 10 & 11.43 & 9.914 & 9.792 & 10.37867 & 0.912523 \\
\hline 11 & 8.384 & 7.405 & 7.733 & 7.840667 & 0.498301 \\
\hline 12 & 5.967 & 4.632 & 3.847 & 4.815333 & 1.071825 \\
\hline 13 & 2.667 & 2.641 & 2.411 & 2.573 & 0.140897 \\
\hline
\end{tabular}

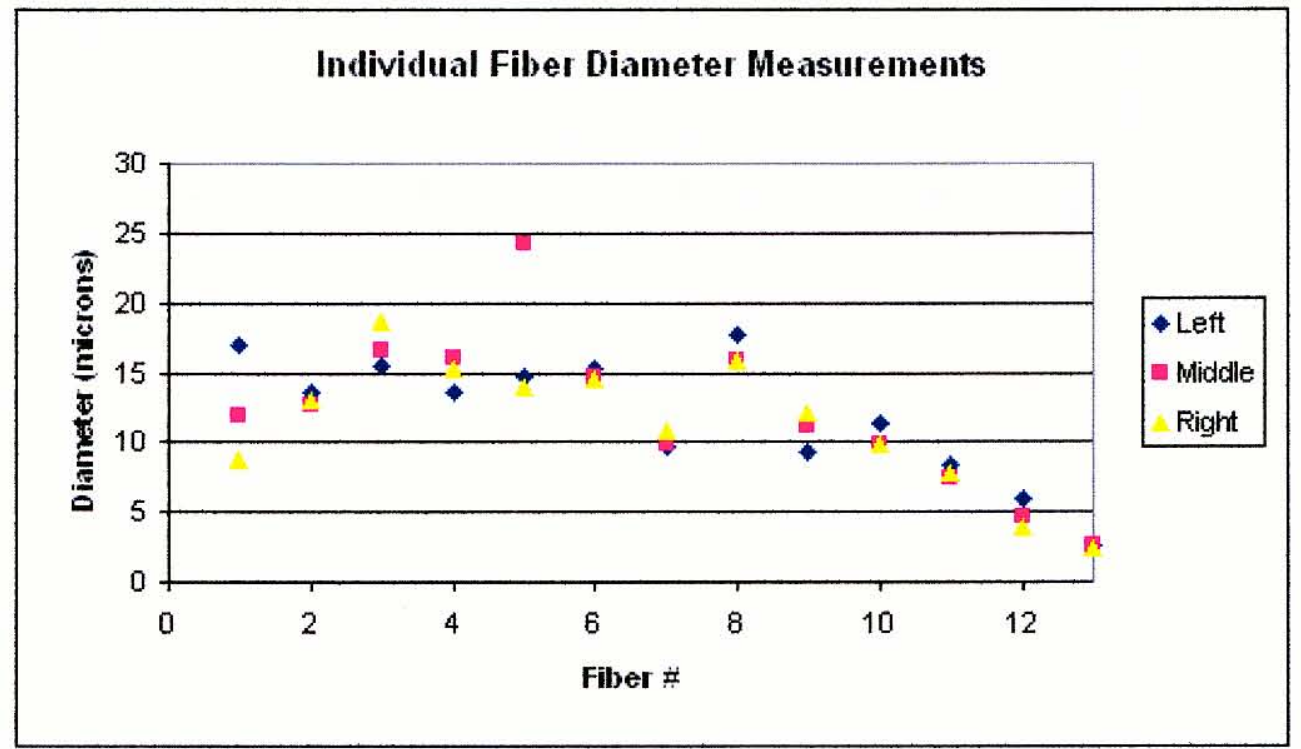


Individual fiber measurements for $950 \mathrm{~kg} / \mathrm{mol}$ solution with $18 \%$ solids and tungsten stylus - (all measurements in microns)

\begin{tabular}{|ll|}
\hline Average & 23.17571429 \\
\hline Standard Deviation & 10.68903258 \\
\hline Yield & 0.777777778 \\
\hline Average Fiber Deviation & 5.424250593 \\
\hline
\end{tabular}

\begin{tabular}{|c|c|c|c|c|c|c|}
\hline Wire \# & Left & & Middle & Right & Average & Std. Dev \\
\hline & 1 & 12.43 & 14.72 & 17.61 & 14.92 & 2.595785 \\
\hline & 2 & 22.58 & 20.78 & 17.13 & 20.163333 & 2.776839 \\
\hline & 3 & 13.51 & 13.77 & 13.78 & 13.686667 & 0.15308 \\
\hline & 4 & 28.34 & 21.17 & 25.99 & 25.166667 & 3.65522 \\
\hline & 5 & 62.81 & 52.35 & 21.68 & 45.613333 & 21.37653 \\
\hline & 6 & 22.05 & 20.53 & 25.74 & 22.773333 & 2.67926 \\
\hline & 7 & 16.61 & 17.78 & 25.33 & 19.906667 & 4.733036 \\
\hline
\end{tabular}

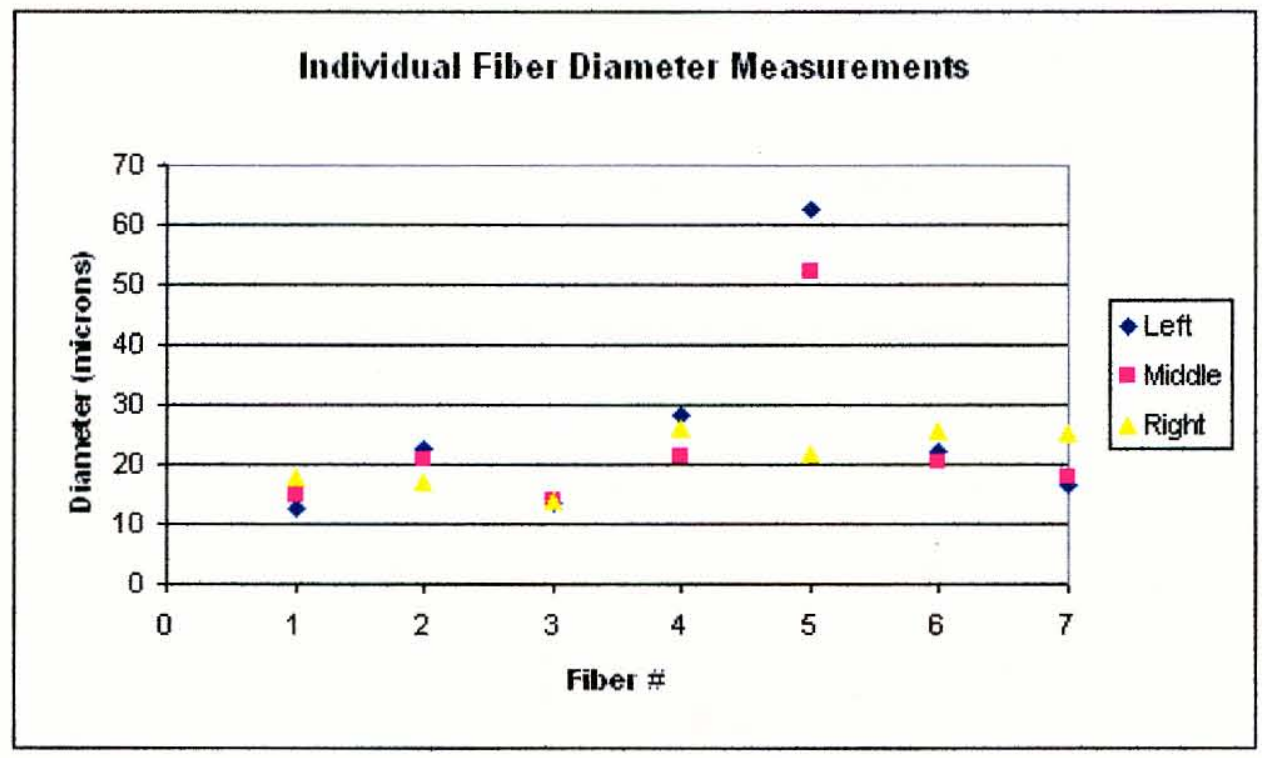


Individual fiber measurements for $950 \mathrm{k} \mathrm{g} / \mathrm{mol}$ solution with $21.3 \%$ solids and tungsten stylus - (all measurements in microns)

\begin{tabular}{|ll|}
\hline Average & 24.75113889 \\
\hline Standard Deviation & 12.36804115 \\
\hline Yield & 0.705882353 \\
\hline Average Fiber Deviation & 4.382276623 \\
\hline
\end{tabular}

\begin{tabular}{rrrrrrr} 
Wire \# & Left & \multicolumn{2}{c}{ Middle } & Right & Average & Std. Dev \\
& 1 & 13.33 & 12.86 & 12.41 & 12.86667 & 0.460036 \\
2 & 4.275 & 5.54 & 5.876 & 5.230333 & 0.844228 \\
3 & 42.72 & 45.45 & 61.41 & 49.86 & 10.0953 \\
4 & 17.68 & 33.4 & 23.05 & 24.71 & 7.990388 \\
5 & 31.94 & 25.2 & 23.4 & 26.84667 & 4.501837 \\
6 & 22.5 & 17.01 & 14.32 & 17.94333 & 4.169105 \\
7 & 23.25 & 20.46 & 18.73 & 20.81333 & 2.280621 \\
8 & 14.99 & 11.64 & 11.23 & 12.62 & 2.062692 \\
9 & 25.57 & 28.22 & 28.7 & 27.49667 & 1.685714 \\
10 & 47.14 & 37.55 & 36.77 & 40.48667 & 5.775139 \\
11 & 33.23 & 29.65 & 34.73 & 32.53667 & 2.610006 \\
12 & 17.16 & 22.84 & 36.81 & 25.60333 & 10.11225
\end{tabular}

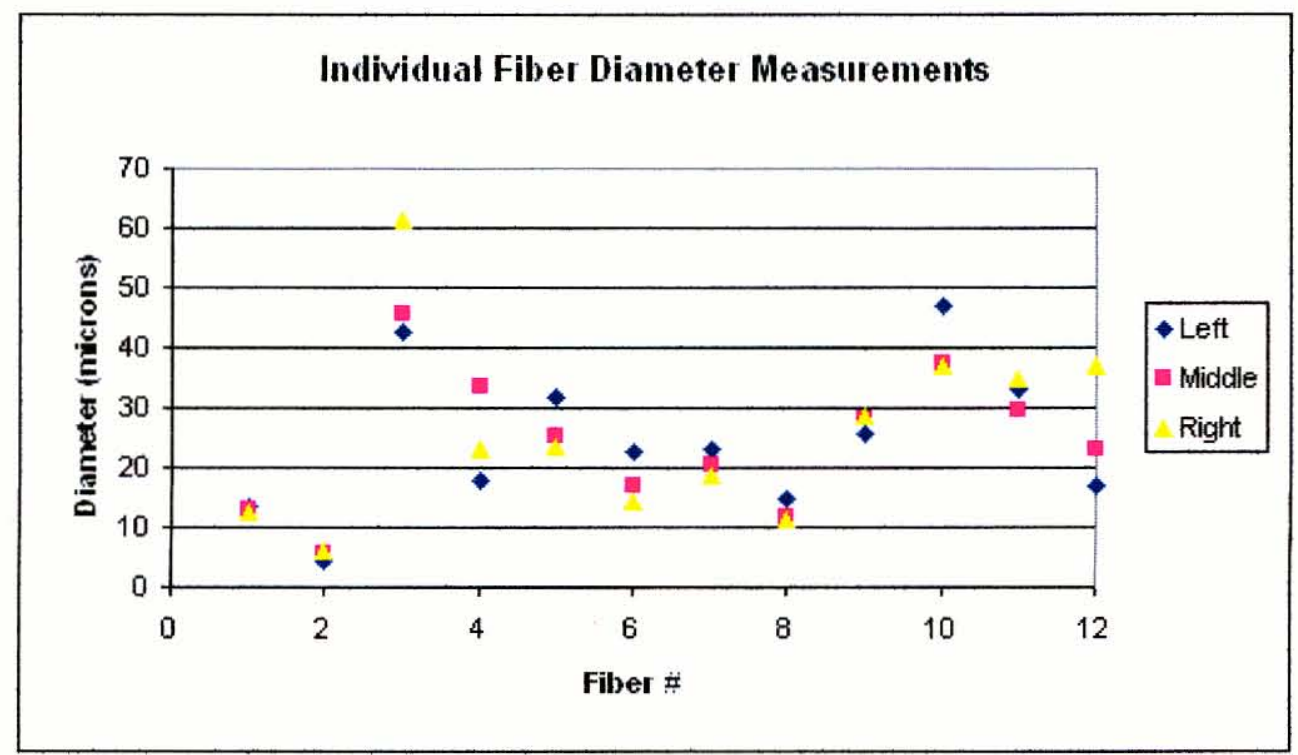


Individual fiber measurements for $495 \mathrm{k} \mathrm{g} / \mathrm{mol}$ solution with $16 \%$ solids and parylene stylus - (all measurements in microns)

\begin{tabular}{|lr|}
\hline Average & 7.411857143 \\
\hline Standard Deviation & 2.48527639 \\
\hline Yield & 0.5 \\
\hline Average Fiber Deviation & 1.960821624 \\
\hline
\end{tabular}

\begin{tabular}{|c|c|c|c|c|c|}
\hline Wire \# & Left & Middle & Right & Average & Std. Dev \\
\hline 1 & 4.448 & 5.968 & 6.916 & 5.777333 & 1.244999 \\
\hline 2 & 3.214 & 4.718 & 6.318 & 4.75 & 1.552247 \\
\hline 3 & 13.16 & 4.809 & 5.493 & 7.820667 & 4.636629 \\
\hline 4 & 6.177 & 6.416 & 8.205 & 6.932667 & 1.108334 \\
\hline 5 & 6.717 & 4.842 & 3.948 & 5.169 & 1.413166 \\
\hline 6 & 13.34 & 10.01 & 8.422 & 10.59067 & 2.509893 \\
\hline 7 & 12.16 & 10.72 & 9.648 & 10.84267 & 1.260485 \\
\hline
\end{tabular}

\section{Individual Fiber Diameter Measurements}

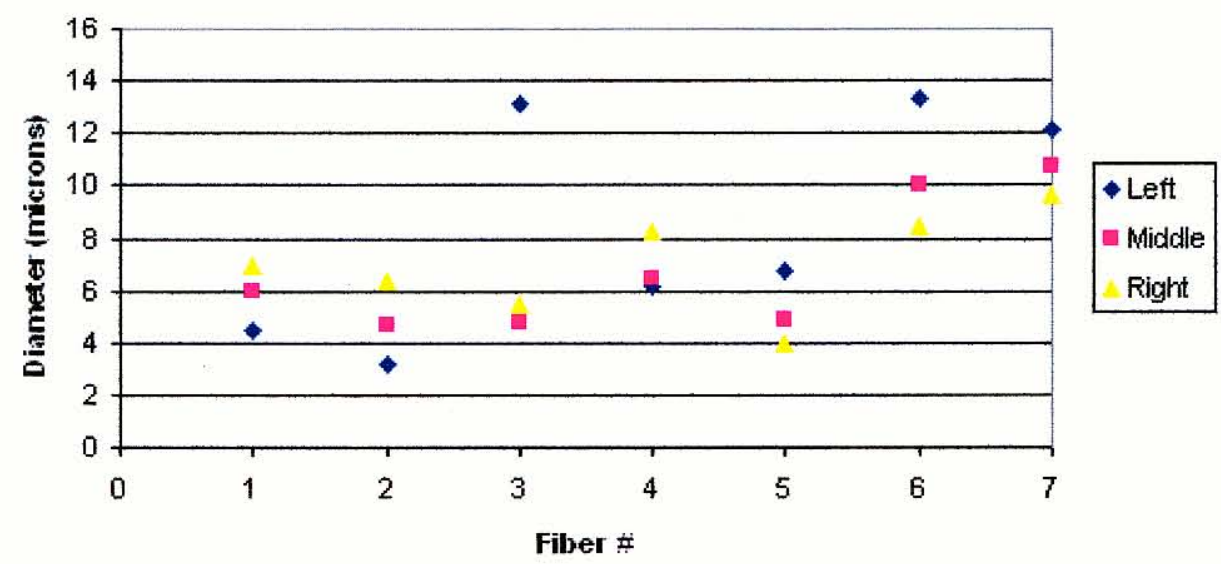


Individual fiber measurements for $495 \mathrm{k} \mathrm{g} / \mathrm{mol}$ solution with $17 \%$ solids and parylene stylus - (all measurements in microns)

\begin{tabular}{|lr|}
\hline Average & 6.776611111 \\
\hline Standard Deviation & 1.379977414 \\
\hline Yield & 0.3 \\
\hline Average Fiber Deviation & 1.106380624 \\
\hline
\end{tabular}

\begin{tabular}{|c|c|c|c|c|c|}
\hline Wire \# & Left & Middle & Right & Average & Std. Dev \\
\hline 1 & 7.87 & 8.223 & 6.417 & 7.503333 & 0.957205 \\
\hline 2 & 6.526 & 6.866 & 6.83 & 6.740667 & 0.186776 \\
\hline 3 & 3.229 & 8.772 & 9.296 & 7.099 & 3.361743 \\
\hline 4 & 3.803 & 4.543 & 5.413 & 4.586333 & 0.805874 \\
\hline 5 & 6.633 & 5.524 & 6.028 & 6.061667 & 0.555266 \\
\hline 6 & 8.831 & 9.346 & 7.829 & 8.668667 & 0.771418 \\
\hline
\end{tabular}

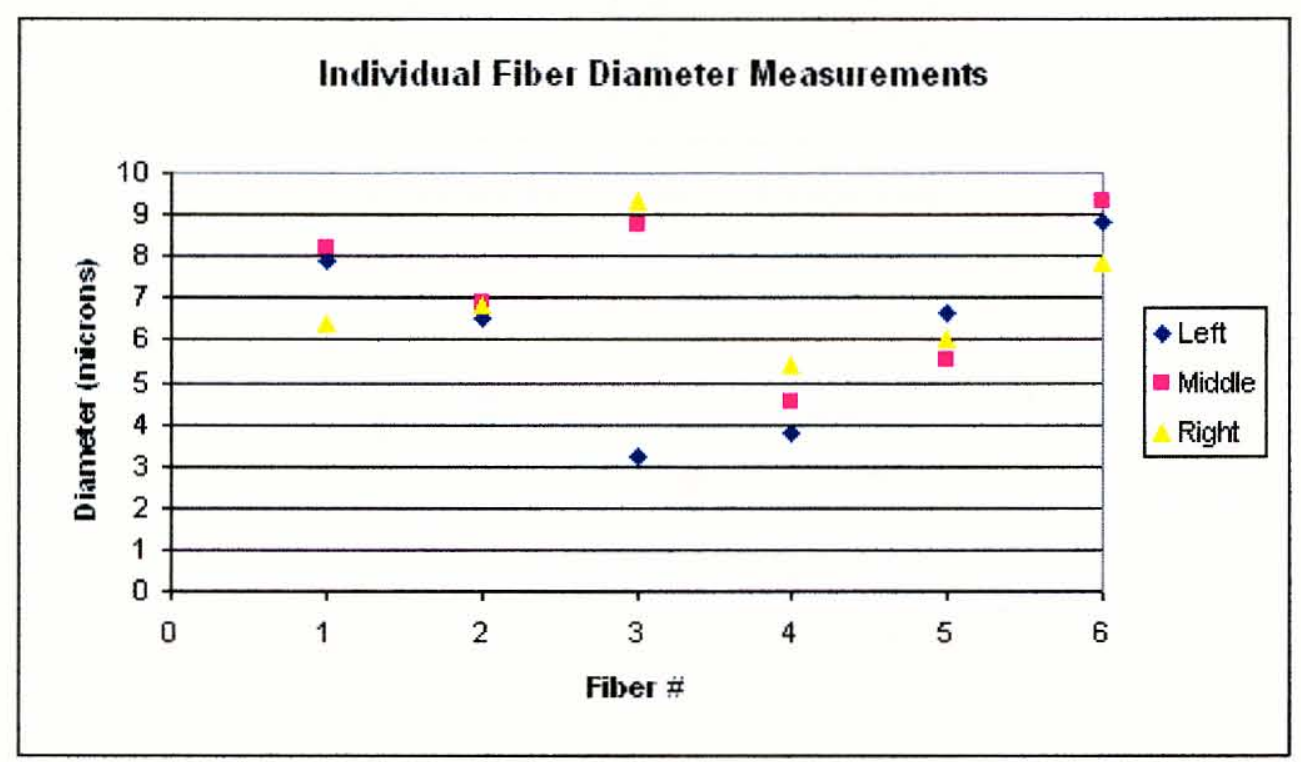


Individual fiber measurements for $495 \mathrm{k} \mathrm{g} / \mathrm{mol}$ solution with $18 \%$ solids and parylene stylus - (all measurements in microns)

\begin{tabular}{|ll|}
\hline Average & 6.265555556 \\
\hline Standard Deviation & 3.016874247 \\
\hline Yield & 0.642857143 \\
\hline Average Fiber Deviation & 0.878477499 \\
\hline
\end{tabular}

\begin{tabular}{|c|c|c|c|c|c|}
\hline Wire \# & Left & Middle & Right & Average & Std. Dev \\
\hline 1 & 9.11 & 9.709 & 9.314 & 9.377667 & 0.304533 \\
\hline 2 & 9.701 & 9.107 & 8.714 & 9.174 & 0.496899 \\
\hline 3 & 9.72 & 10.69 & 11.49 & 10.63333 & 0.88636 \\
\hline 4 & 4.36 & 3.762 & 1.694 & 3.272 & 1.398915 \\
\hline 5 & 6.987 & 7.691 & 8.32 & 7.666 & 0.666852 \\
\hline 6 & 4.735 & 5.602 & 7.203 & 5.846667 & 1.252059 \\
\hline 7 & 4.336 & 2.591 & 1.484 & 2.803667 & 1.437844 \\
\hline 8 & 4.36 & 3.261 & 2.41 & 3.343667 & 0.977625 \\
\hline 9 & 3.813 & 4.226 & 4.78 & 4.273 & 0.48521 \\
\hline
\end{tabular}

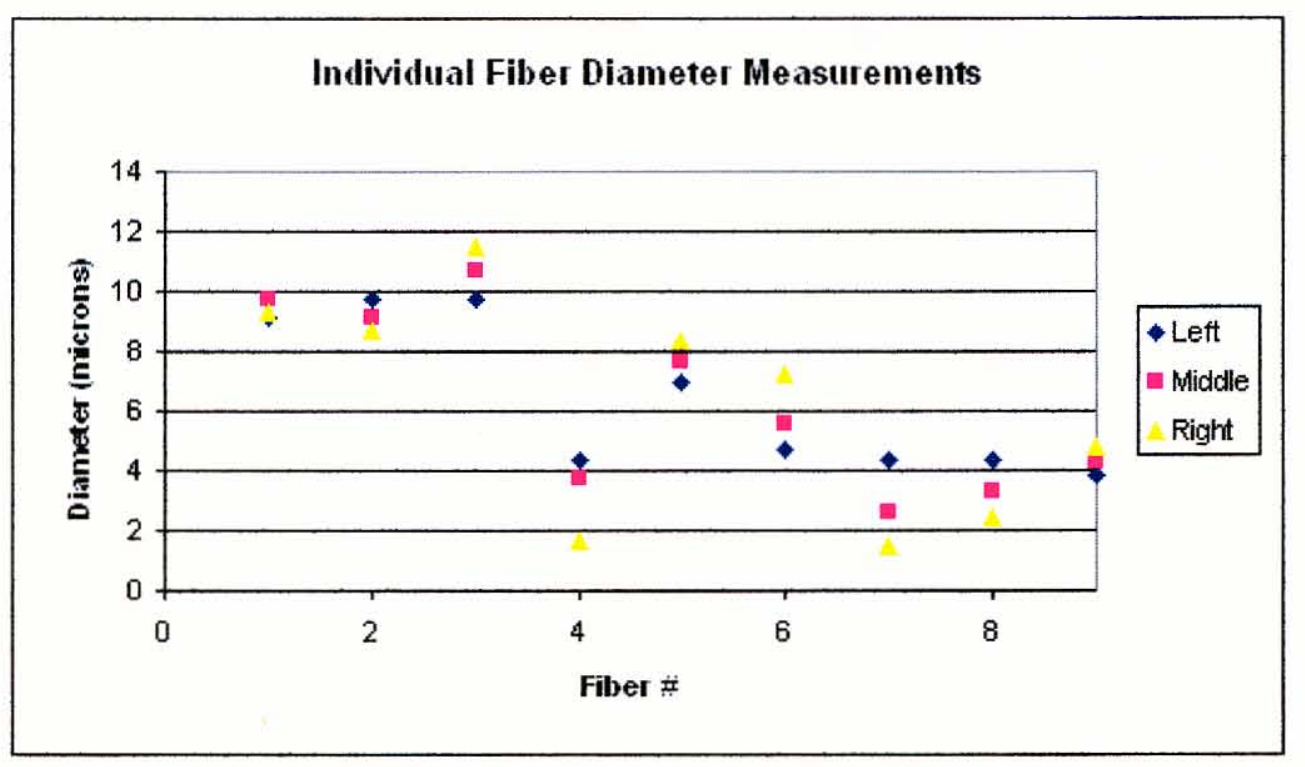


Individual fiber measurements for $495 \mathrm{k} \mathrm{g} / \mathrm{mol}$ solution with $21.6 \%$ solids and parylene stylus - (all measurements in microns)

\begin{tabular}{|lr|}
\hline Average & 19.02916667 \\
\hline Standard Deviation & 1.399283878 \\
\hline Yield & 0.4 \\
\hline Average Fiber Deviation & 1.368953154 \\
\hline
\end{tabular}

\begin{tabular}{|c|c|c|c|c|c|}
\hline Wire \# & Left & Middle & Right & Average & Std. Dev \\
\hline 1 & 15.92 & 18.89 & 20.43 & 18.41333 & 2.292473 \\
\hline 2 & 18.43 & 17.44 & 16.91 & 17.59333 & 0.771514 \\
\hline 3 & 19.63 & 20.8 & 22.18 & 20.87 & 1.27644 \\
\hline 4 & 18.54 & 18.63 & 20.55 & 19.24 & 1.135385 \\
\hline
\end{tabular}

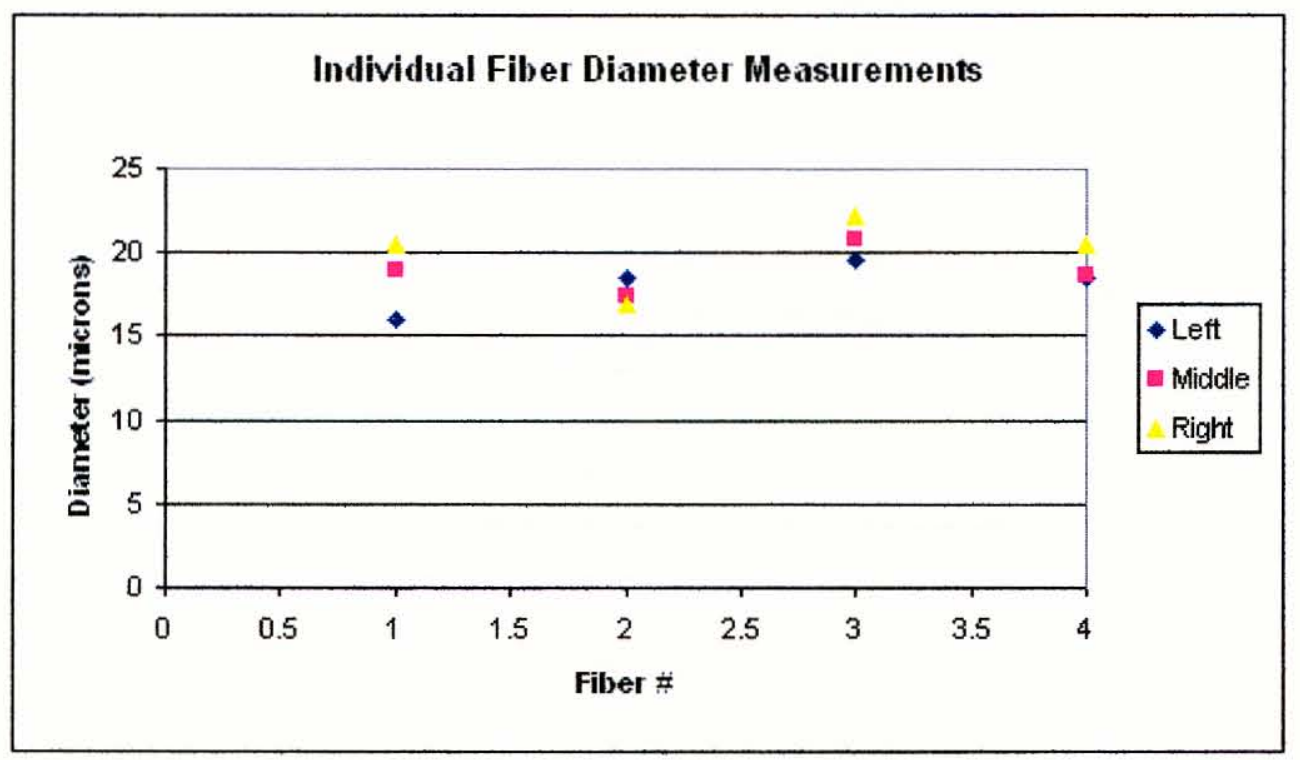


Individual fiber measurements for $495 \mathrm{k} \mathrm{g} / \mathrm{mol}$ solution with $23 \%$ solids and parylene stylus - (all measurements in microns)

\begin{tabular}{|lr|}
\hline Average & 26.9825 \\
\hline Standard Deviation & 2.031776043 \\
\hline Yield & 0.4 \\
\hline Average Fiber Deviation & 5.415085708 \\
\hline
\end{tabular}

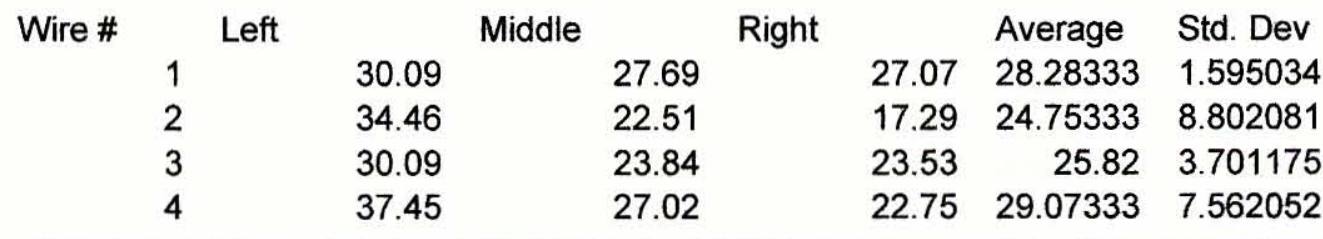

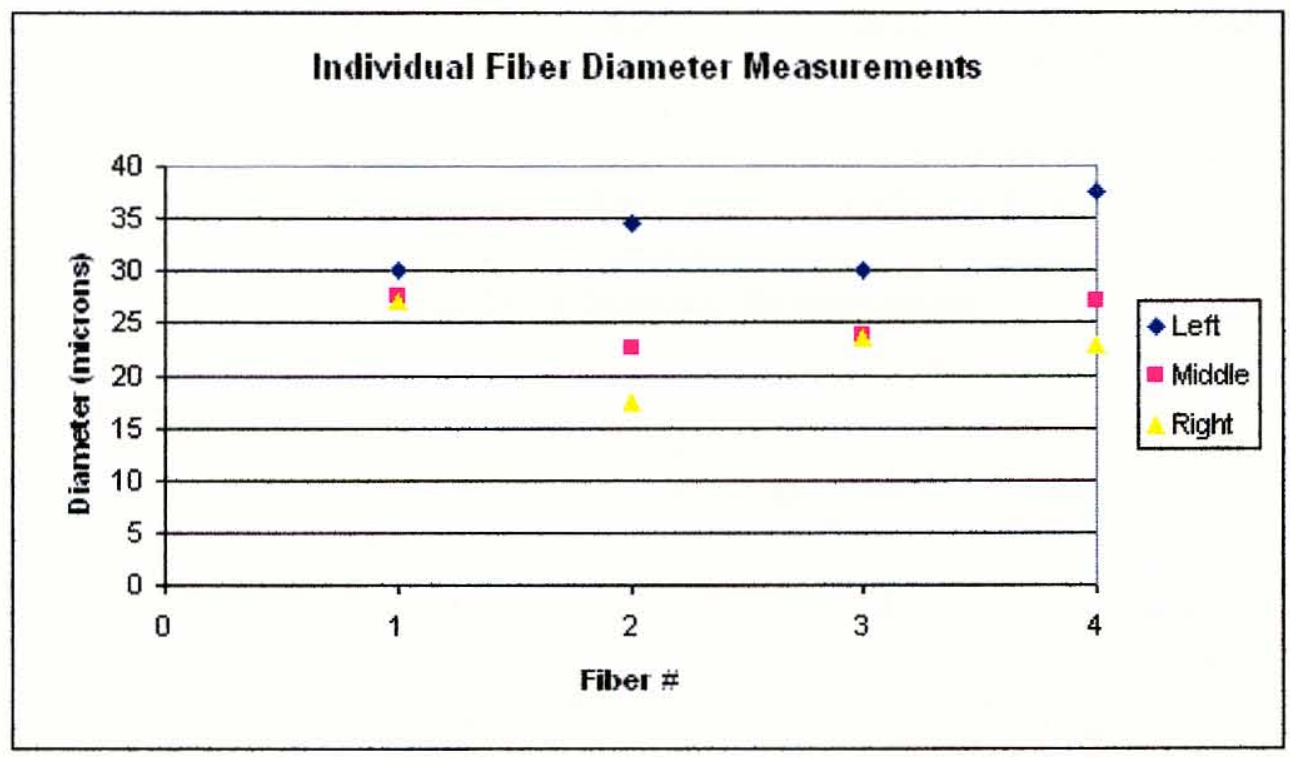


Individual fiber measurements for $495 \mathrm{k} \mathrm{g} / \mathrm{mol}$ solution with $15.5 \%$ solids and non-stick stylus - (all measurements in microns)

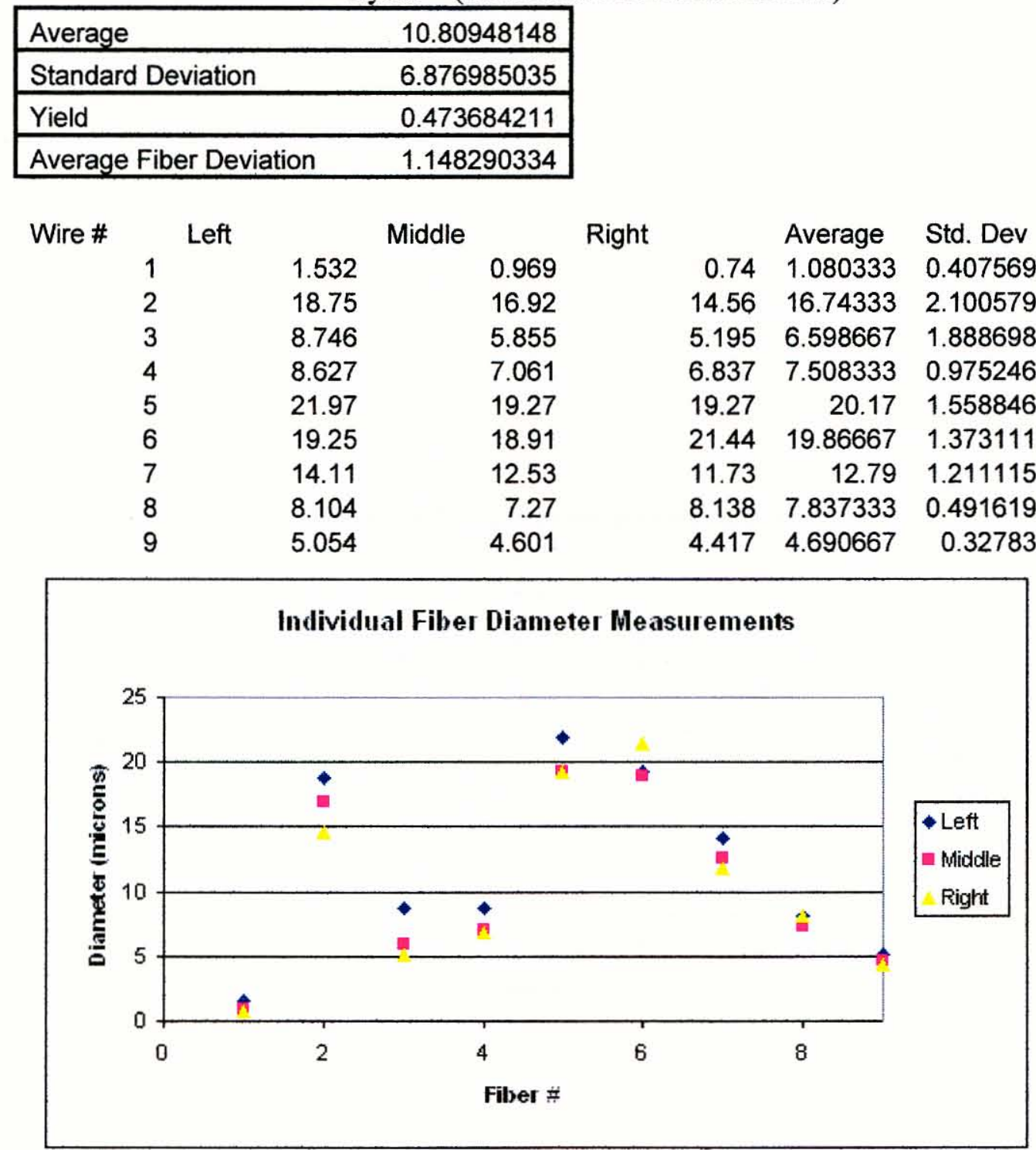


Individual fiber measurements for $495 \mathrm{k} \mathrm{g} / \mathrm{mol}$ solution with $16 \%$ solids and non-stick stylus - (all measurements in microns)

\begin{tabular}{|lr|}
\hline Average & 8.757444444 \\
\hline Standard Deviation & 2.842715014 \\
\hline Yield & 0.3 \\
\hline Average Fiber Deviation & 1.064841568 \\
\hline
\end{tabular}

\begin{tabular}{|c|c|c|c|c|c|}
\hline Wire \# & Left & Middle & Right & Average & Std. Dev \\
\hline 1 & 7.864 & 6.55 & 4.484 & 6.299333 & 1.703885 \\
\hline 2 & 11.04 & 11.04 & 12.85 & 11.64333 & 1.045004 \\
\hline 3 & 9.497 & 9.252 & 7.649 & 8.799333 & 1.003721 \\
\hline 4 & 11.68 & 10.77 & 10.72 & 11.05667 & 0.540401 \\
\hline 5 & 9.633 & 10.44 & 10.77 & 10.281 & 0.5849 \\
\hline 6 & 5.986 & 4.445 & 2.964 & 4.465 & 1.51 \\
\hline
\end{tabular}

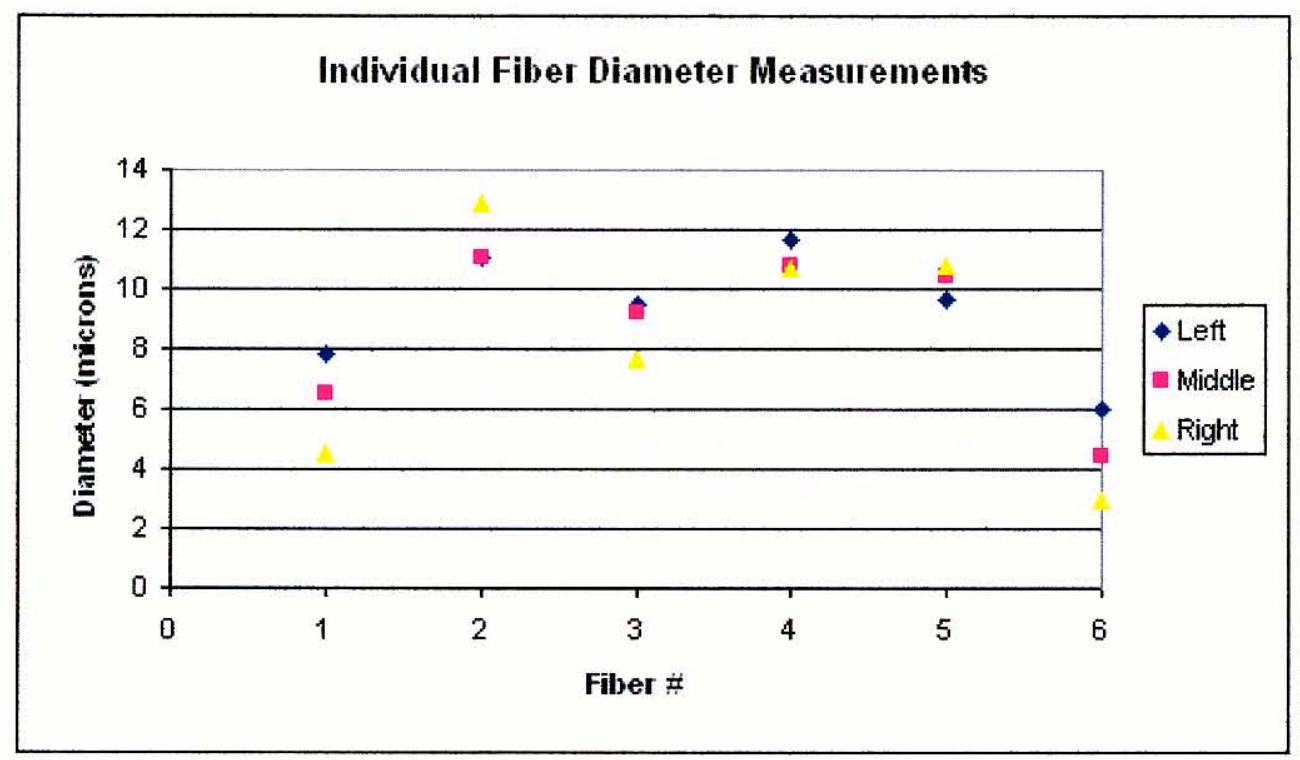


Individual fiber measurements for $495 \mathrm{~kg} / \mathrm{mol}$ solution with $17 \%$ solids and non-stick stylus - (all measurements in microns)

\begin{tabular}{|lr|}
\hline Average & 7.918111111 \\
\hline Standard Deviation & 5.076768901 \\
\hline Yield & 0.25 \\
\hline Average Fiber Deviation & 1.295413475 \\
\hline
\end{tabular}

\begin{tabular}{|c|c|c|c|c|c|}
\hline Wire \# & Left & Middle & Right & Average & Std. Dev \\
\hline 1 & 13.88 & 14.86 & 16.44 & 15.06 & 1.291666 \\
\hline 2 & 1.999 & 2.354 & 4.943 & 3.098667 & 1.607072 \\
\hline 3 & 5.774 & 7.656 & 8.132 & 7.187333 & 1.246907 \\
\hline 4 & 6.131 & 3.83 & 1.947 & 3.969333 & 2.095477 \\
\hline 5 & 5.506 & 5.701 & 3.403 & 4.87 & 1.274195 \\
\hline 6 & 13.51 & 13.03 & 13.43 & 13.32333 & 0.257164 \\
\hline
\end{tabular}

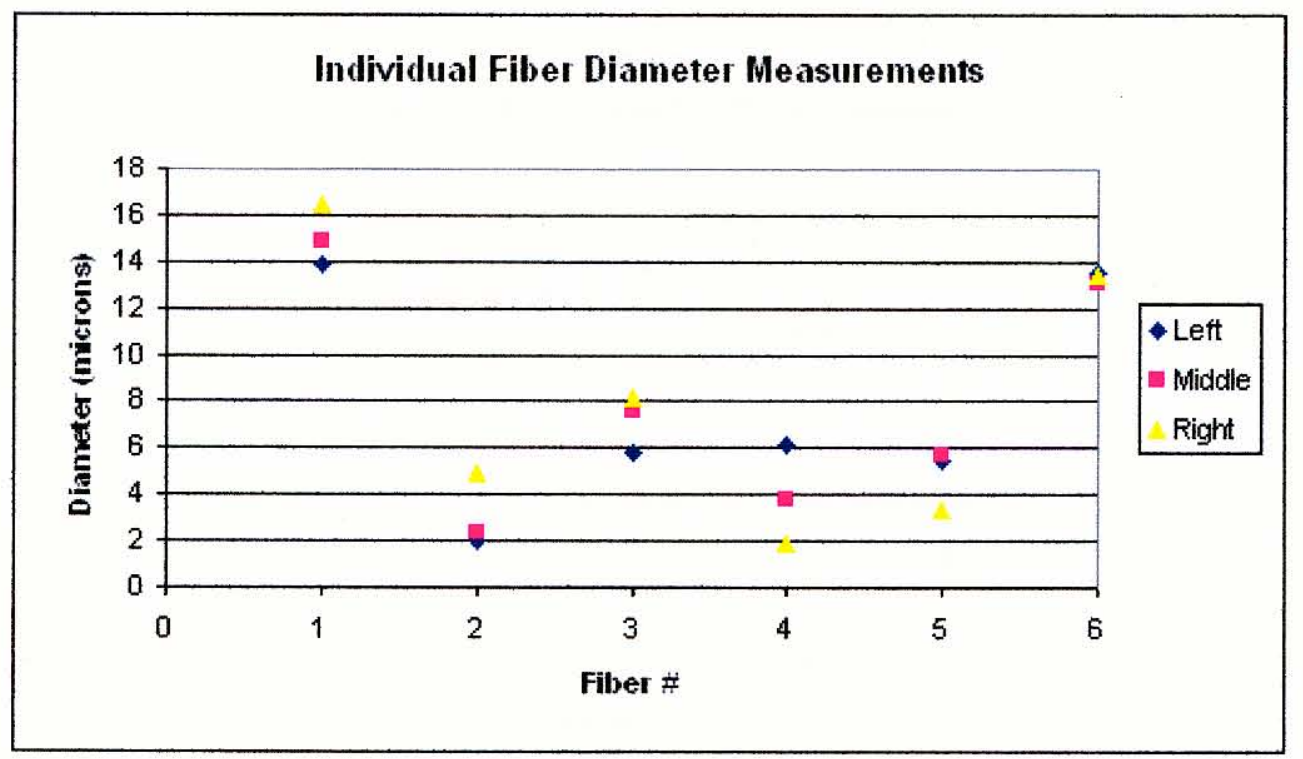


Individual fiber measurements for $495 \mathrm{~kg} / \mathrm{mol}$ solution with $18 \%$ solids and non-stick stylus - (all measurements in microns)

\begin{tabular}{|lr|}
\hline Average & 4.696833333 \\
\hline Standard Deviation & 2.688757282 \\
\hline Yield & 0.35 \\
\hline Average Fiber Deviation & 0.966768349 \\
\hline
\end{tabular}

\begin{tabular}{|c|c|c|c|c|c|}
\hline Wire \# & Left & Middle & Right & Average & Std. Dev \\
\hline 1 & 5.329 & 4.448 & 3.173 & 4.316667 & 1.083984 \\
\hline 2 & 8.644 & 8.151 & 6.917 & & 0.8896 \\
\hline 3 & 8.776 & 7.998 & 6.761 & 7.845 & 1.016176 \\
\hline 4 & 8.996 & 7.636 & 6.475 & 7.702333 & 1.261808 \\
\hline 5 & 3.544 & 1.958 & 1.193 & 2.231667 & 1.199154 \\
\hline 6 & 1.647 & 1.408 & 1.094 & 1.383 & 0.277346 \\
\hline 7 & 5.021 & 5.545 & 3.541 & 4.702333 & 1.03931 \\
\hline
\end{tabular}

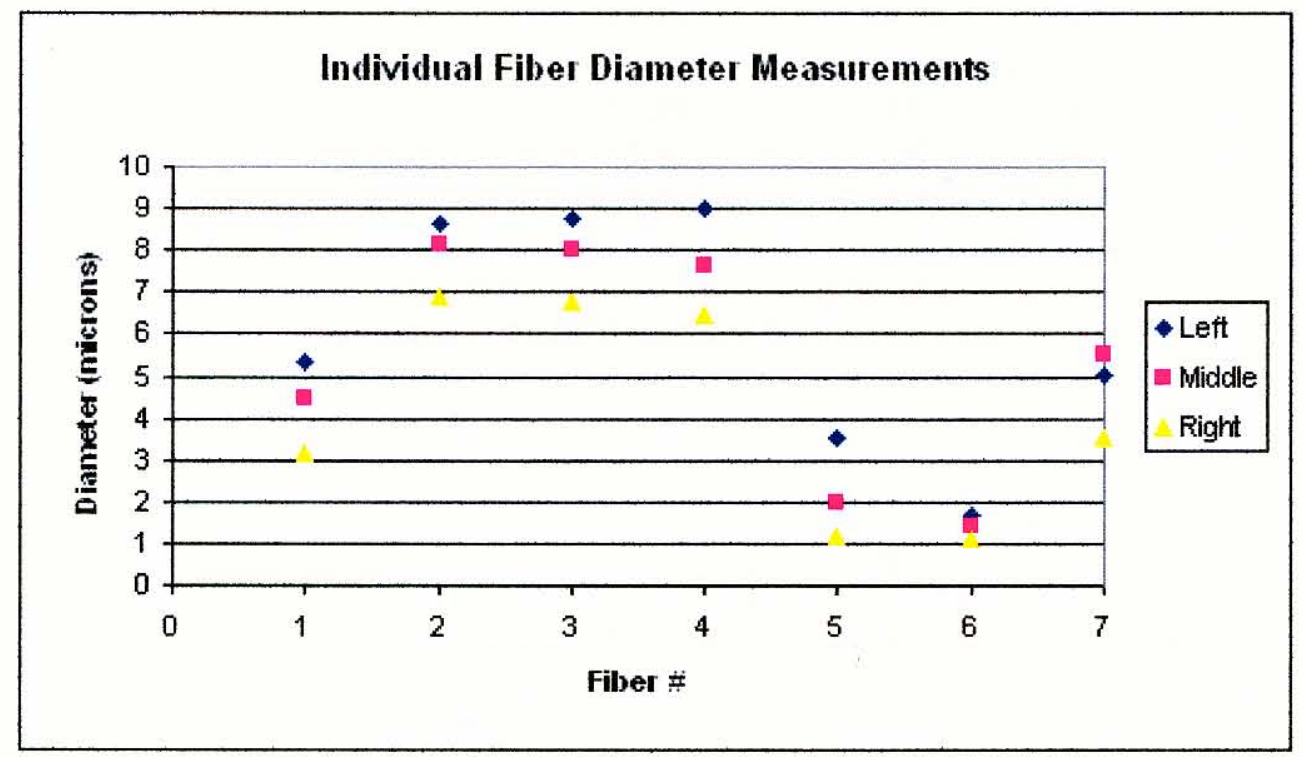


Individual fiber measurements for $495 \mathrm{k} \mathrm{g} / \mathrm{mol}$ solution with $21.6 \%$ solids and non-stick stylus - (all measurements in microns)

\begin{tabular}{|ll|}
\hline Average & 15.23787179 \\
\hline Standard Deviation & 7.575145573 \\
\hline Yield & 0.928571429 \\
\hline Average Fiber Deviation & 1.283374453 \\
\hline
\end{tabular}

\begin{tabular}{|c|c|c|c|c|c|}
\hline Wire \# & Left & Middle & Right & Average & Std. Dev \\
\hline 1 & 3.788 & 2.675 & 2.358 & 2.940333 & 0.751017 \\
\hline 2 & 2.448 & 2.858 & 3.499 & 2.935 & 0.529714 \\
\hline 3 & 7.835 & 7.232 & 6.091 & 7.052667 & 0.885722 \\
\hline 4 & 9.044 & 9.599 & 12.22 & 10.28767 & 1.696302 \\
\hline 5 & 12.46 & 10.96 & 10.44 & 11.28667 & 1.048872 \\
\hline 6 & 15.66 & 14.55 & 14.52 & 14.91 & 0.649692 \\
\hline 7 & 22.4 & 19.62 & 19.85 & 20.62333 & 1.54293 \\
\hline 8 & 20.24 & 17.71 & 18.78 & 18.91 & 1.27 \\
\hline 9 & 22.8 & 22.55 & 22.55 & 22.63333 & 0.144338 \\
\hline 10 & 21.06 & 21.88 & 15.7 & 19.54667 & 3.356447 \\
\hline 11 & 20.19 & 18.46 & 20.16 & 19.60333 & 0.990269 \\
\hline 12 & 22.37 & 23.41 & 22.77 & 22.85 & 0.524595 \\
\hline 13 & 28.3 & 22.93 & 22.31 & 24.51333 & 3.293969 \\
\hline
\end{tabular}

Individual Fiber Diameter Measurements

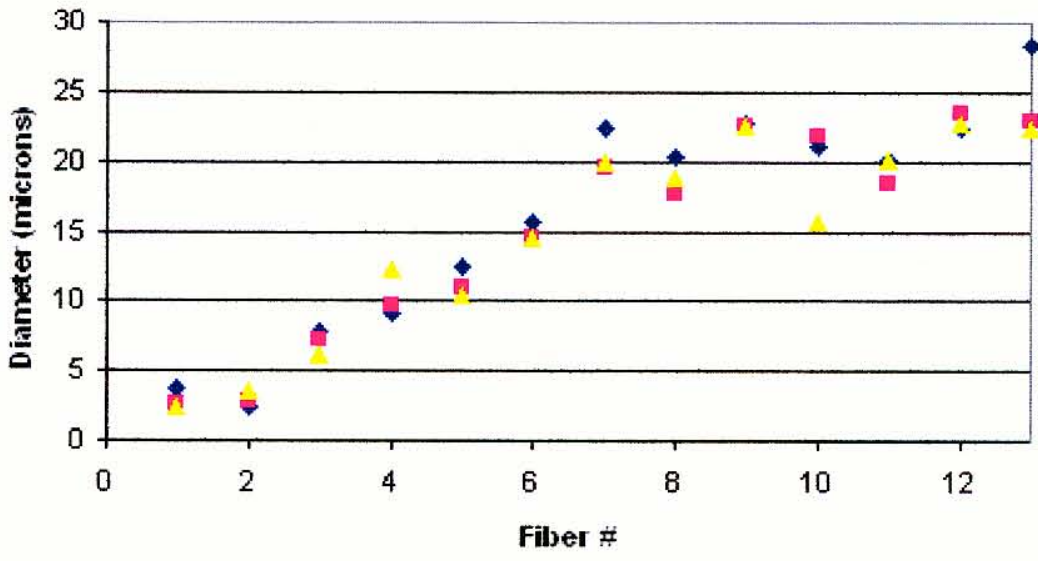

- Left

Middle

Right 
Individual fiber measurements for $495 \mathrm{k} \mathrm{g} / \mathrm{mol}$ solution with $23 \%$ solids and non-stick stylus - (all measurements in microns)

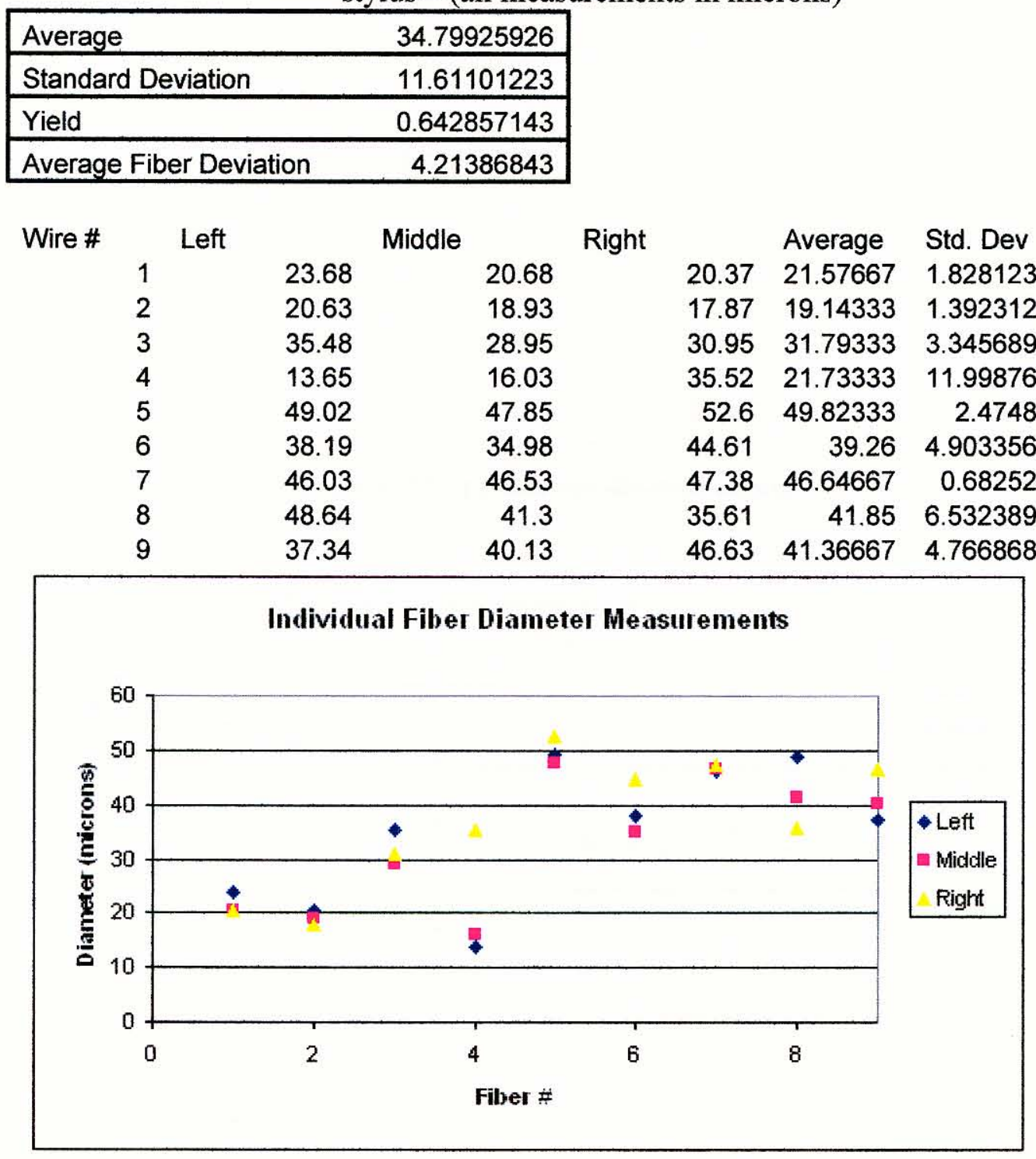


Individual fiber measurements for $495 \mathrm{k} \mathrm{g} / \mathrm{mol}$ solution with $15.5 \%$ solids and glass stylus

\begin{tabular}{|lr|}
\hline \multicolumn{1}{l}{} & - (all measurem \\
\hline Average & 2.425733333 \\
\hline Standard Deviation & 1.085074227 \\
\hline Yield & 0.263157895 \\
\hline Average Fiber Deviation & 1.738031476 \\
\hline
\end{tabular}

\begin{tabular}{|c|c|c|c|c|c|}
\hline Wire \# & Left & Middle & Right & Average & Std. Dev \\
\hline 1 & 7.144 & 3.527 & 2.318 & 4.329667 & 2.51113 \\
\hline 2 & 3.209 & 1.638 & 0.906 & 1.917667 & 1.176696 \\
\hline 3 & 3.526 & 1.181 & 0.843 & 1.85 & 1.461264 \\
\hline 4 & 4.771 & 1.445 & 0.676 & 2.297333 & 2.17649 \\
\hline 5 & 3.233 & 1.405 & 0.564 & 1.734 & 1.364577 \\
\hline
\end{tabular}

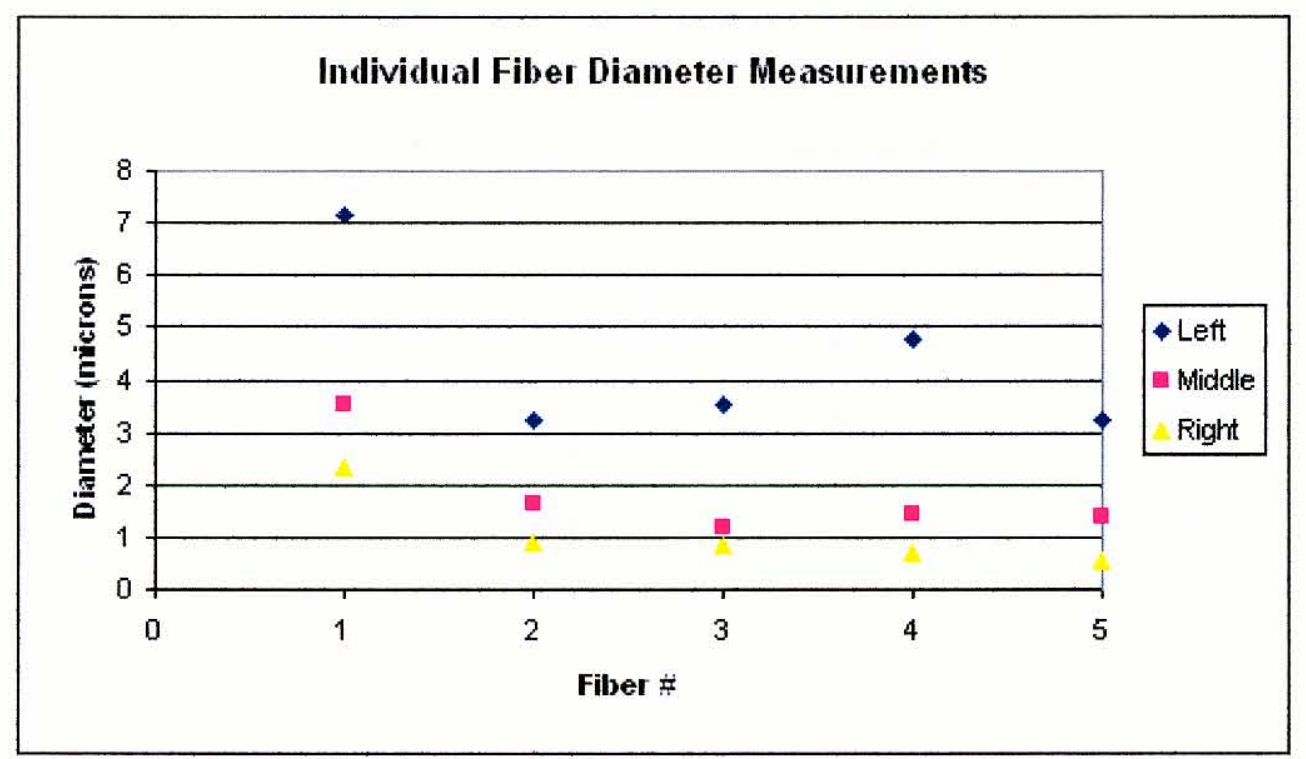


Individual fiber measurements for $495 \mathrm{k} \mathrm{g} / \mathrm{mol}$ solution with $16 \%$ solids and glass stylus (all measurements in microns)

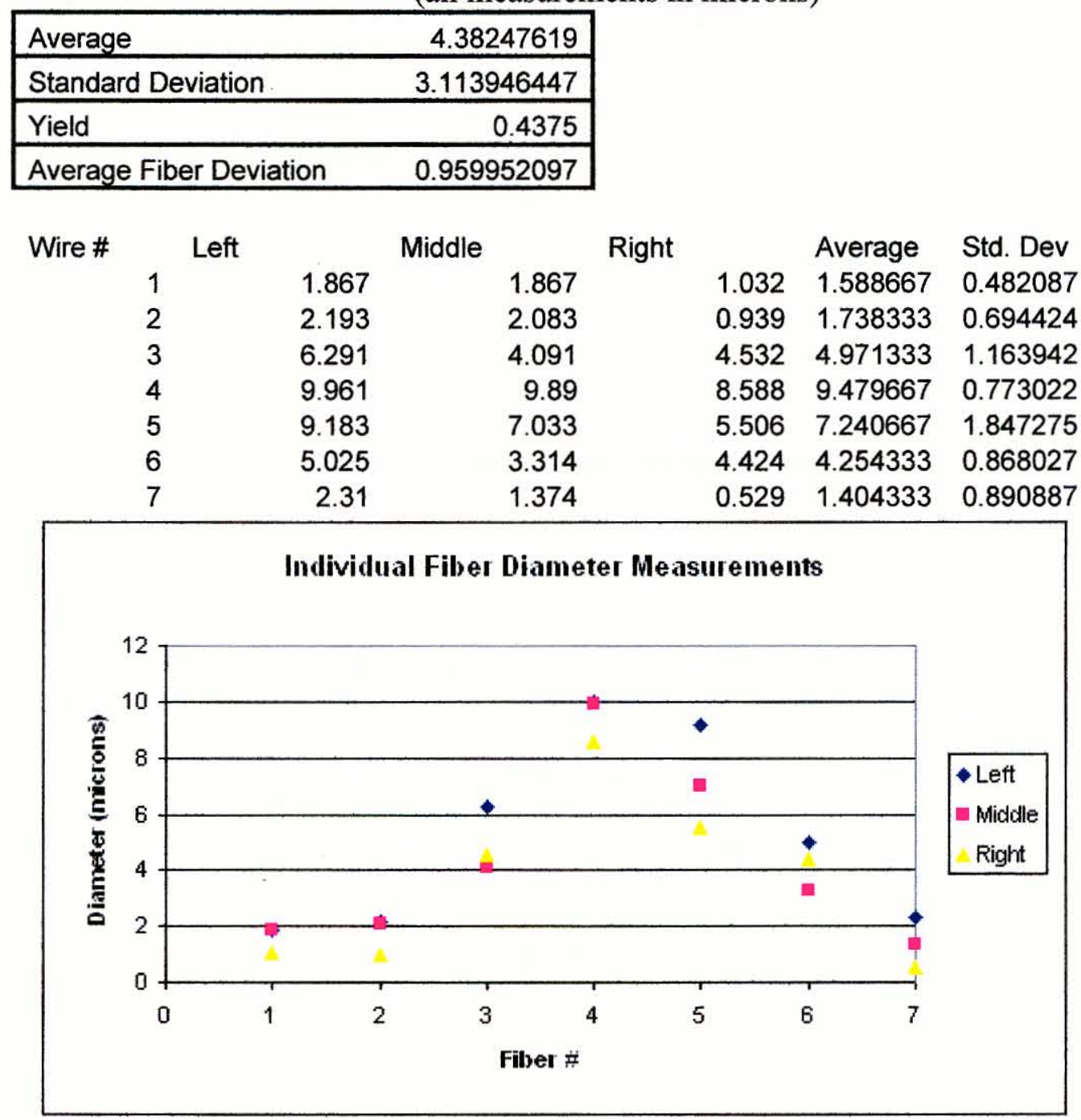


Individual fiber measurements for $495 \mathrm{k} \mathrm{g} / \mathrm{mol}$ solution with $17 \%$ solids and glass stylus (all measurements in microns)

\begin{tabular}{|lr|}
\hline Average & 4.198 \\
\hline Standard Deviation & 2.041012294 \\
\hline Yield & 0.2 \\
\hline Average Fiber Deviation & 1.702355093 \\
\hline
\end{tabular}

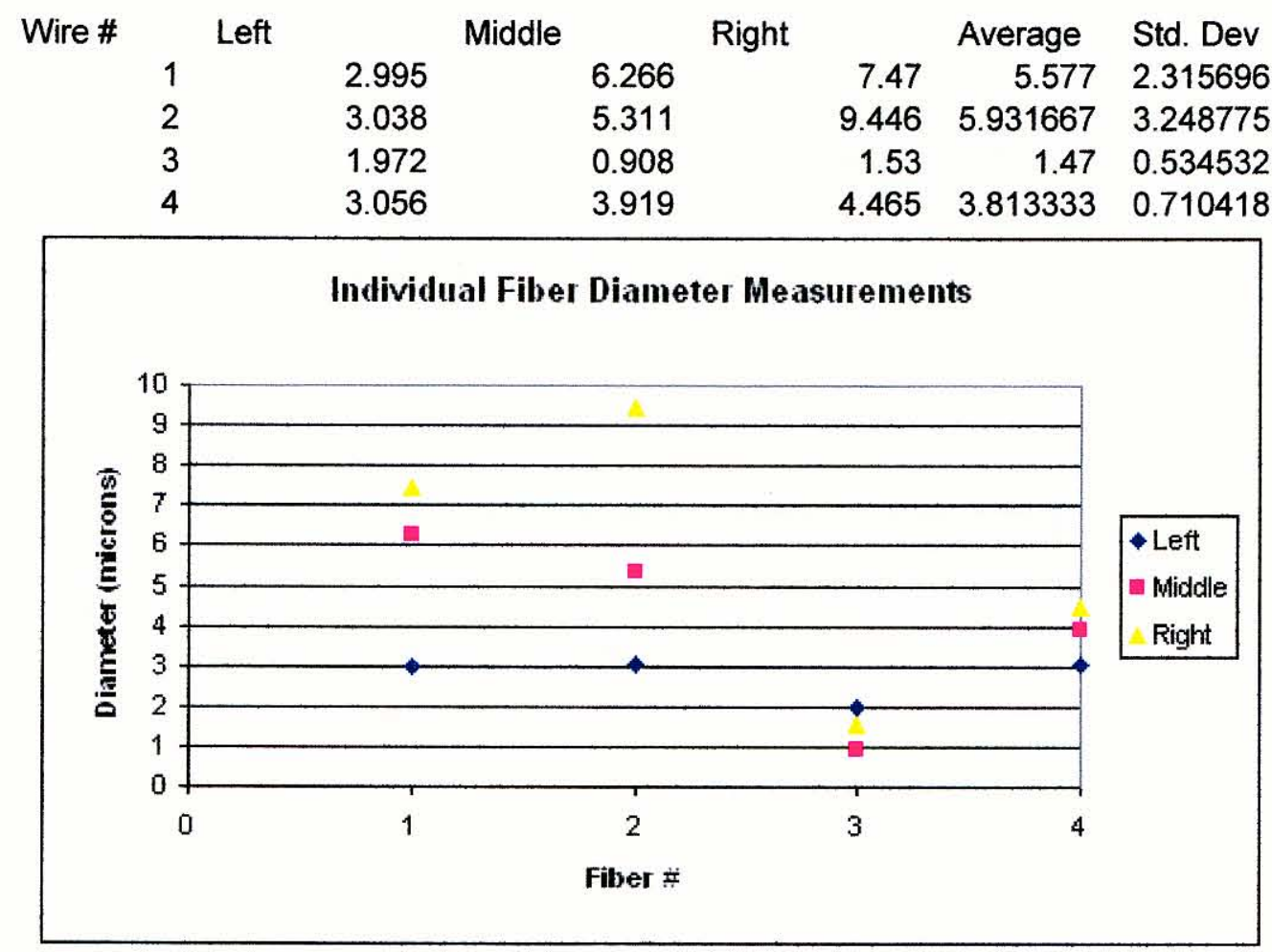


Individual fiber measurements for $495 \mathrm{k} \mathrm{g} / \mathrm{mol}$ solution with $18 \%$ solids and glass stylus (all measurements in microns)

\begin{tabular}{|lr|}
\hline Average & 4.841833333 \\
\hline Standard Deviation & 2.708741767 \\
\hline Yield & 0.25 \\
\hline Average Fiber Deviation & 1.072648343 \\
\hline
\end{tabular}

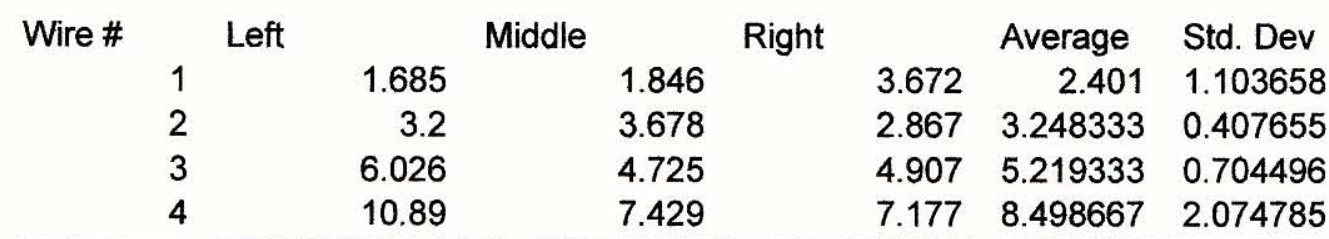

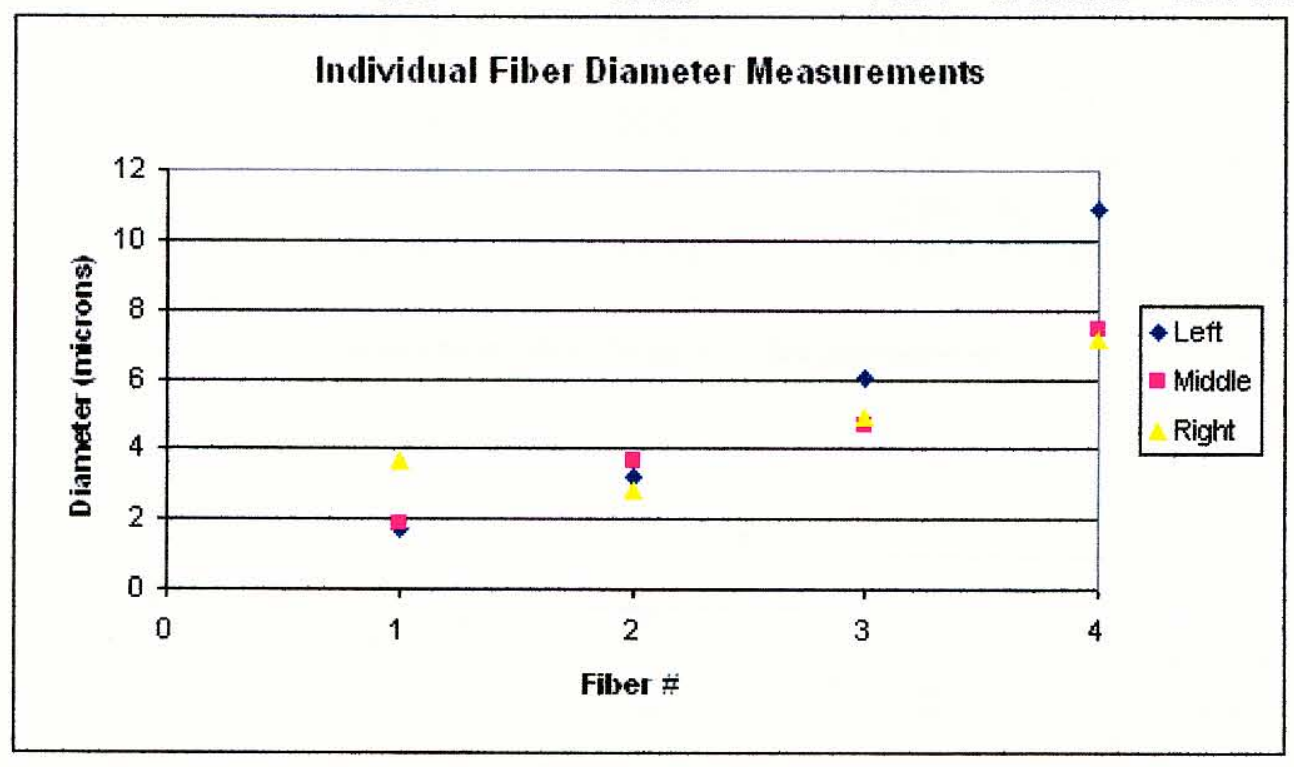


Individual fiber measurements for $495 \mathrm{k}$ g/mol solution with $21.6 \%$ solids and glass stylus - (all measurements in microns)

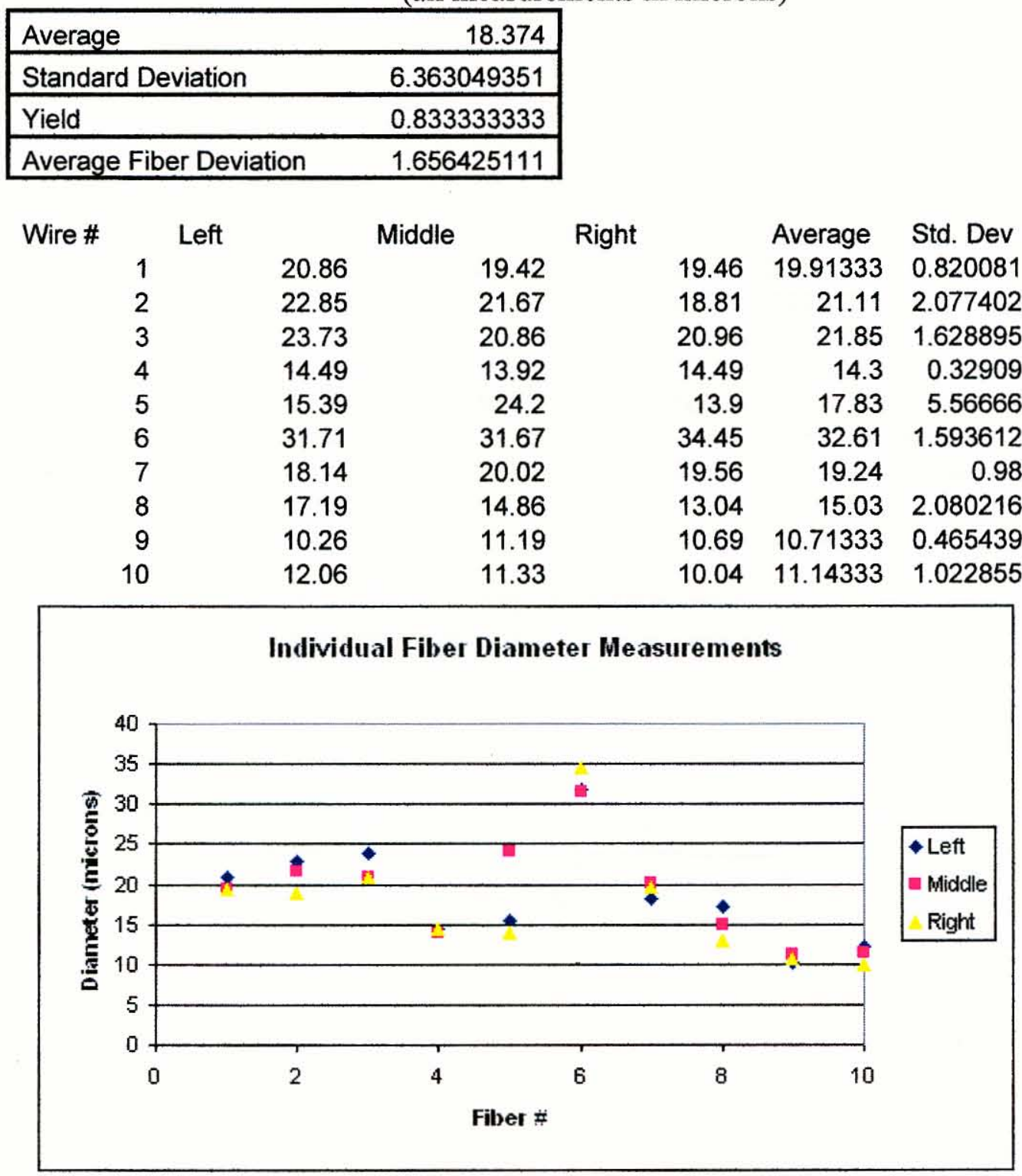


Individual fiber measurements for $495 \mathrm{k} \mathrm{g} / \mathrm{mol}$ solution with $23 \%$ solids and glass stylus (all measurements in microns)

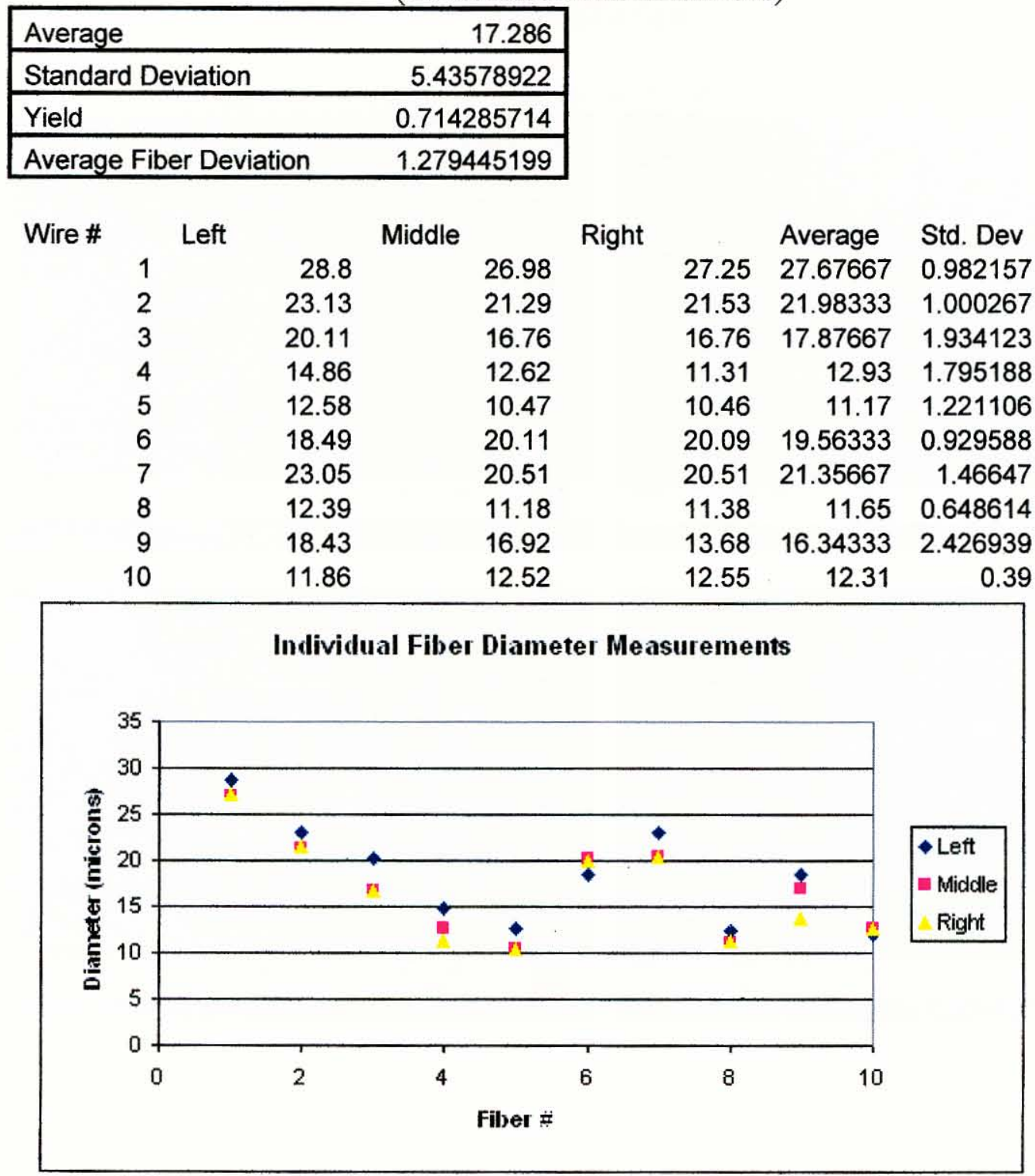




\section{APPENDIX III}

\section{SEM IMAGES}

SEM images for $495 \mathrm{k} \mathrm{g} / \mathrm{mol}$ solution with $16 \%$ solids and tungsten stylus
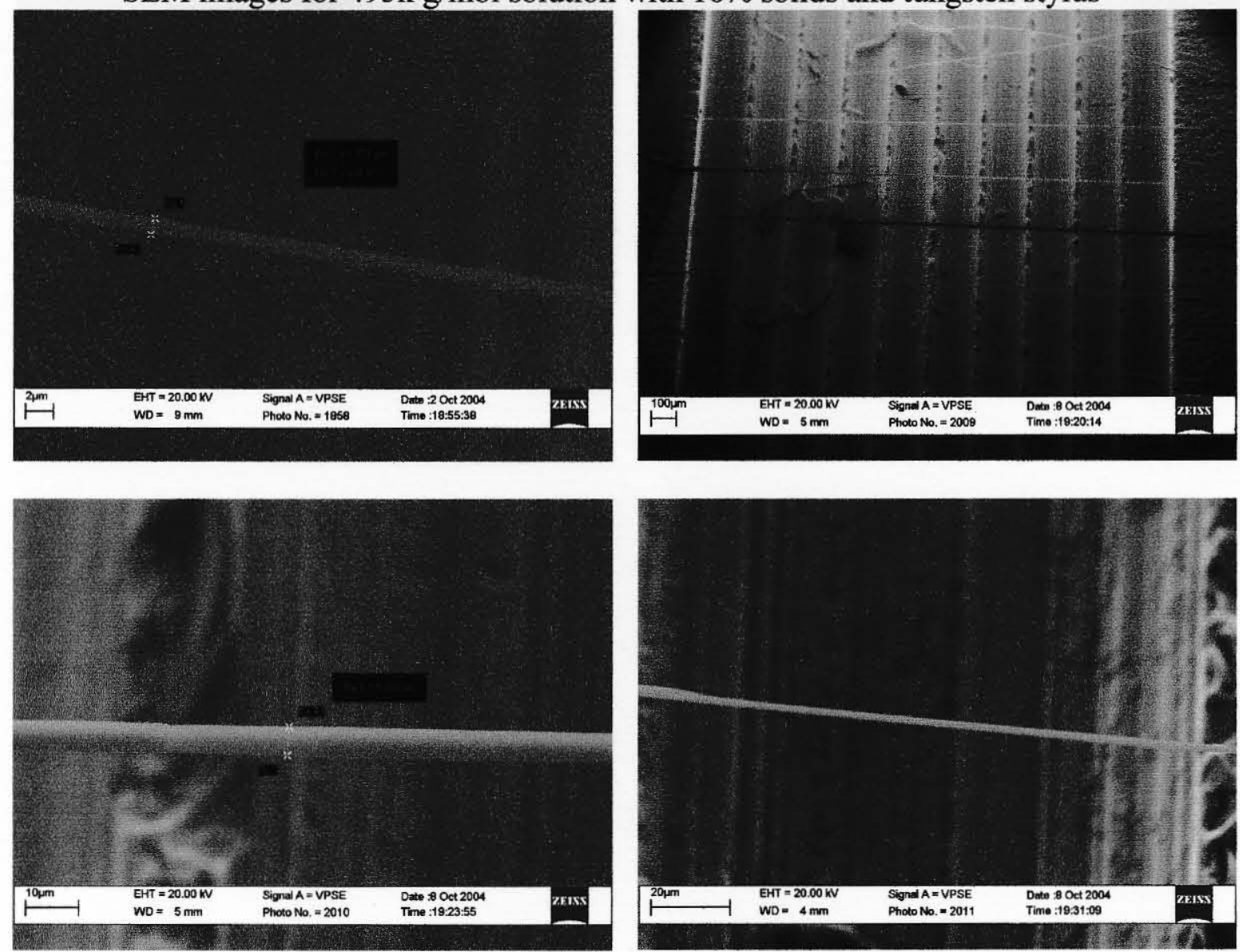
SEM images for $495 \mathrm{k} \mathrm{g} / \mathrm{mol}$ solution with $17 \%$ solids and tungsten stylus
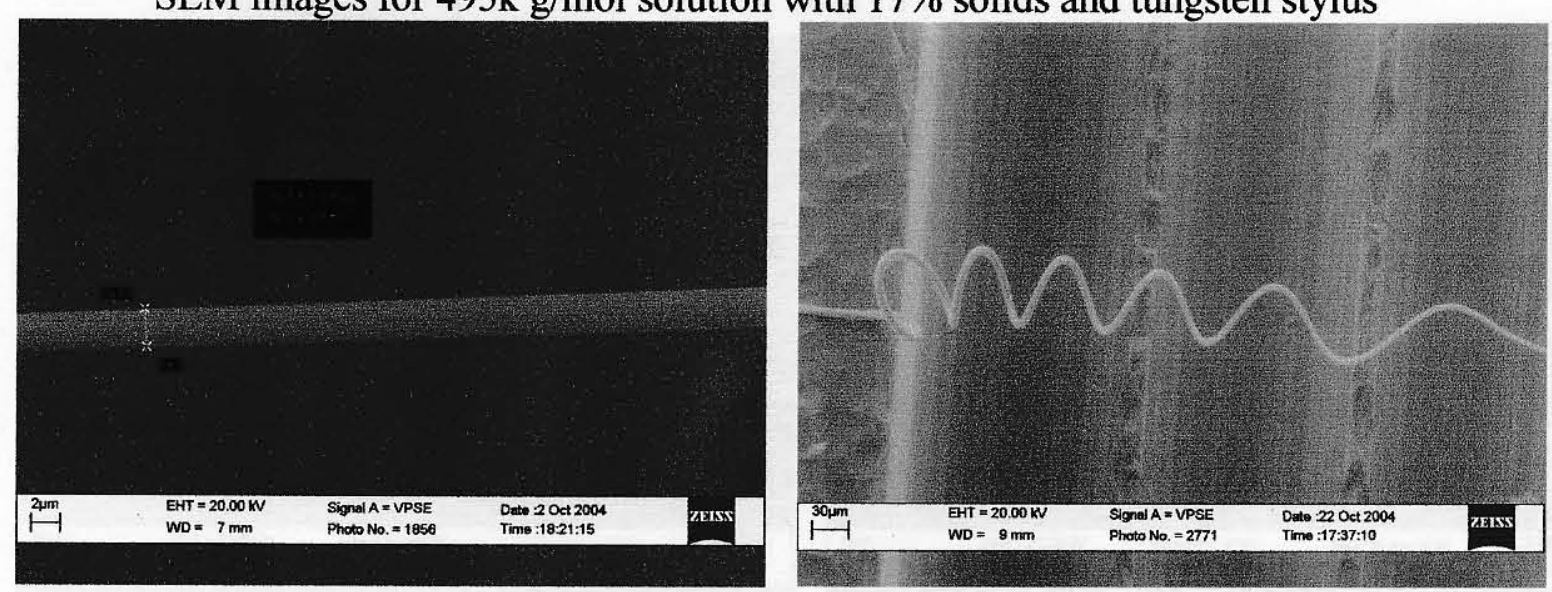
SEM images for $495 \mathrm{k} \mathrm{g} / \mathrm{mol}$ solution with $18 \%$ solids and tungsten stylus
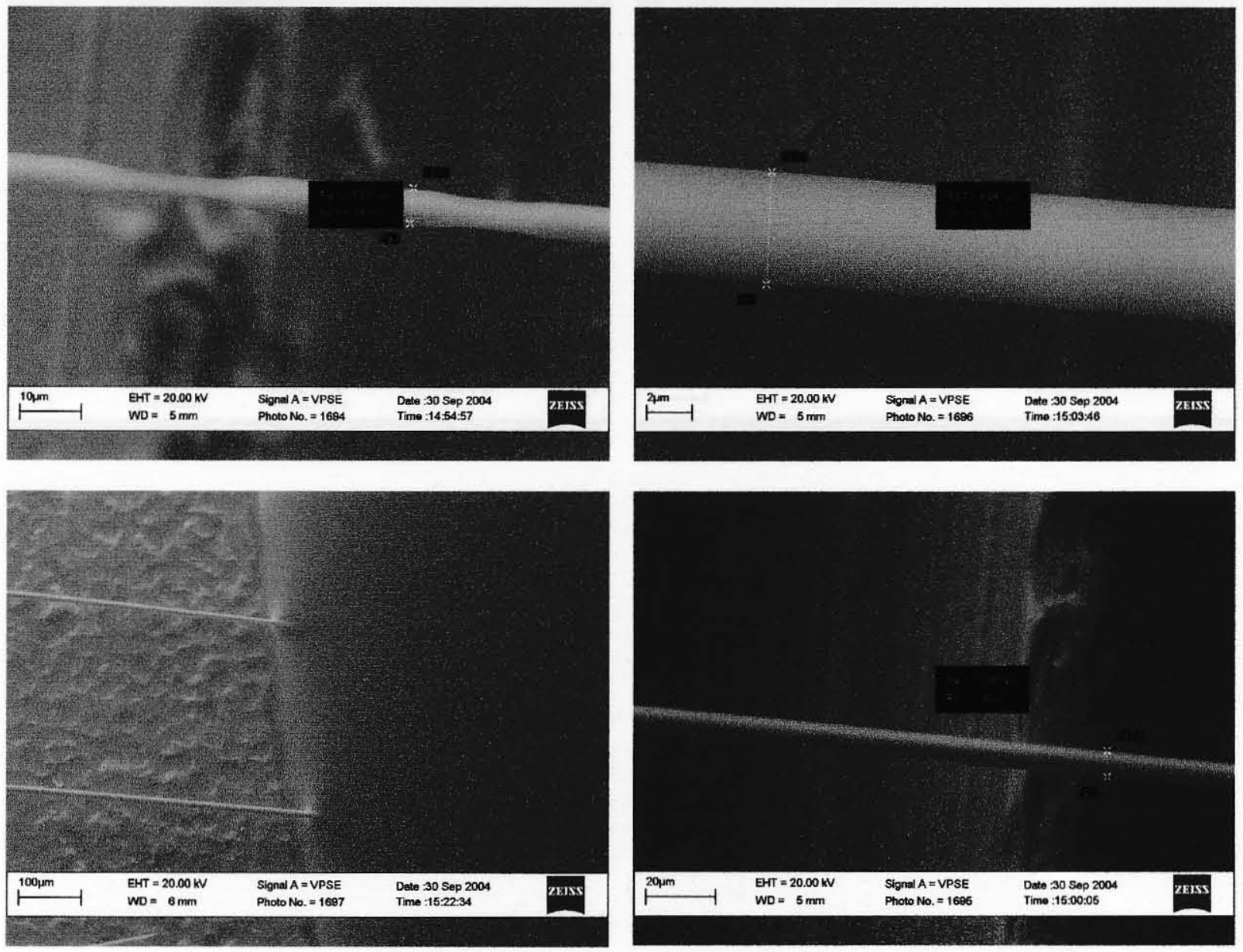
SEM images for $495 \mathrm{k} \mathrm{g} / \mathrm{mol}$ solution with $21.6 \%$ solids and tungsten stylus
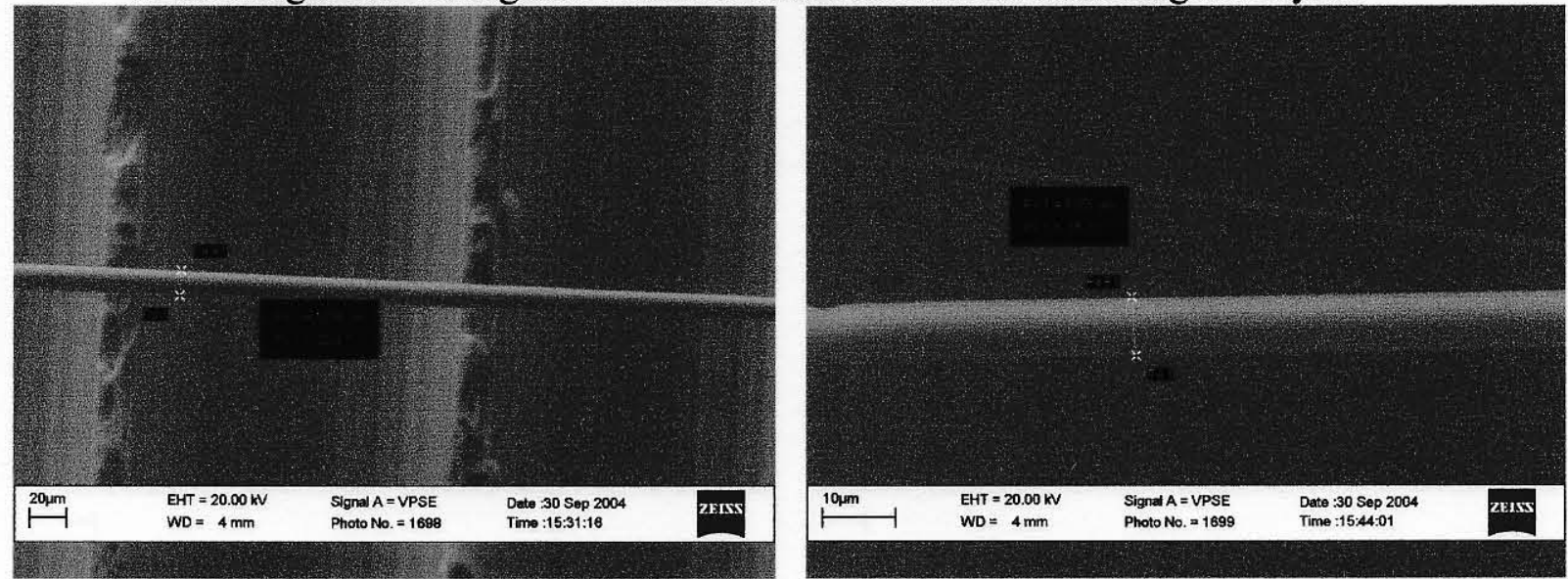
SEM images for $950 \mathrm{k} \mathrm{g} / \mathrm{mol}$ solution with $13 \%$ solids and tungsten stylus
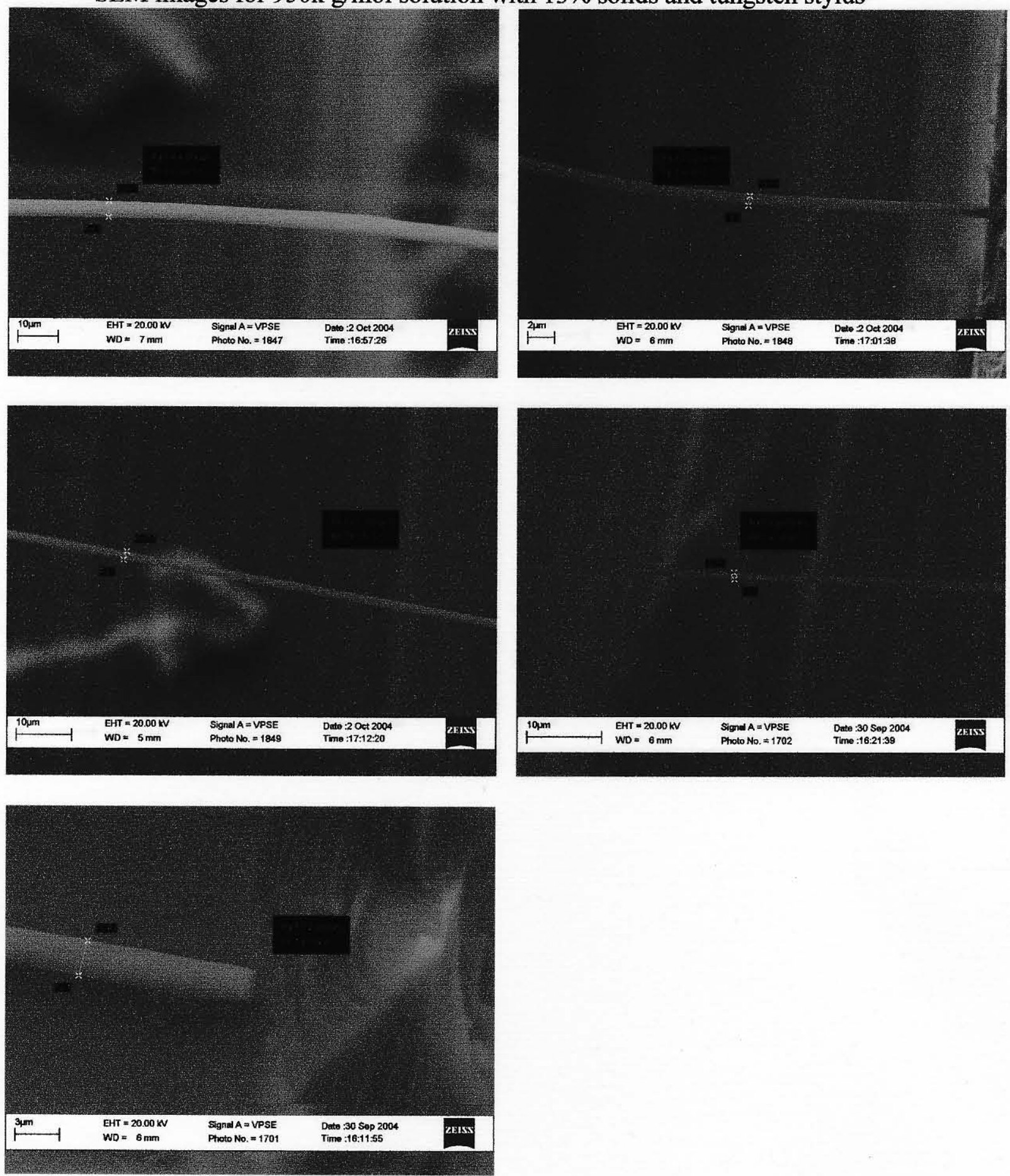
SEM images for $950 \mathrm{k} \mathrm{g} / \mathrm{mol}$ solution with $15 \%$ solids and tungsten stylus
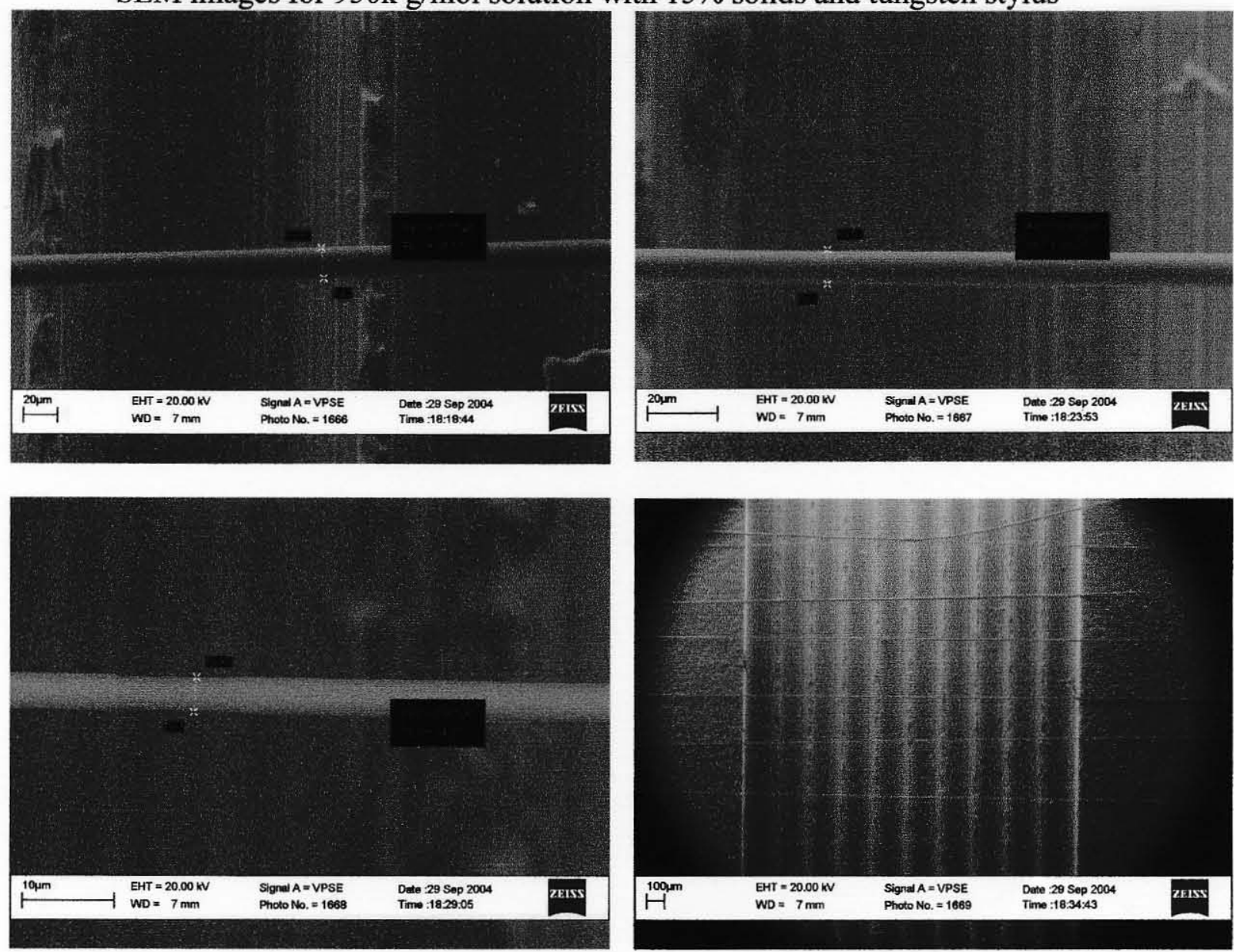
SEM images for $950 \mathrm{k} \mathrm{g} / \mathrm{mol}$ solution with $18 \%$ solids and tungsten stylus
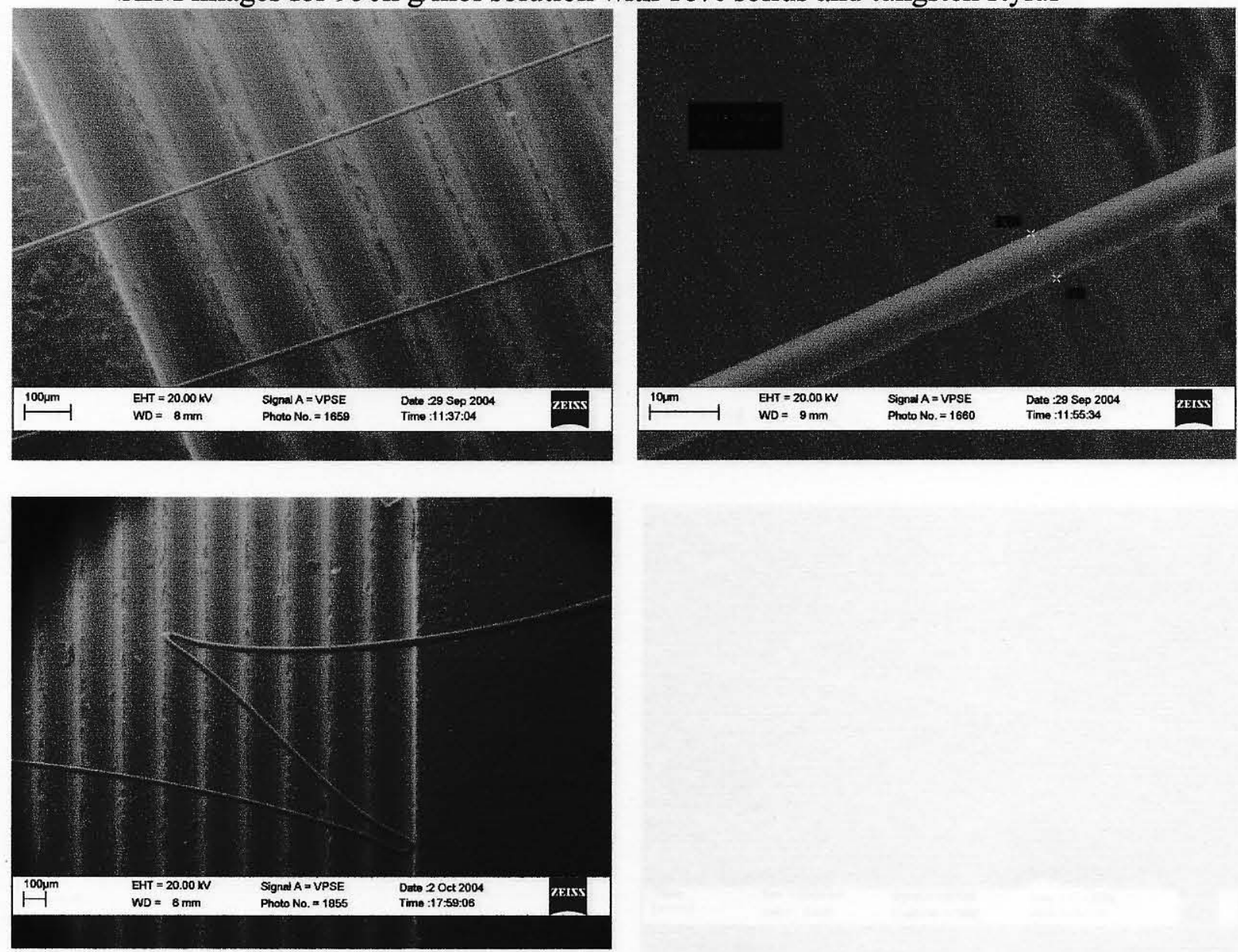
SEM images for $950 \mathrm{k} \mathrm{g} / \mathrm{mol}$ solution with $21.3 \%$ solids and tungsten stylus
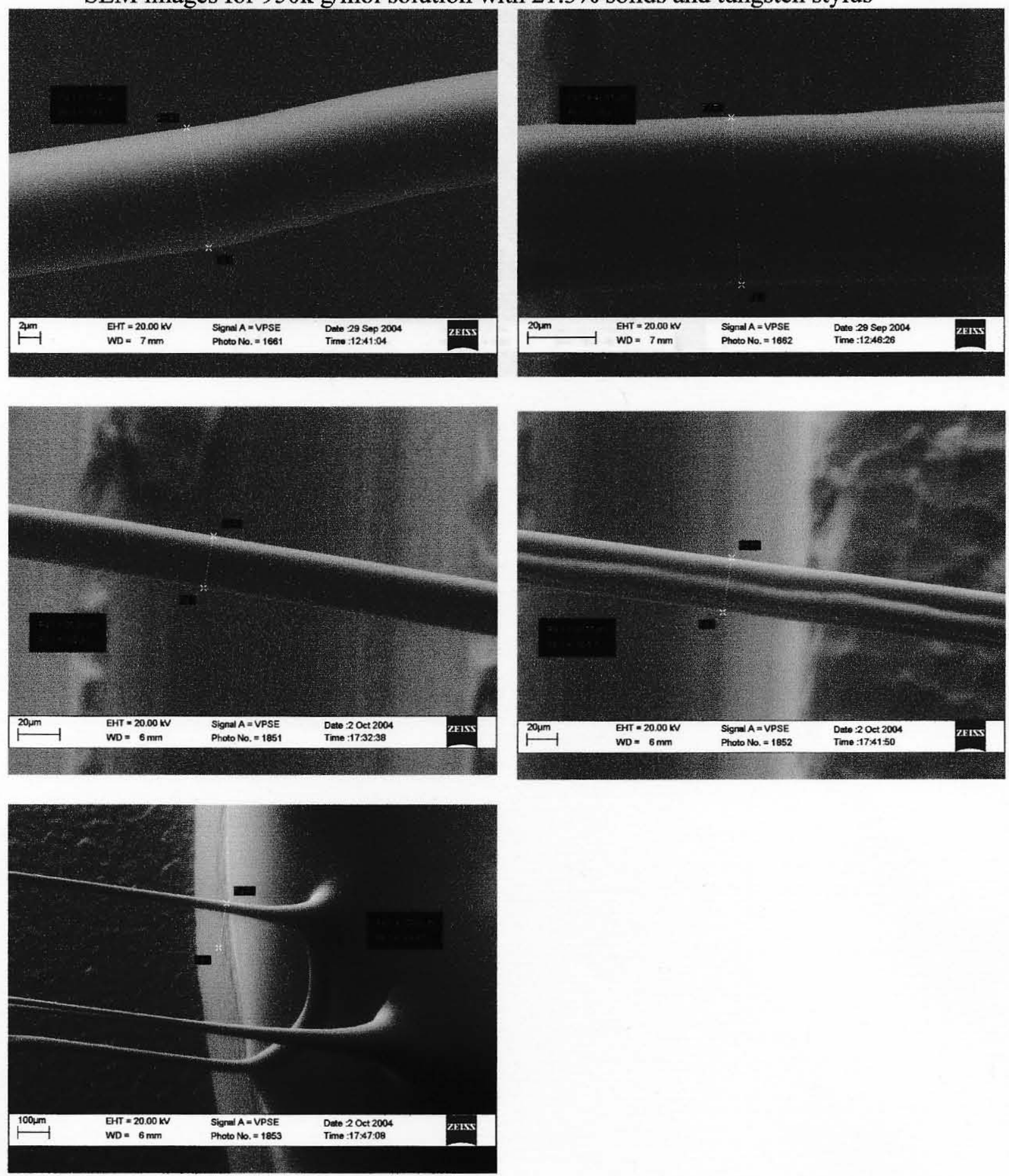
SEM images for $495 \mathrm{k} \mathrm{g} / \mathrm{mol}$ solution with $16 \%$ solids and parylene stylus

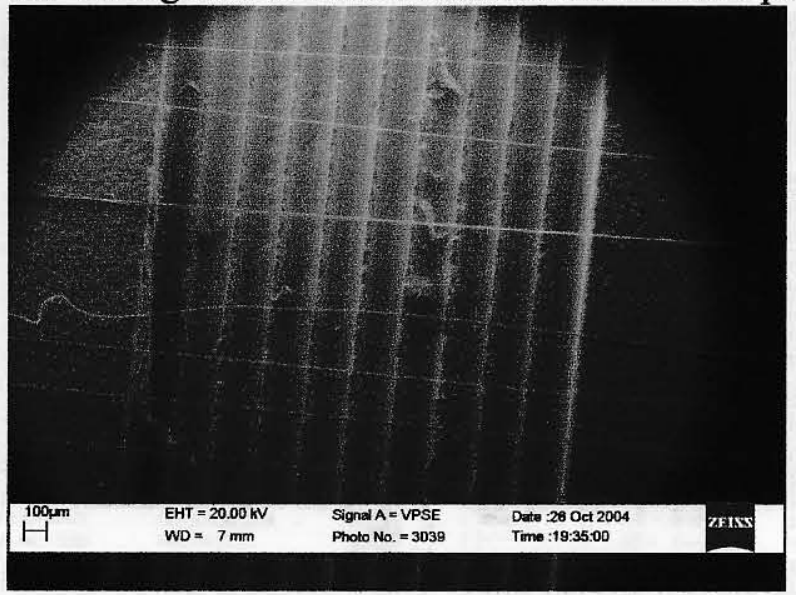


SEM images for $495 \mathrm{k} \mathrm{g} / \mathrm{mol}$ solution with $17 \%$ solids and parylene stylus
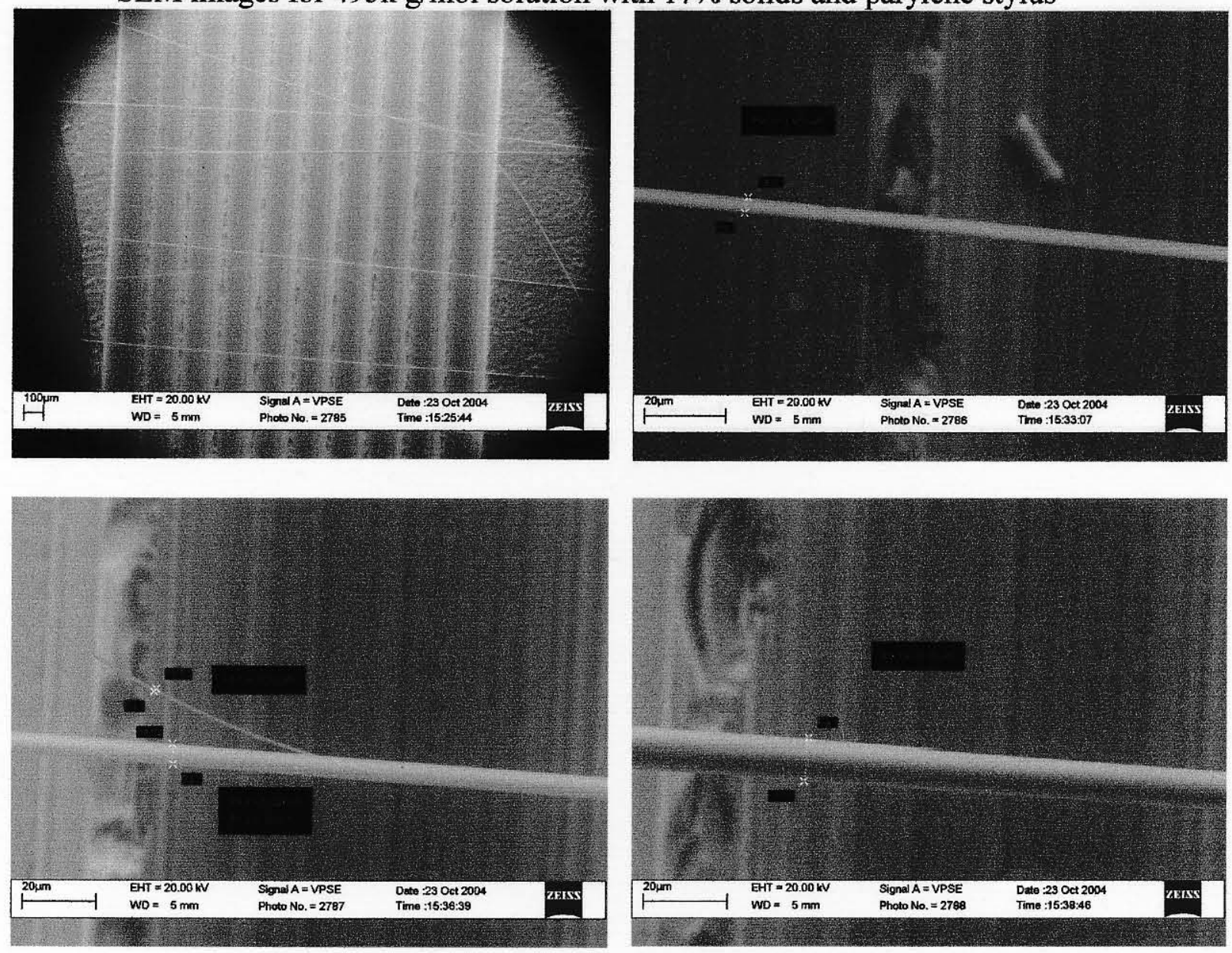
SEM images for $495 \mathrm{k} \mathrm{g} / \mathrm{mol}$ solution with $18 \%$ solids and parylene stylus
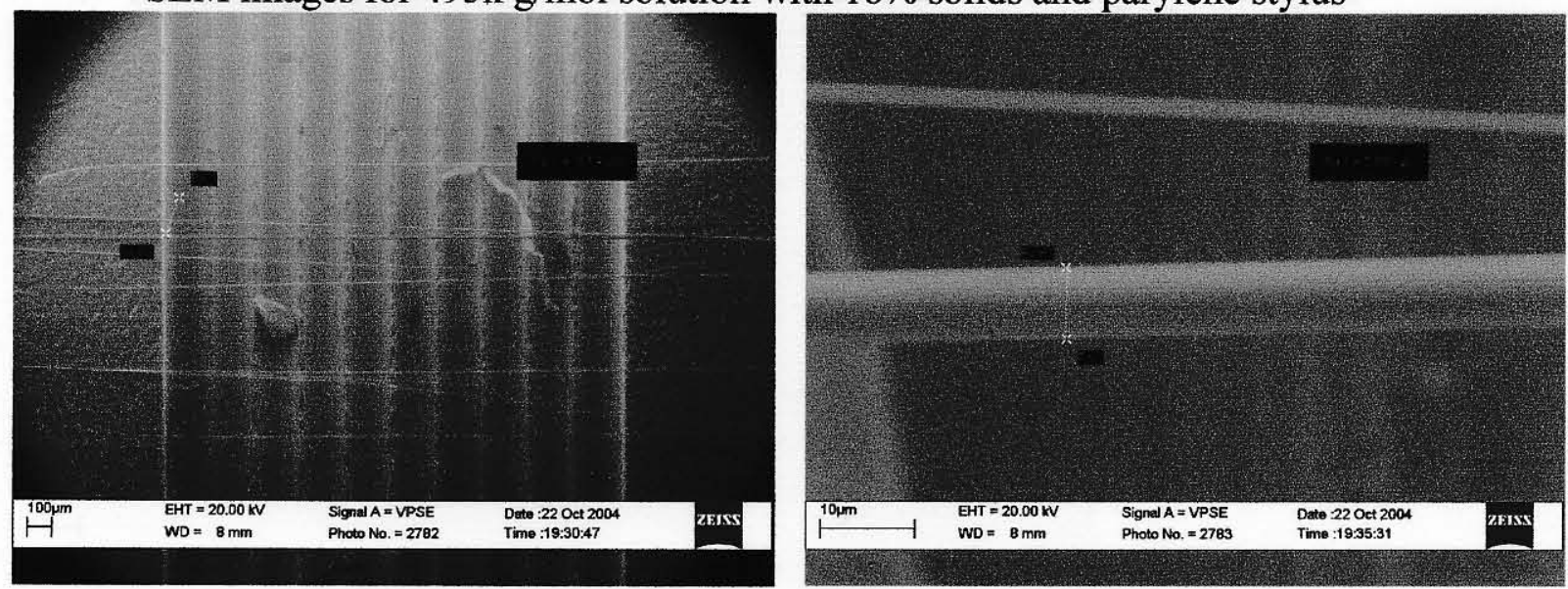
SEM images for $495 \mathrm{k} \mathrm{g} / \mathrm{mol}$ solution with $21.6 \%$ solids and parylene stylus
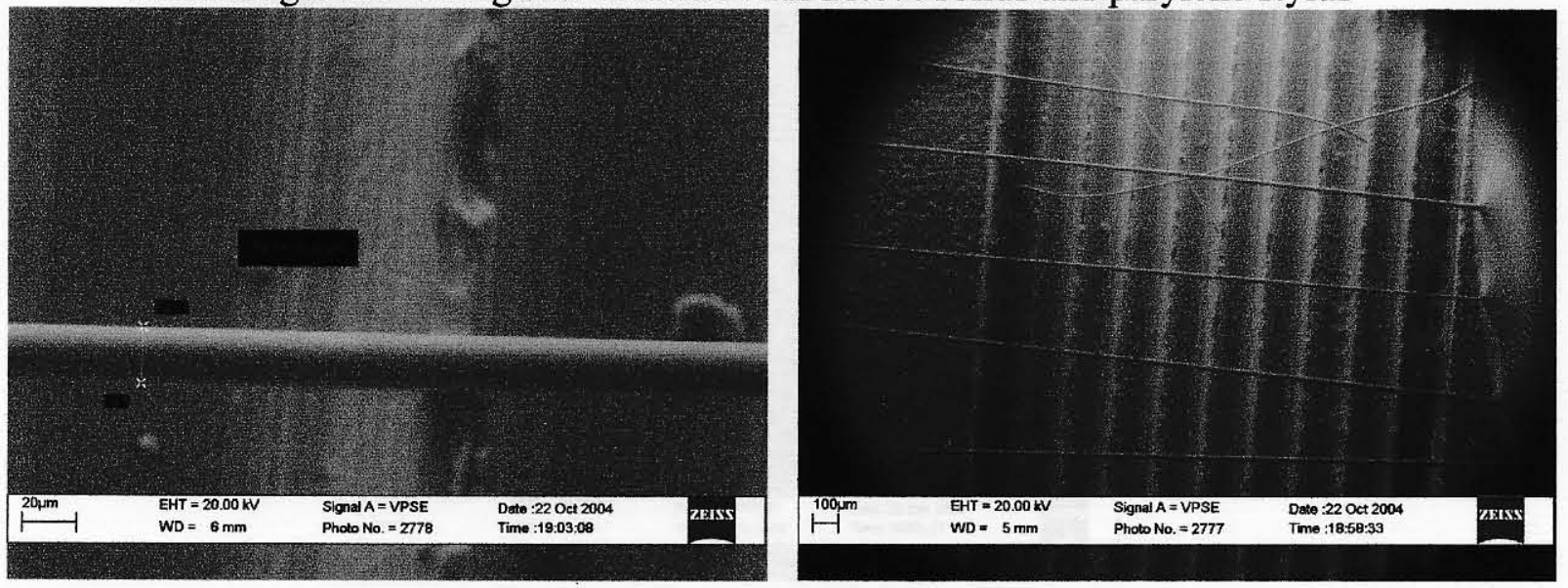
SEM images for $495 \mathrm{k} \mathrm{g} / \mathrm{mol}$ solution with $23 \%$ solids and parylene stylus

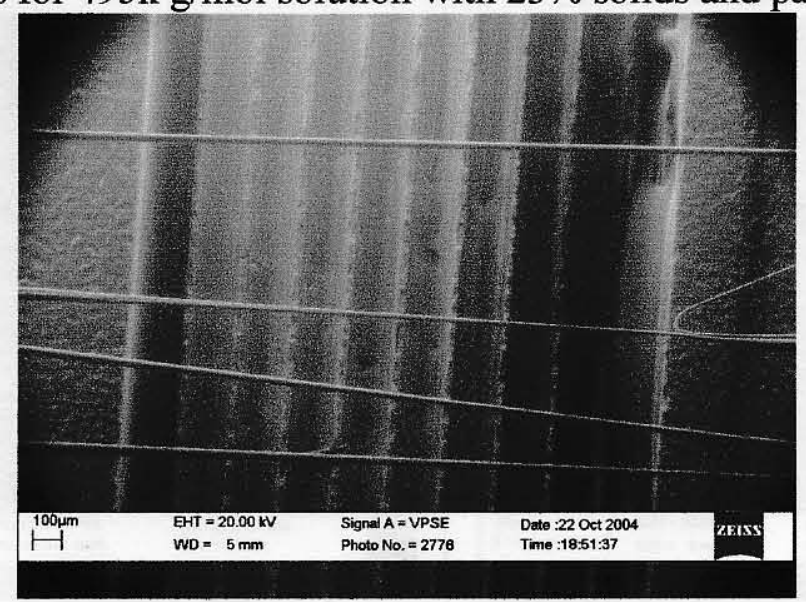


SEM images for $495 \mathrm{k} \mathrm{g} / \mathrm{mol}$ solution with $15.5 \%$ solids and nonstick stylus
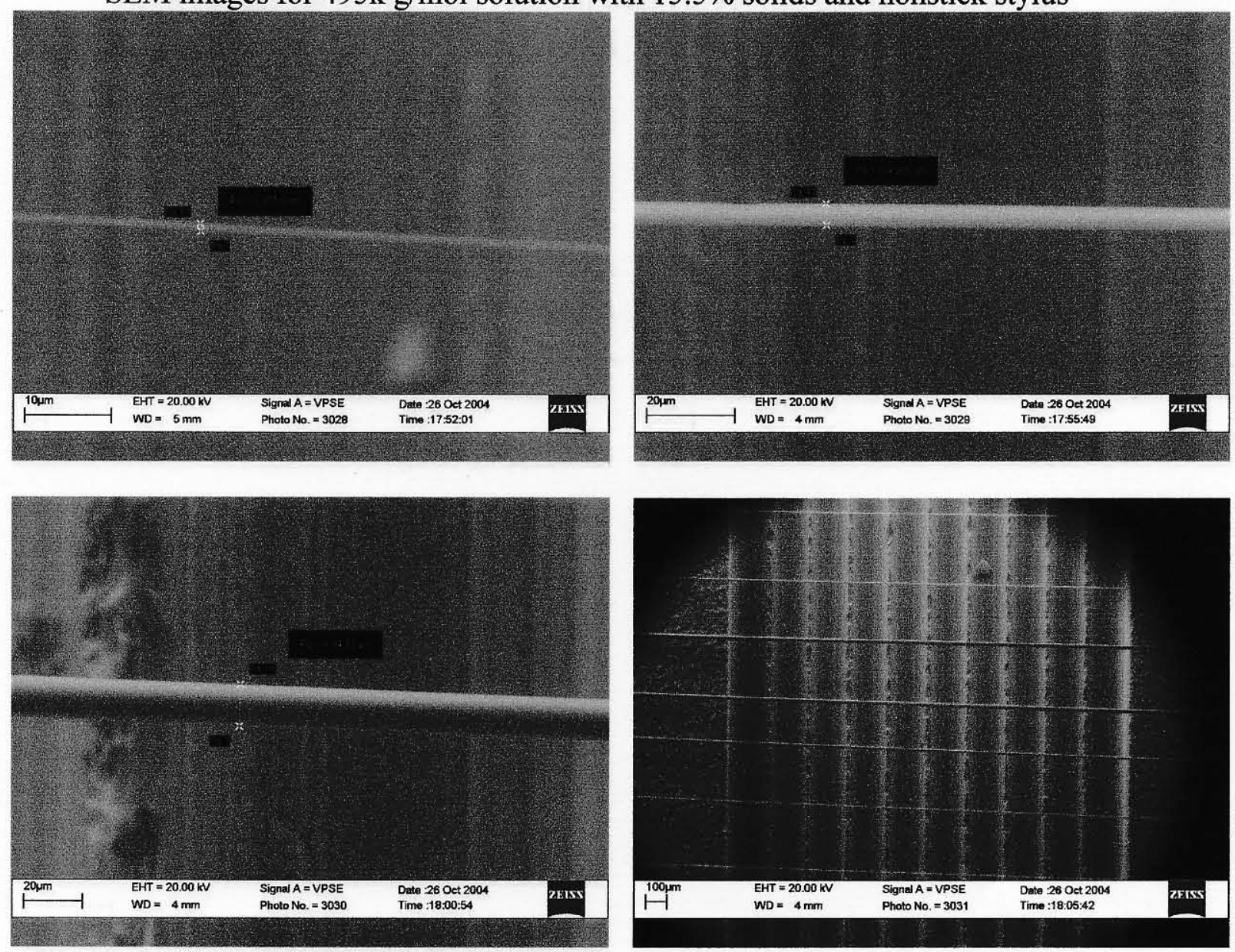
SEM images for $495 \mathrm{k} \mathrm{g} / \mathrm{mol}$ solution with $16 \%$ solids and nonstick stylus
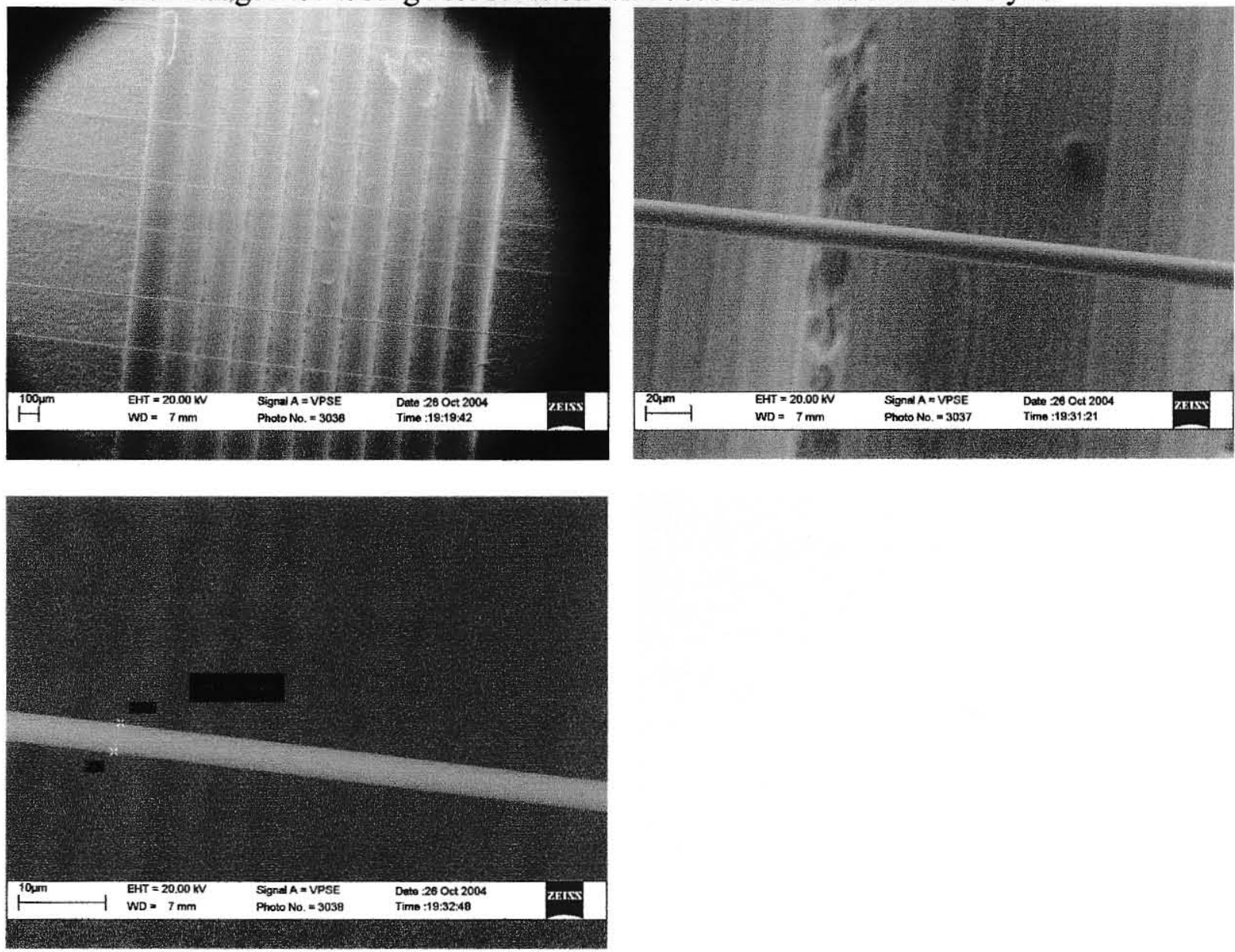
SEM images for $495 \mathrm{k} \mathrm{g} / \mathrm{mol}$ solution with $17 \%$ solids and nonstick stylus
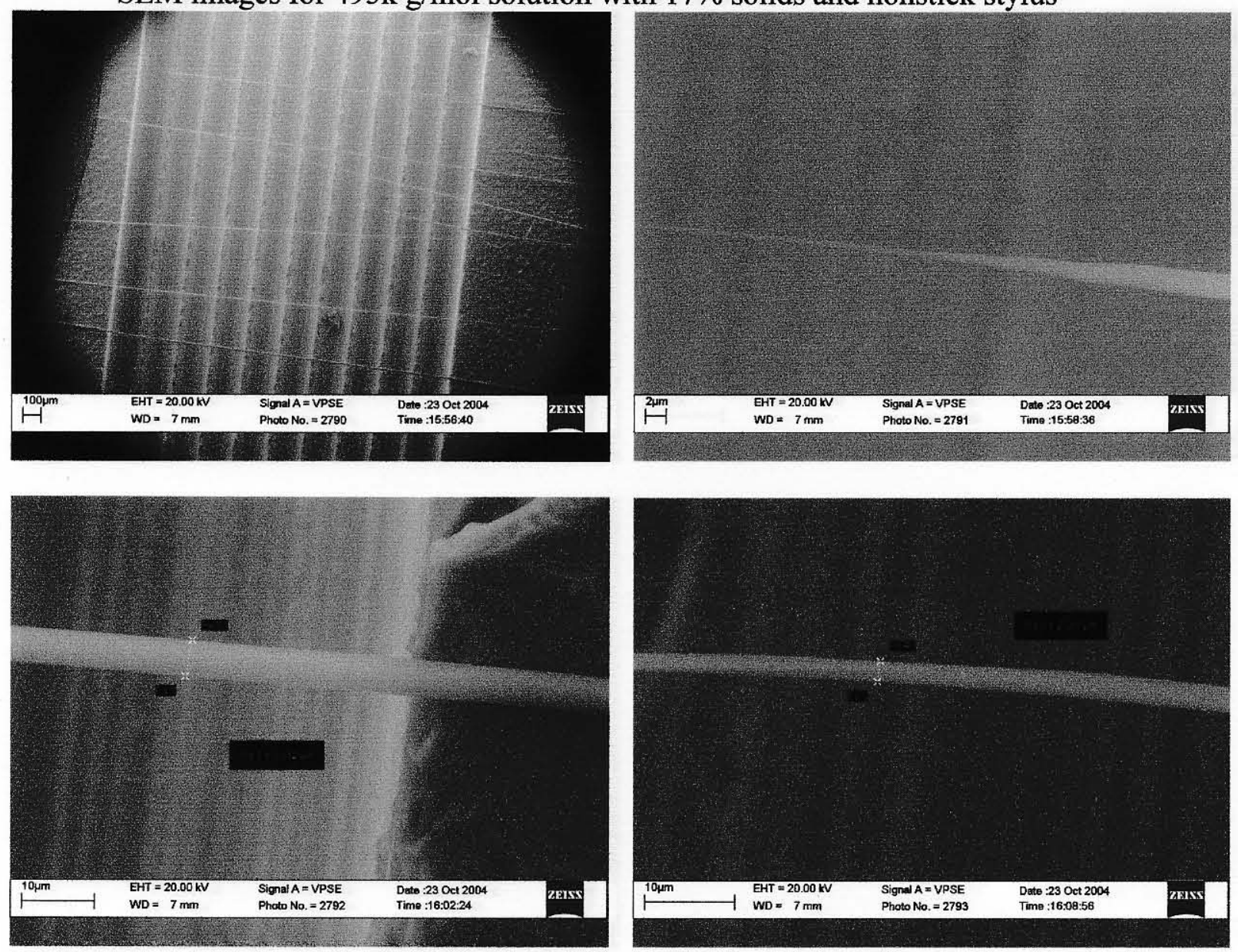
SEM images for $495 \mathrm{k} \mathrm{g} / \mathrm{mol}$ solution with $18 \%$ solids and nonstick stylus
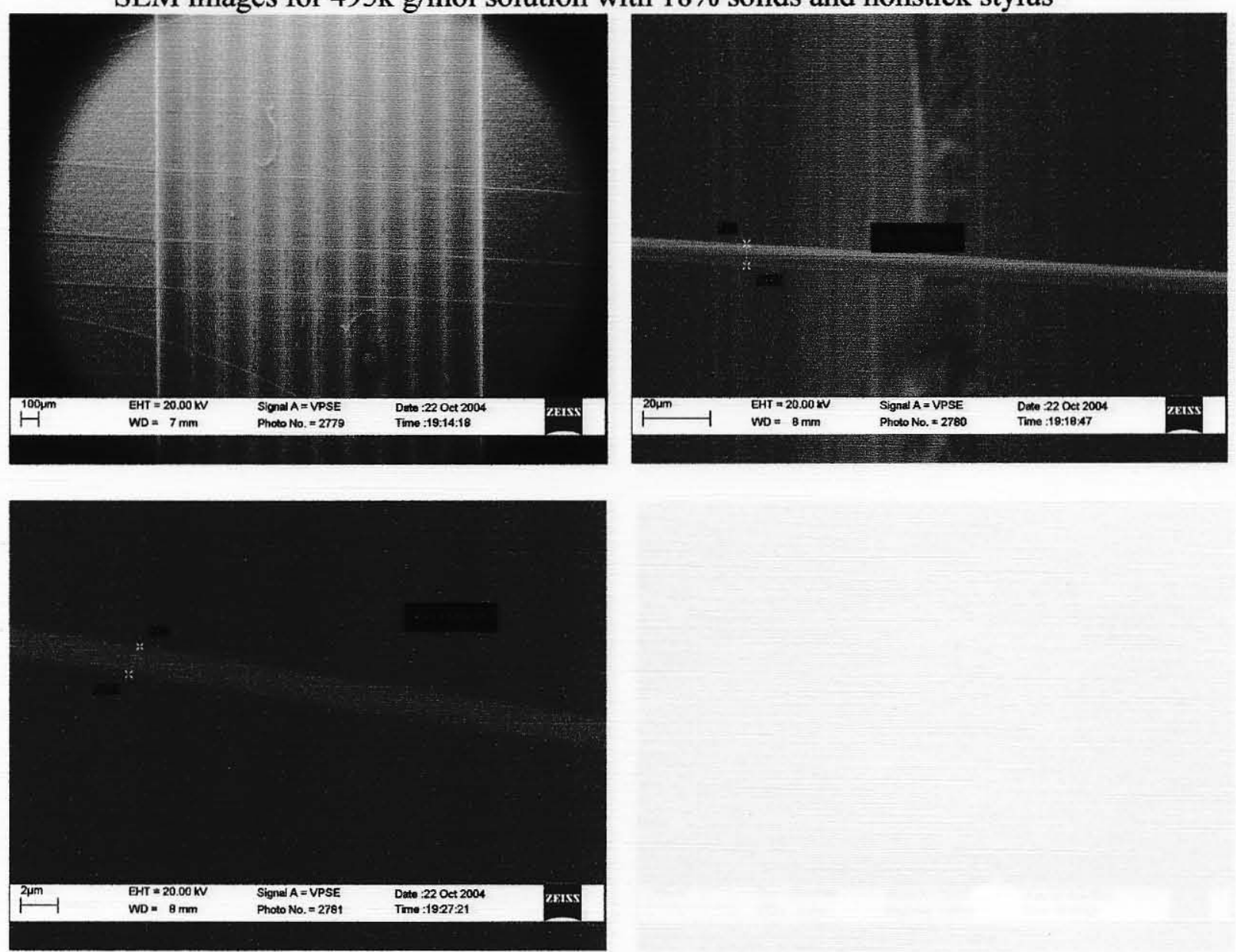
SEM images for $495 \mathrm{k} \mathrm{g} / \mathrm{mol}$ solution with $21.6 \%$ solids and nonstick stylus
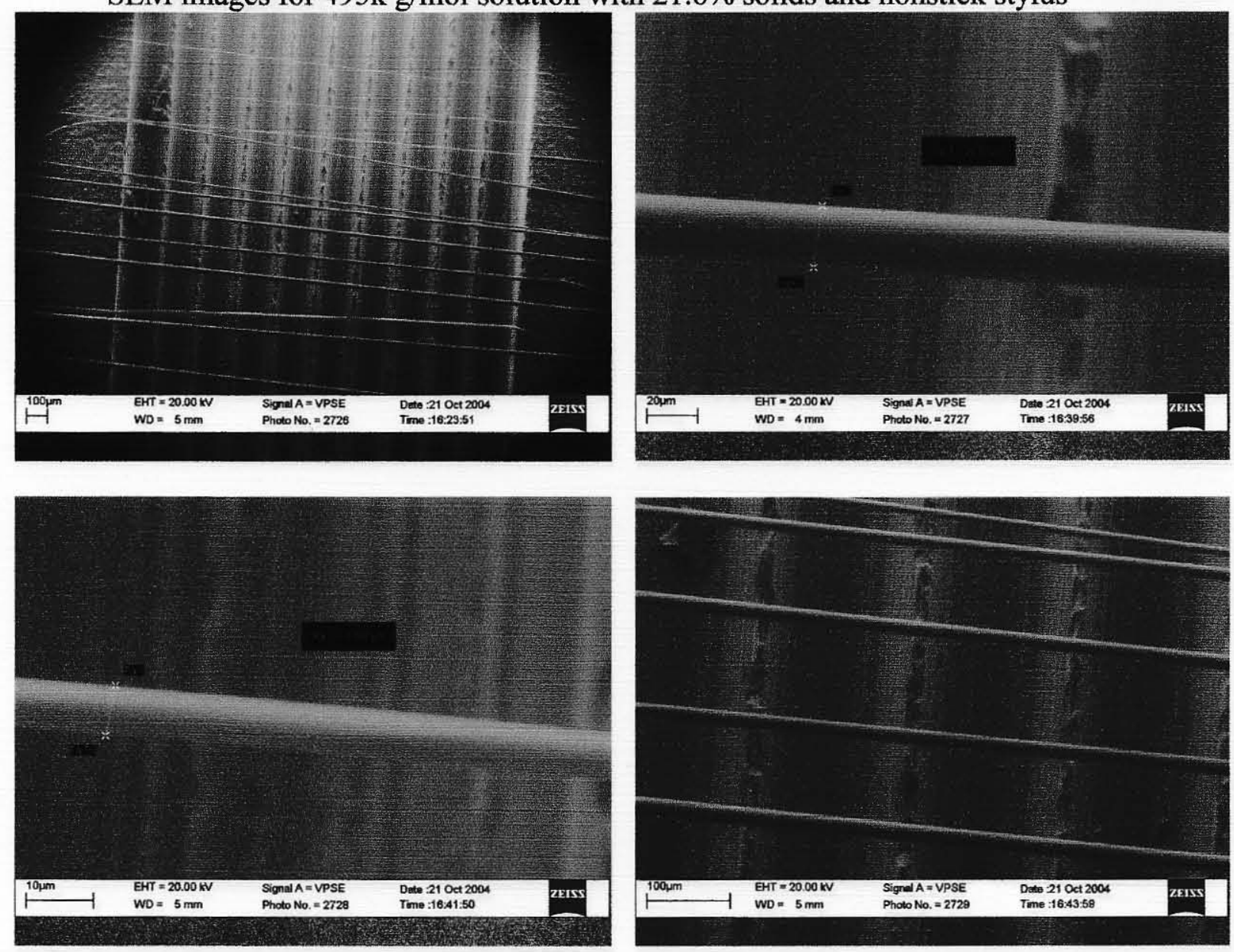
SEM images for $495 \mathrm{k} \mathrm{g} / \mathrm{mol}$ solution with $23 \%$ solids and nonstick stylus
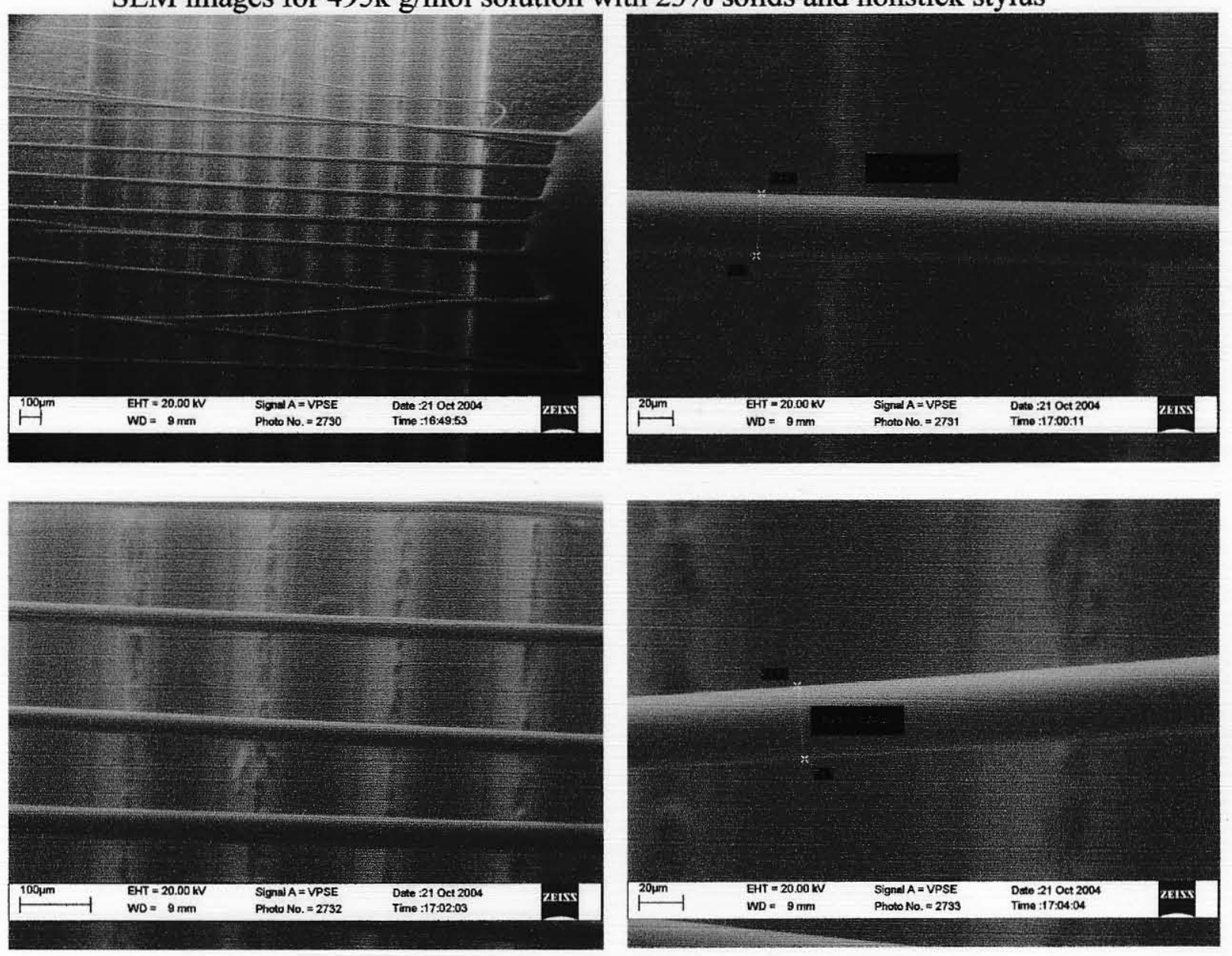
SEM images for $495 \mathrm{k} \mathrm{g} / \mathrm{mol}$ solution with $15.5 \%$ solids and glass stylus
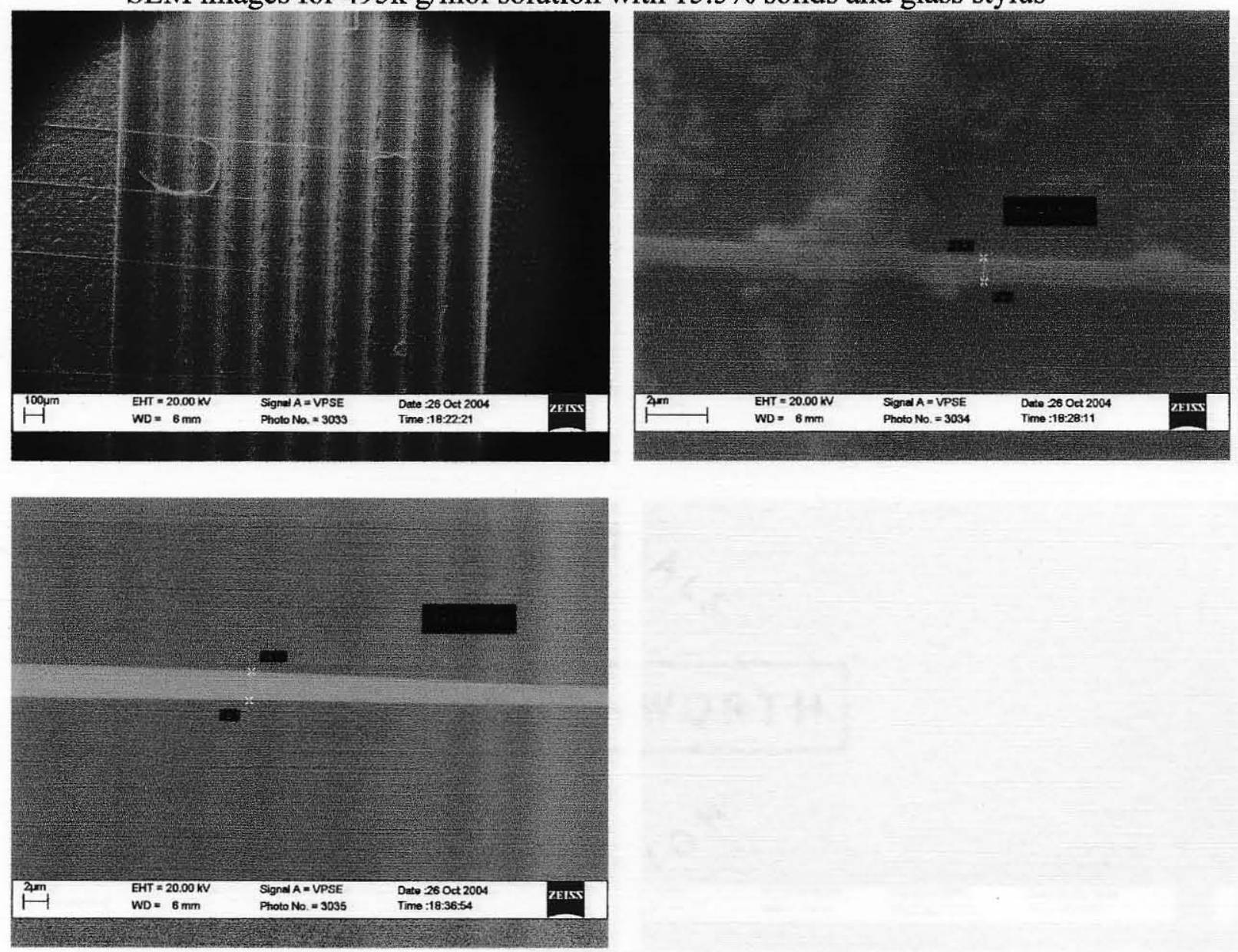
SEM images for $495 \mathrm{k} \mathrm{g} / \mathrm{mol}$ solution with $17 \%$ solids and glass stylus
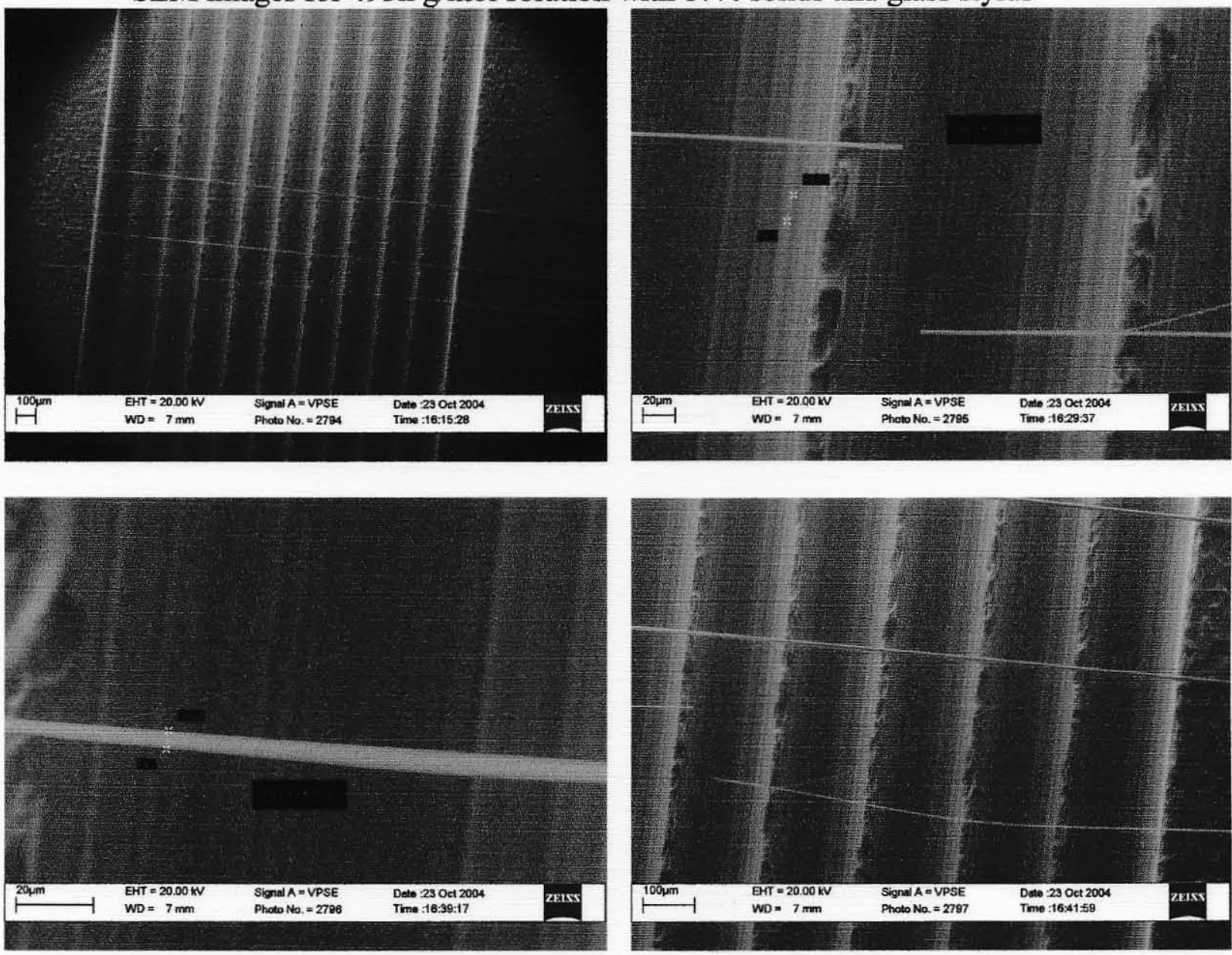
SEM images for $495 \mathrm{k} \mathrm{g} / \mathrm{mol}$ solution with $16 \%$ solids and glass stylus
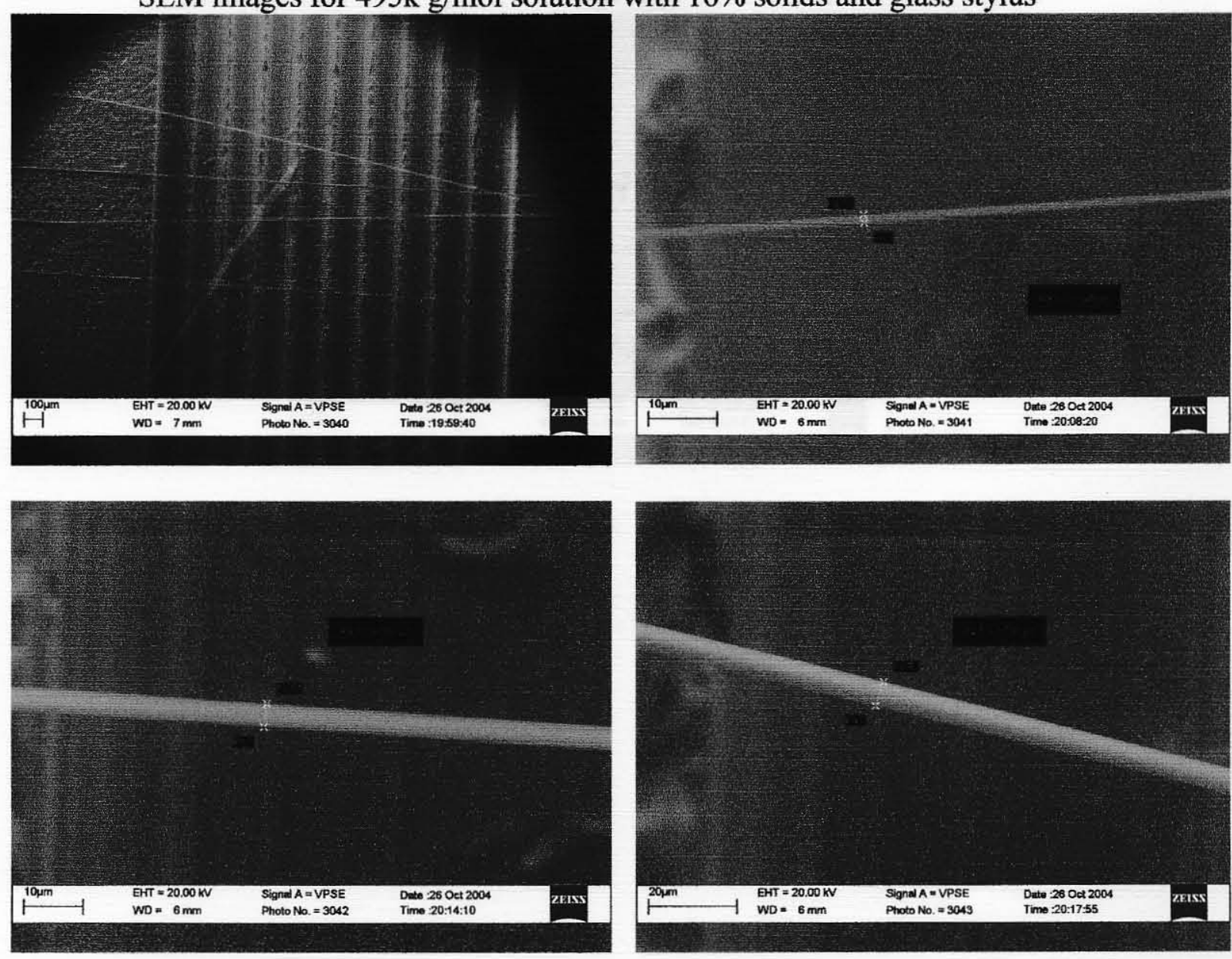
SEM images for $495 \mathrm{k} \mathrm{g} / \mathrm{mol}$ solution with $18 \%$ solids and glass stylus

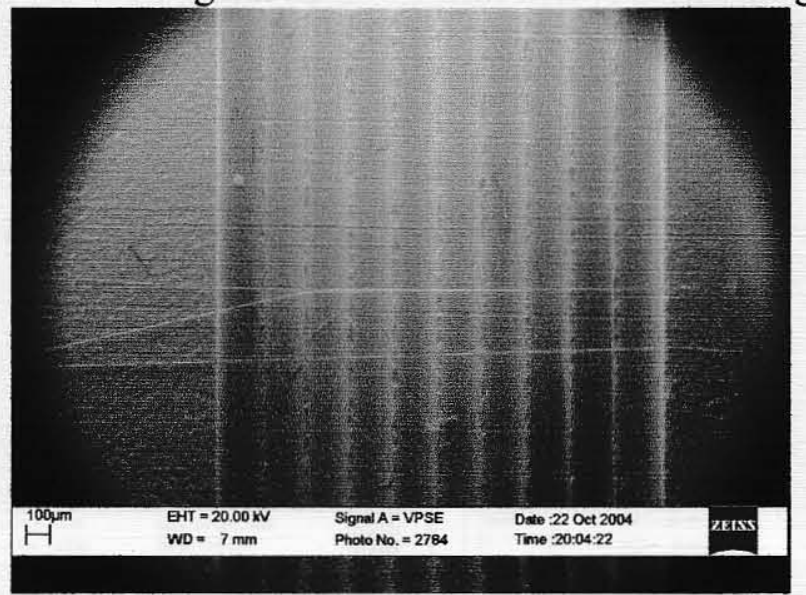


SEM images for $495 \mathrm{k} \mathrm{g} / \mathrm{mol}$ solution with $21.6 \%$ solids and glass stylus
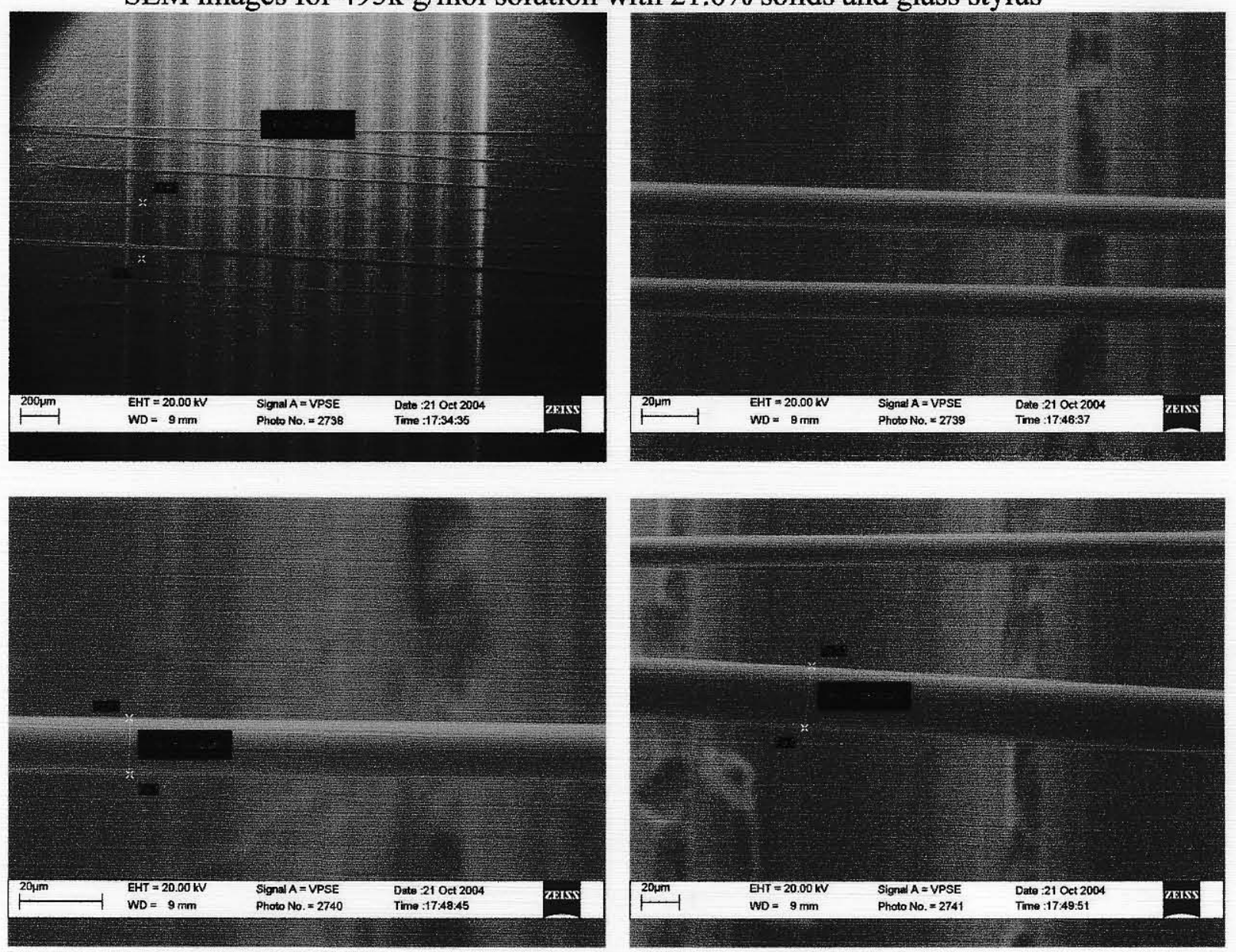
SEM images for $495 \mathrm{k} \mathrm{g} / \mathrm{mol}$ solution with $23 \%$ solids and glass stylus
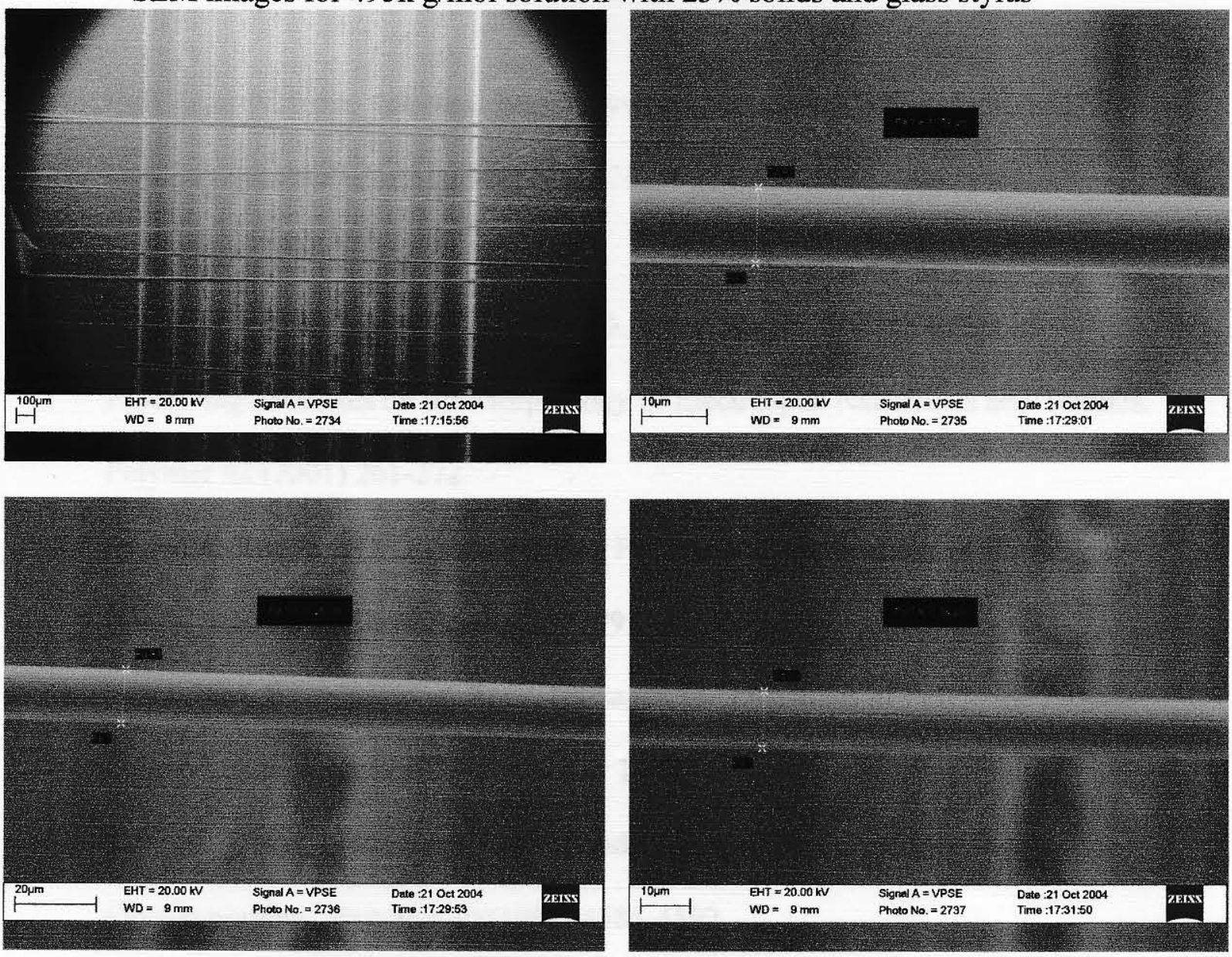


\section{LIST OF REFERENCES}

1. Carl Zeiss Website. Internet. http://www.smt.zeiss.com/C1256E4600305472/ Contents-Frame/84E6E310B4773CB3C1256E54003A31FE. Accessed November, 2004.

2. Deitzel, J. M., Kleinmeyer, J., Harris, D., Beck Tan, N. C. The Effect of Processing Variables on the Morphology of Electrospun Nanofibers and Textiles. Polymer 42 (2001) 261-272.

3. Doshi, J., Reneker, D. Electrospinning Process and Applications of Electrospun Fibers. Journal of Electrostatics 35 (1995) 151-160.

4. Byron Bird, R., Armstrong, R. C., Hassager, O. Dynamics of Polymeric Liquids: Fluid Mechanics. John Wiley \& Sons. 1977.

5. Fong, H., Chun, I, Reneker, D. H. Beaded Nanofibers Formed During Electrospinning. Polymer 40 (1999) 4585-4592.

6. Frenot, A., Chronakis, I. Polymer Nanofibers Assembled by Electrospinning. Current Opinion in Colloid and Interface Science 8 (2003) 64-75.

7. Friedrich, C., Vasile, M. Development of the Micromilling Process for High Aspect Ratio Microstructures. Journal of Microelectromechanical Systems, vol. 5, no. 1, March 1996, pp. 33-38.

8. Harfenist, S. A., Cambron, A. D., Nelson, E. W., Berry, S. M., Isham, A. W., Crain, M. M., Walsh, K. M., Keynton, R. S., Cohn, R. W. Direct Drawing of Suspended Filamentary Micro- and Nanostructures from Liquid Polymers. Nanoletters Vol. 4, No. 10 (2004) 1931-1937. 
9. Sperling, L. H. Introduction to Physical Polymer Science $3^{\text {rd }}$ Edition. WileyInterscience. 2001.

10. Koski, A., Yim, K., Shivkumar, S. Effect of Molecular Weight on Fibrous PVA Produced by Electrospinning. Materials Letters 58 (2004) 493-497.

11. Mok, S., Worsfold, D. J., Fouda, A. E., Matsuura, T., Wang, S., Chan, K. Study on the Effect of Spinning Conditions and Surface Treatment on the Geometry and Performance of Polymeric Hollow-Fiber Membranes. Journal of Membrane Science 100 (1995) 183-192.

12. Operating Instructions. Brookfield DV-II+ Programmable Viscometer. Manual No. M/97-164-B299.

13. Pereira, C., Nobrega, R., Peinemann, K.-V., Borges, C. Hollow Fiber Membranes Obtained by Simultaneous Spinngin of Two Polymer Solutions: A Morphological Study. Journal of Membrane Science 226 (2003) 35-50.

14. Pomfret, S., Adams, P. N., Comfort, N. P., Monkman, A. P. Electrical and Mechanical Properties of Polyaniline Fibers Produced by a One-Step Wet Spinning Process. Polymer 41 (2000) 2265-2269.

15. Qin, J., Gu, J., Chung, T. Effect of Wet and Dry-Jet Wet Spinning on the ShearInduced Orientation During the Formation of Ultrafiltration Hollow Fiber Membranes. Journal of Membrane Science 182 (2001) 57-75.

16. Samon, J., Schultz, J. M., Hsiao, B. S. Structure Development in the Early Stages of Crystallization During Melt Spinning. Polymer 43 (2002) 1873-1875.

17. Sandler, J. K., Pegel, S., Cadek, M., Gojny, F., van Es, M., Lohmar, J., Blau, W. J., Schulte, K., Windle, A. H., Shaffer, M. S. P. A Comparative Study of Melt 
Spun Polyamide-12 Fibers Reinforced with Carbon Nanotubes and Nanofibers. Polymer 45 (2004) 2001-2015.

18. Theron, S. A., Zussman, E., Yarin, A. L. Experimental Investigation of the Governing Parameters in the Electrospinning or Polymer Solutions. Polymer 45 (2004) 2017-2030.

19. Tripathi, A., Whittingstall, P., McKinley, G. H. Using Filament Stretching Rheometry to Predict Strand Formation and "Processability" in Adhesives and Other Non-Newtonian Fluids. Rheol Acta 39 (2000) 321-337.

20. Weisbuch, F. Millimeter Long PMMA Nanofibers - A New Form of Material Removal in Laser Ablation. Thin Solid Films 453-454 (2004) 394-398.

21. Wienk, I. M., Olde Scholtenhuis, F. H. A., van den Boomgaard, T., Smolders, C. A. Spinning of Hollow Fiber Ulrtafiltration Membranes from a Polymer Blend. Journal of Membrane Science 106 (1995) 233-243.

22. Wu, G., Li, H., Wu, Y., Cuculo, J. A. Structure and Propety Studies of Poly(Trimethylene Terephthalate High-Speed Melt Spun Fibers. Polymer 43 (2002) 4915-4922.

23. Wu, G., Li, Q., Cuculo, J. A. Fiber Structure and Properties of Poly(ethylene-2,6napthalate) Obtained by High Speed Melt Spinning. Polymer 41 (2001) 81398150.

24. Yang, S., Teo, W. K., Li, K. Formation of Annular Hollow Fibers for Immobilization of Yeast Passages. Journal of Membrane Science 184 (2001) 107-115. 
25. Zachmann, H. G. New Insights into the Structure and Phase Transitions of Polymers. Nuclear Instruments and Methods in Physics Research B 97 (1995) 209-215.

26. Zeng, J., Saltysiak, B., Johnson, W. S., Schiraldi, D. A., Kumar, S. Processing and Properties of Poly(methyl methacrylate) / Carbon Nano Fiber Composites. Composites: Part B 35 (2004) 173-178. 


\section{VITA}

\section{EDUCATION}

- University of Louisville

Undergraduate in Mechanical Engineering and Pre-Med

114 Credit Hours Completed - Cumulative GPA of 3.97

Bachelors of Science - Completed May 2003

- DuPont Manual High School - Louisville, KY

Graduated in 1999 with GPA of 3.8

\section{WORK EXPERIENCE}

1/04 - Present

$5 / 03-12 / 03$

- Graduate Research Assistant - University of Louisville Characterization of polymer micro- and nanofibers using high-precision micromill

Supervised by Dr. Robert Keynton

- Graduate Research Assistant - University of Louisville Design of Low-Load Prolonged Stretch Device Characterization of pneumatic muscles

Supervised by Dr. Peter Quesdada

$5 / 02-8 / 02$

$8 / 01-1 / 02$

$1 / 01-5 / 01$

- Louisville Gas \& Electric - Mill Creek Station - Co-op Project supervision / management Engineering analysis of pumps, systems, filters, boilers, tanks, condensers, and other power plant components

- Louisville Gas \& Electric - Mill Creek Station - Co-op Project supervision

Performance testing of power generation unit Analysis of systems operating at low efficiency

- Louisville Gas \& Electric - Mill Creek Station - Co-op Performance testing on coal mills and cooling systems Power plant inspections Fluid flow calculation in pump systems Clerical duties related to engineering

\section{COMPUTER SKILLS}

- MS Excel, MS Word, MS PowerPoint, Fathom Pipe-Flo, Solid Edge, AutoCAD 2000, Visual Basic, Fortran, Web page design, Maple, MathCAD, I-DEAS, Milestones, ANSYS

AWARDS

- University of Louisville Fellowship 
- Finalist in the $50^{\text {th }}$ Intel International Science and Engineering Fair in Philadelphia, PA. - 1999

- Winner of Sigma Xi award for scientific research. - 1999

- Norfolk Southern Railroad Scholarship

- University of Louisville Trustee's Scholarship

- Golden Key Honor Society

- Tau Beta Pi Honor Society

\section{PUBLICATIONS}

- Harfenist, S. A., Cambron, A. D., Nelson, E. W., Berry, S. M., Isham, A. W., Crain, M. M., Walsh, K. M., Keynton, R. S., Cohn, R. W. Direct Drawing of Suspended Filamentary Micro- and Nanostructures from Liquid Polymers. Nanoletters Vol. 4, No. 10 (2004) 1931-1937. 